\title{
WestVirginiaUniversity
}

THE RESEARCH REPOSITORY @ WVU

Graduate Theses, Dissertations, and Problem Reports

2014

\section{Electroplating of Cr-Ni Alloy and Ni-Cr/Ni Multilayer Coatings}

Liaowang Liu

West Virginia University

Follow this and additional works at: https://researchrepository.wvu.edu/etd

Part of the Electro-Mechanical Systems Commons

\section{Recommended Citation}

Liu, Liaowang, "Electroplating of Cr-Ni Alloy and Ni-Cr/Ni Multilayer Coatings" (2014). Graduate Theses, Dissertations, and Problem Reports. 8161.

https://researchrepository.wvu.edu/etd/8161

This Thesis is protected by copyright and/or related rights. It has been brought to you by the The Research Repository @ WVU with permission from the rights-holder(s). You are free to use this Thesis in any way that is permitted by the copyright and related rights legislation that applies to your use. For other uses you must obtain permission from the rights-holder(s) directly, unless additional rights are indicated by a Creative Commons license in the record and/ or on the work itself. This Thesis has been accepted for inclusion in WVU Graduate Theses, Dissertations, and Problem Reports collection by an authorized administrator of The Research Repository @ WVU. For more information, please contact researchrepository@mail.wvu.edu. 


\title{
Electroplating of Cr-Ni Alloy and Ni-Cr/Ni Multilayer Coatings
}

\author{
Liaowang Liu
}

Thesis submitted to the

Benjamin M. Statler College of Engineering and Mineral Resources at West Virginia University

in partial fulfillment of the requirements for the degree of

\author{
Master of Science \\ in \\ Mechanical Engineering
}

Xingbo Liu, Ph.D., Chair

Hui Zhang, Ph.D.

Xueyan Song, Ph.D.

Department of Mechanical and Aerospace Engineering

Morgantown, West Virginia

2014

Keywords: Electroplating, Trivalent Chromium, Nickel, Crack-free, Multilayers, Organic Electrolyte 


\section{ABSTRACT \\ Electroplating of Cr-Ni Alloy and Ni-Cr/Ni Multilayer Coatings}

\section{Liaowang Liu}

The major interests of developing $\mathrm{Ni}-\mathrm{Cr}$ alloy plating lie in the possible formation of a passive film by chromium and its good chemical and mechanical properties. And nano scale multilayer coatings exhibit improved properties due to nano scale effects (e.g.: high hardness and strength) and they combine and enhance different properties from individual components. Thus, electroplating of $\mathrm{Ni}-\mathrm{Cr}$ multilayer coatings could have high potential for numerous engineering applications. Electroplating in aqueous and in organic solution by direct current were studied for $\mathrm{Ni}-\mathrm{Cr}$ alloy coatings, and $\mathrm{Ni}-\mathrm{Cr}$ multilayer coatings were prepared by pulse current electroplating in single bath.

Traditionally, chromium or chromium alloy coatings were deposited from $\mathrm{Cr}(\mathrm{VI})$ bath. The main advantage of a $\mathrm{Cr}(\mathrm{III})$ plating bath in comparison with a $\mathrm{Cr}(\mathrm{VI})$ bath is that $\mathrm{Cr}^{3+}$ ions are non-toxic. However, it is almost impossible to deposit the $\mathrm{Cr}$ coating from a simple aqueous $\mathrm{Cr}(\mathrm{III})$ solution due to a very stable $\left[\mathrm{Cr}\left(\mathrm{H}_{2} \mathrm{O}\right)_{6}\right]^{3+}$ complex. In this study, two complex agents were used to promote the discharge of $\mathrm{Cr}^{3+}$ at the cathode side. A good ratio of main salts and complexes agents with a decent wide range of current densities for $\mathrm{Ni}-\mathrm{Cr}$ alloy was determined by Hull cell test. The control of $\mathrm{Cr}$ content in $\mathrm{Ni}$ $\mathrm{Cr}$ alloy coating was achieved in the optimized plating bath.

The effects of Dimethylformamide (DMF) content in the solvent and current density on the surface morphology, chemical state and hydrogen evolution were studied. Hydrogen evolution and crack density decrease with the increase of DMF content. Crack-free $\mathrm{Ni}-\mathrm{Cr}$ alloy coatings with $\mathrm{Cr}$ content up to $58 \%$ were successfully obtained from $40 \%$ DMF mixture electrolyte with wetting agent.

$\mathrm{Cr}-\mathrm{Ni}$ multilayer coatings were achieved by pulse-current electroplating from a $\mathrm{Cr}(\mathrm{III})-$ $\mathrm{Ni}(\mathrm{II})$ bath at room temperature without cracks. The thickness of each layer was 
controlled to be tens nanometers by varying the duration of each pulse cycle, as characterized by transmission electron microscopy (TEM). The $\mathrm{Cr}$-Ni multilayers were composed of alternate amorphous $\mathrm{Cr}$-rich and nanocrystalline Ni-rich layers. 
Electroplating of $\mathrm{Cr}-\mathrm{Ni}$ Alloy and Ni-Cr/Ni Multilayer Coatings

Liaowang Lu

Thesis submitted to the

Benjamin M. Stater College of Engineering and Mineral Resources at West Virginia University

in partial fulfillment of the requirements for the degree of

Master of Science in Mechanical Engineering

Department of Mechanical and Aerospace Engineering

APPROVAL OF THE EXAMINING COMMITTEE

$\frac{2 / 20 / 2014}{\text { Date }}$

$\frac{\text { Sun Song, Ph.D }}{\text { Xueyan }}$

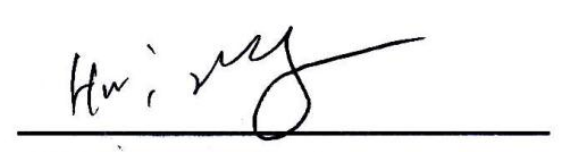

Hui Chang, Ph.D..

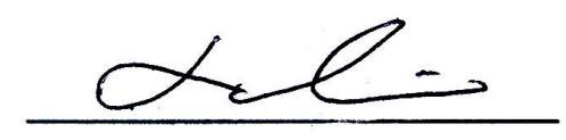

Xingbo Lu, Ph.D., Chair

iii 
Oedicated to my parents and grandparents 


\section{ACKNOWLEDGMENTS}

My deepest gratitude goes first and foremost to my advisor Dr. Xingbo Liu for his continuous support of my master's study and research, for his patience, enthusiasm, inspiration, and expertise. It's my pleasure to have the opportunity to finish the master degree under his guidance. I am also extremely grateful to Dr. Hui Zhang for her mentoring and assistance in experimental and discussions, as well as being my committee members. Suggestions from another committee member Dr. Xueyan Song are also highly acknowledged.

We acknowledge use of the WVU Shared Research Facilities. Thanks for Dr. Weiqiang Ding, Dr. Marcela Redigolo, and Harley Hart for their skills and help in XPS, SEM/EDS, XRD analysis. I also appreciate the help from Institute of Metal Research, Chinese Academy of Sciences for the TEM sample preparation and observation. The guidance and assistance from Dr. Lei Lu, Shengjing Bai, Hailing Wang and Yaobing Xu are highly appreciated.

I also appreciate the help from my group members, Dr. Greg Collins, Dr. Yinglu Jiang, Naingnaing Aung, Dr. Mingyang Gong, Dr. Yihong Li, Dr. Laiqi Zhang, Jared Nutter, Wenyuan Li, Meng Yao, Bo Guan, Xinxin Zhang, Jairus Morton, Ryan Watson for their assistance in experimental and discussions. Special thanks to Dr. Ting Chen and visiting professors, Dr. Weiping Li for the generous and knowledgeable suggestions.

Last but not the least; I would like to thank my family: my parents Yan Liu and Yanhua Liao, for giving birth to me at the first place and supporting me spiritually throughout my life. 


\section{TABLE OF CONTENTS}

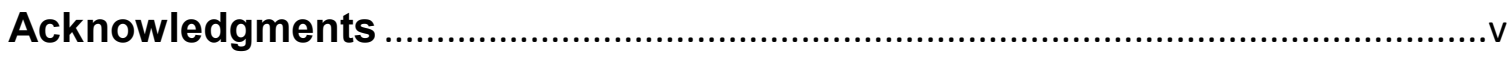

List of Figures

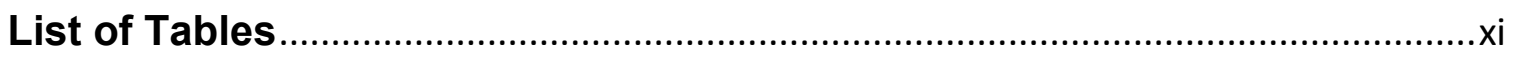

Chapter 1 Introduction and Literature Review........................................................... 1

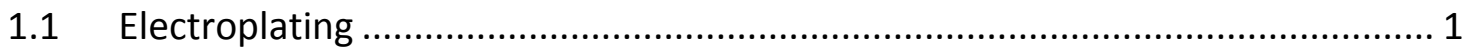

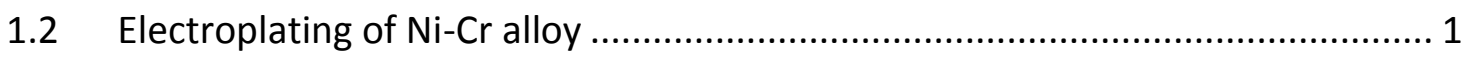

1.2.1 Trivalent Chrome Plating …………………...................................... 2

1.2.2 Internal stress in the deposits..........................................................

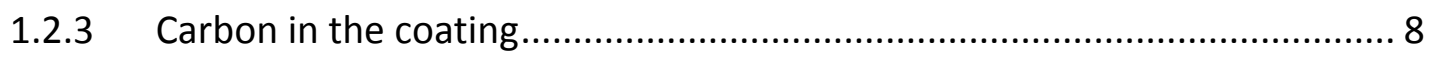

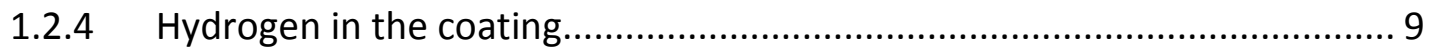

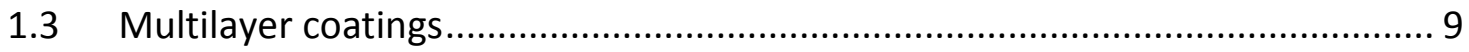

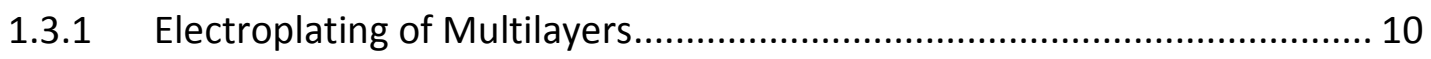

Chapter 2 Experimental Method _........................................................................ 11

2.1 Electroplating Set-up ................................................................................. 11

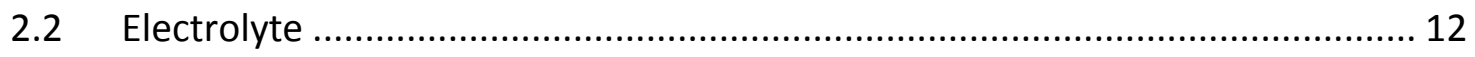

2.2.1 Formula of Electrolyte ...................................................................... 12

2.2.2 Preparation of the electrolyte for deposition......................................... 13

2.2.3 Influence of the components.................................................................. 14

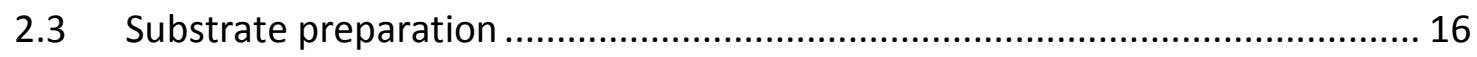

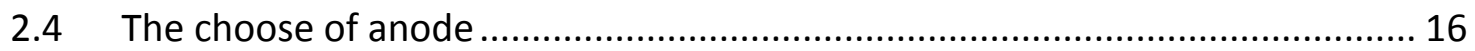

2.4.1 Dimensionally stable anodes (DSA) …................................................. 17 


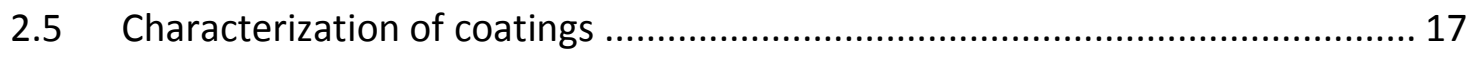

2.5.1 Scanning Electron Microscopy (SEM) ........................................... 17

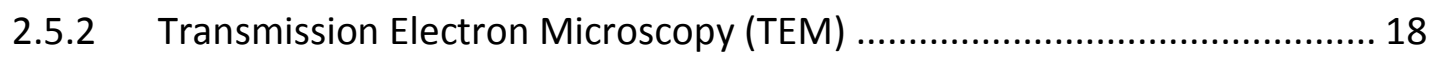

2.5.3 X-ray photoelectron spectroscopy (XPS) …........................................ 18

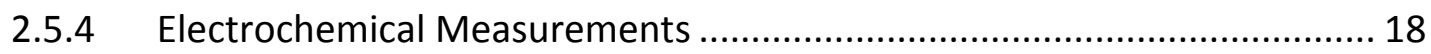

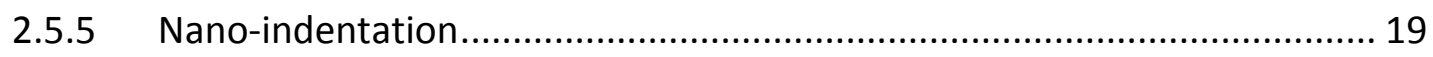

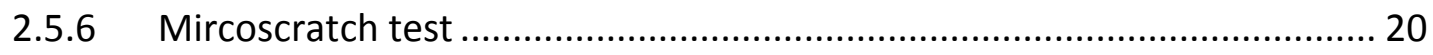

Chapter 3 Electroplating of Nickel-Chrome alloys in aqueous solution .................... 20

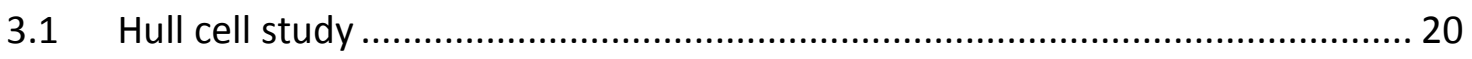

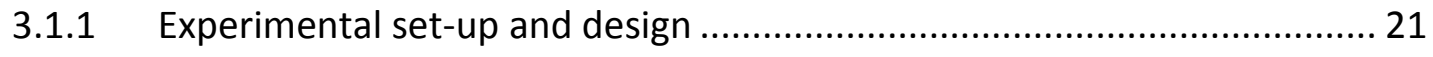

3.1.2 The effect of the concentrations for main salts .................................. 21

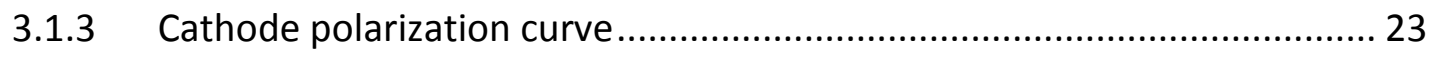

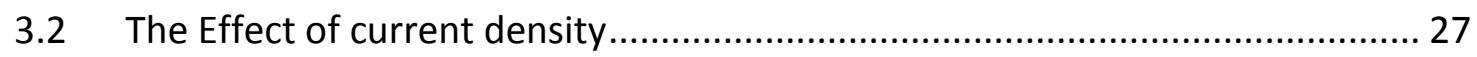

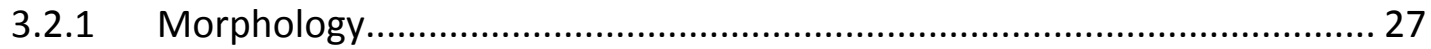

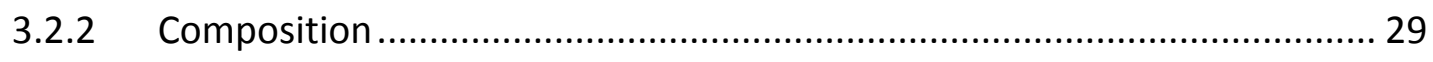

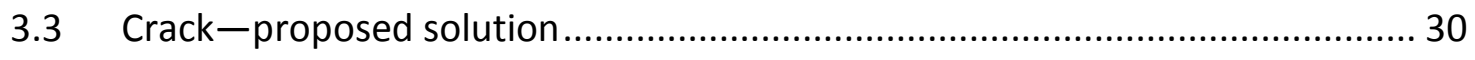

Chapter 4 Electroplating of Nickel-Chrome alloys in DMF-Mixture Solution.............. 32

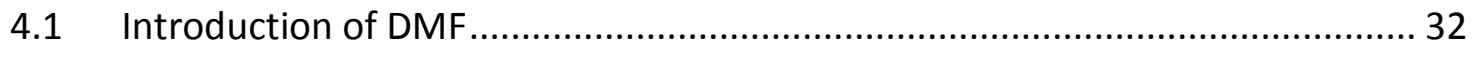

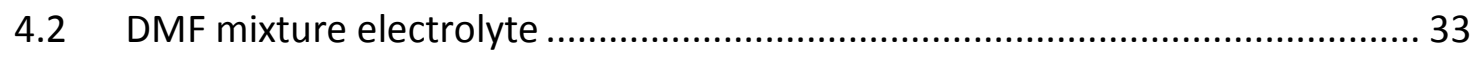

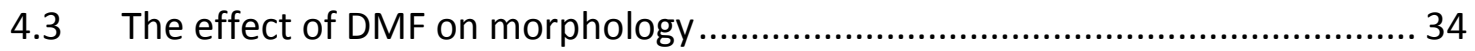

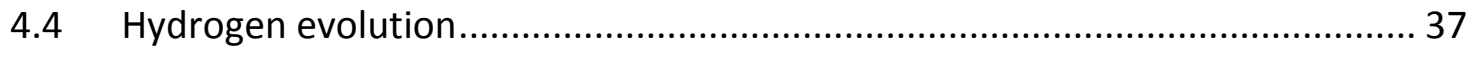

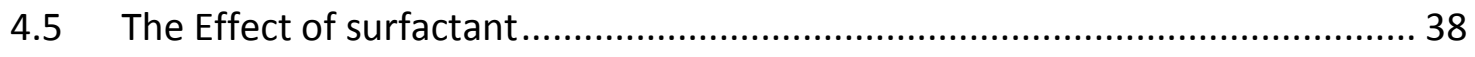

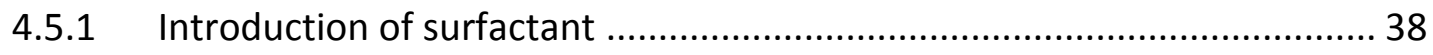

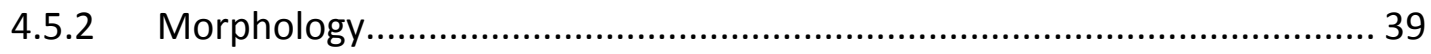




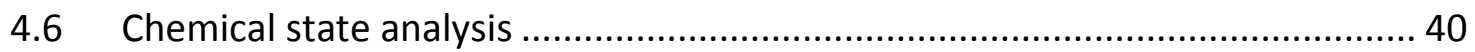

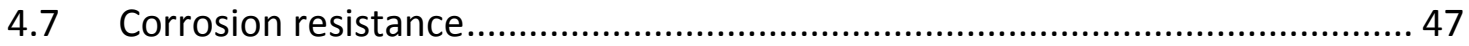

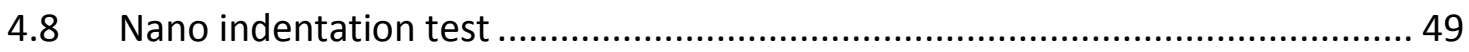

Chapter 5 Electroplating of Ni-Cr Multilayers in Single Bath ................................... 49

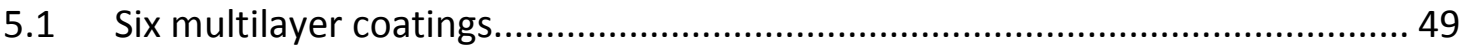

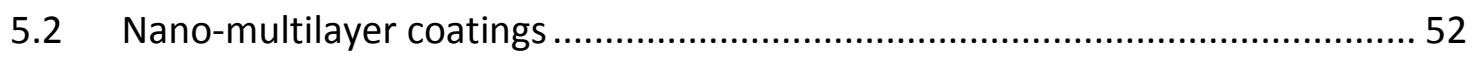

5.2.1 The preparation of cross section for thin film ..................................... 53

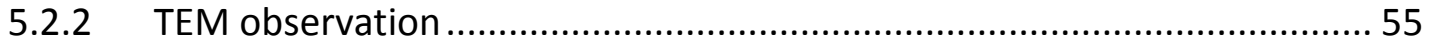

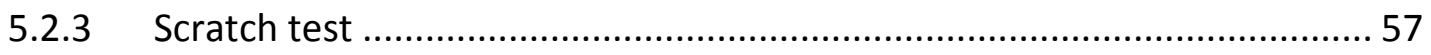

Chapter 6 Conclusions and Recommendations for Future Studies......................... 59

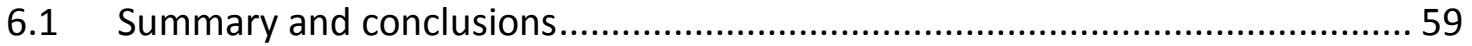

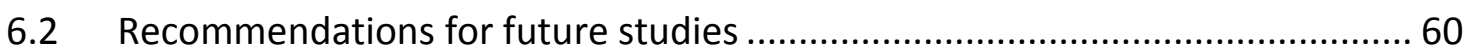

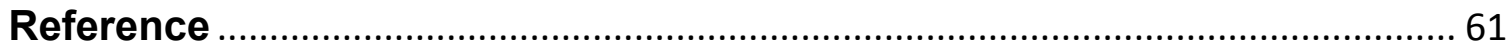




\section{LIST OF FIGURES}

Figure 1.1 Equilibrium geometric structures of (a) $\left[\mathrm{Cr}\left(\mathrm{H}_{2} \mathrm{O}\right)_{6}\right]^{3+},(\mathrm{b})\left[\mathrm{Cr}\left(\mathrm{H}_{2} \mathrm{O}\right)_{5} \mathrm{CHOO}\right]^{2+}$, (c)

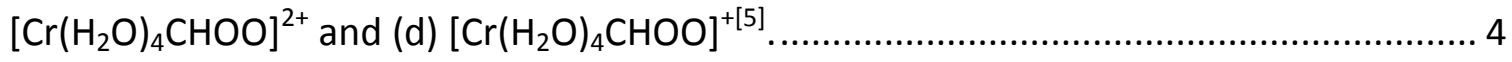

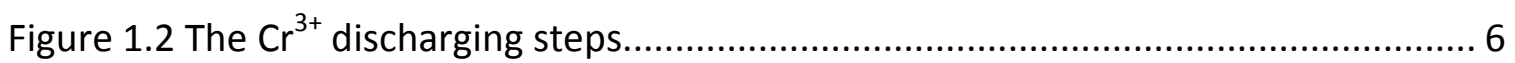

Figure 2.1 Electroplating power supply-Dynatronix DRP 20-10-30 ........................... 12

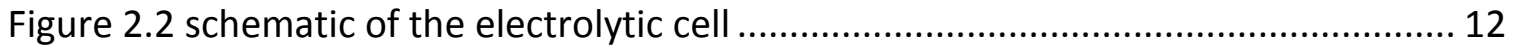

Figure 3.1 Schematic diagram for the Hull cell electroplating setup ............................ 21

Figure 3.2 Deposits obtained from solution 1,2,3,4,5, and 6 in Hull cell tests ................ 22

Figure 3.3 Cathodic polarization curves recorded in basic solution 5 with different scan

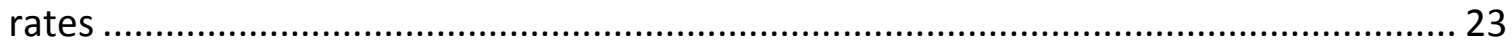

Figure 3.4 Cathodic polarization curves recorded in solution 1 and 2 with $5 \mathrm{mv} / \mathrm{s}$ scan rate 25

Figure 3.5 Cathodic polarization curves recorded in solution 2, 4, and 6 with $5 \mathrm{mv} / \mathrm{s}$ scan rate 26

Figure 3.6 SEM imaging of coatings deposit from solution 5 using different current

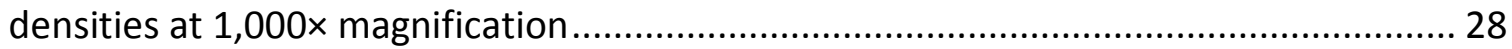

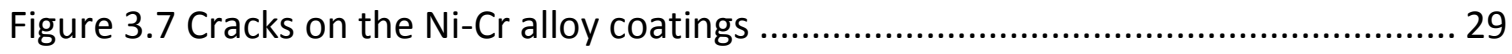

Figure 3.8 Effect of current density on the composition of $\mathrm{Cr}-\mathrm{Ni}$ coatings electroplated from the $\mathrm{Cr}(\mathrm{III})$ and $\mathrm{Ni}(\mathrm{II})$ bath using $\mathrm{DC}$ current. 30

Figure 4.1 SEM imaging of coatings deposit from bath 2 to bath 4 at $(\mathrm{a})(\mathrm{c})(\mathrm{e})(\mathrm{g})(\mathrm{i}) 1,000 \times$ and $(b)(d)(f)(h)(j) 5,000 \times$ magnification 36 Figure 4.2 Cathodic polarization curves for electrodes recorded in the basic electrolyte ( bath 4 and bath 1 without main salts) $\mathrm{pH} 2.0$, temperature $20{ }^{\circ} \mathrm{C}$, potential scan rate $5 \mathrm{mV} / \mathrm{s}$ 37

Figure 4.3 Schematic diagram showing the adsorption of surfactant molecules on the hydrogen bubble[62] 39 
Figure 4.4 SEM imaging of $\mathrm{Ni}-\mathrm{Cr}$ coating deposited from bath 4 at (a) 1,000x and (b) $5,000 \times$ magnification

Figure 4.5 XPS survey spectra for $\mathrm{Ni}-\mathrm{Cr}$ coating from bath 4 before and after sputtering for one minute

Figure 4.6 XPS spectra for (a) $\mathrm{C} 1 \mathrm{~s}$ (b) $\mathrm{Ni} 2 \mathrm{p}_{3 / 2}$ (c) $\mathrm{Cr} 2 \mathrm{p}_{3 / 2}$ recorded respectively for $\mathrm{Ni}-\mathrm{Cr}$ coating from bath 4 before and after sputtering for one minute

Figure 4.7 Fitting result of XPS spectra for $\mathrm{O} 1 \mathrm{~s}$ recorded for $\mathrm{Ni}-\mathrm{Cr}$ coating from bath 4 (a) before and (b) after sputtering for one minute.

Figure 4.8 Fitting result of XPS spectra for $\mathrm{C}$ 1s recorded for $\mathrm{Ni}-\mathrm{Cr}$ coating from (a) bath 1 and (b) bath 4 after sputtering for one minute

Figure 4.9 Fitting result of XPS spectra for $\mathrm{Cr}_{2} \mathrm{p}_{3 / 2}$ recorded for $\mathrm{Ni}-\mathrm{Cr}$ coating from (a) bath 1 and (b) bath 4 after sputtering for one minute.

Figure 4.10 Potentiodynamic polarization curves for different specimens in $3.5 \mathrm{wt} \% \mathrm{HCl}$ solutions.....

Figure 5.1 The current density waveform for 6 layers coating 50

Figure 5.2 SEM imaging of 6 multilayer coatings (a) morphology, (b) cross section ....... 51

Figure 5.3 Cross section EDS line scan of 6 multilayer coating.

Figure 5.4 Morphologies of the nano-multilayers at (a) $500 x$ and (b) $5,000 x$ magnification 52

Figure 5.5 (a) Petropoxy 154, (b) clamp 54

Figure 5.6 Cross-sectional TEM images of $\mathrm{Cr}-\mathrm{Ni}$ multilayers (a), (b) under different magnification, (c) HRTEM micrograph, and (d) SAED pattern of the coating shown in (b)

Figure 5.7 The EDS spectrum of (a) Ni-rich layer, (c) Cr-rich layer, and line scan result of (e) 56

Figure 5.8 Coefficient of friction profiles as a function of increasing normal load and SEM images of three regions over scratches..... 58 


\section{LIST OF TABLES}

Table 1.1 Standard electrode potential .................................................................... 1

Table 2.1 The composition of plating solution used to deposit the $\mathrm{Cr}-\mathrm{Ni}$ coatings at $25^{\circ} \mathrm{C}$

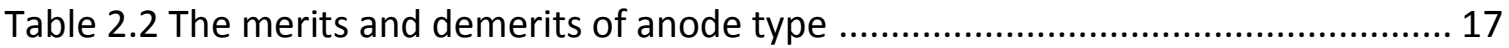

Table 3.1 Component of electrolytes used in Hull cell studies $\left(25^{\circ} \mathrm{C}\right)$............................. 22

Table 3.2 Constituent of electrolytes for cathodic polarization curves measurement.... 24

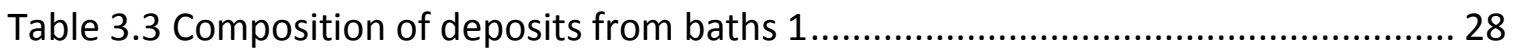

Table 4.1 Constituent of electrolytes with different volume ratio of DMF $\left(25^{\circ} \mathrm{C}\right) \ldots \ldots . . .34$

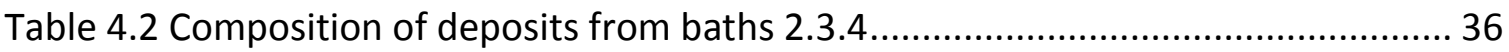

Table 4.3 Parameters of the photoelectron spectra of $\mathrm{C} 1 \mathrm{~s}$ of chromium deposits from

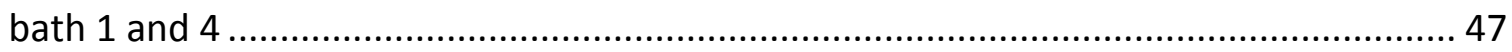

Table 4.4 The electrochemical parameters of potentiodynamic polarization curves in 3.5

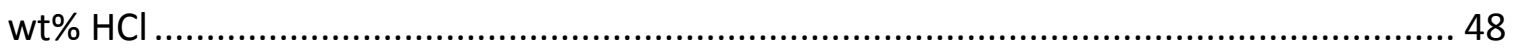

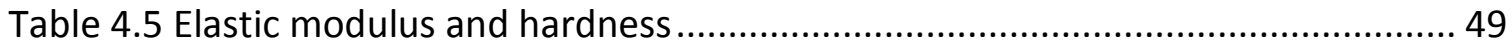

Table 5.1 Constituent of electrolytes for 6 multilayer coatings $\left(25^{\circ} \mathrm{C}\right)$........................ 50

Table 5.2 The quantitative chemical compositions in the Cr-rich and Ni-rich layers...... 52

Table 5.3 Deposition parameters for nano-multilayers for TEM observation ................ 52

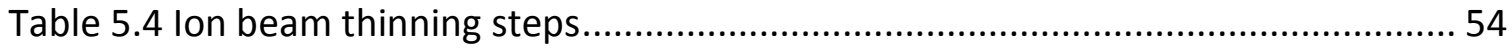

Table 5.5 The quantitative chemical compositions in the Cr-rich and Ni-rich layers....... 57

Table 5.6 Deposition parameters for nano-multilayers for hardness and wear resistance

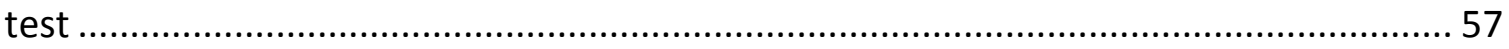




\section{Chapter 1 Introduction and Literature Review}

\subsection{Electroplating}

One of the less expensive and most popular techniques for the preparation of alloys is electroplating. Electroplating has considerable advantages over the other means of production of alloys because the technique is relatively easy, technically simple, fast and productive, and for certain system is the only method of preparation. Surface coatings produced by electroplating can much improve the substrate so that materials can be harder or more resistant to corrosive environments. Furthermore, electroplating is one of the most popular methods to produce amorphous alloy or so called metallic glass other than the rapid quenching method.

\subsection{Electroplating of $\mathrm{Ni}-\mathrm{Cr}$ alloy}

The major interests of developing $\mathrm{Ni}-\mathrm{Cr}$ alloy plating lies in the possible formation of a passive film by chromium and its good chemical and mechanical properties. The codeposition of nickel and chromium from aqueous solutions has been hampered by the large potential difference between the deposition of individual chromium and nickel. While, due to the significant difference alloys very rich in one of the two metals may be obtained.

Table 1.1 Standard electrode potential

$\begin{array}{cc}\text { Element } & \mathrm{E}^{\circ}(\mathrm{V}) \\ \mathrm{Ni}^{2+} / \mathrm{Ni} & -0.25 \\ \mathrm{Cr}^{3+} / \mathrm{Cr} & -0.74\end{array}$

In most cases, the electrodeposition of $\mathrm{Ni}-\mathrm{Cr}$ alloys is a co-deposition of anomalous plating types that is the electrochemically less noble nickel metal deposits preferentially on the cathodes with respect to chromium the more noble metal. Edigaryan[1] found 
that during the co-reduction of the ions with the formation of an alloy, the discharge rate of nickel ions is sharply decreased and the deposition of chromium is accelerated, compared to the electrodeposition of individual metals. The phenomenon observed was accounted for by a sharp decrease in the rate constant of the electrochemical reaction of nickel discharge on the surface of an alloy.

Usually, we use complex agent to control the active ion of the noble element (Ni) to realize co-deposition. According to Song's calculation[2], only $4 \%$ of the $\mathrm{Cr}^{3+}$ ions in the bulk solution participated in the overall reduction reaction $\mathrm{Cr}^{3+}$ to $\mathrm{Cr}(\mathrm{s})$. Hence, for the $\mathrm{Cr} / \mathrm{Ni}$ co-deposition, the complex agent is mainly used to increase the concentration of active $\mathrm{Cr}^{3+}$.

\subsubsection{Trivalent Chrome Plating}

Among many potential alternatives, trivalent $\mathrm{Cr}$ plating has been considered as a very promising technology to replace hexavalent $\mathrm{Cr}$ plating both in property and in cost. In the past 30 years, many articles and patents in trivalent $\mathrm{Cr}$ plating were published. In the US, Europe and Japan, commercial decorative trivalent $\mathrm{Cr}$ plating process has been in use since mid-1970s [14]. Thus, in recent years, the researches on the trivalent $\mathrm{Cr}$ plating have focused on the development of brightener, elimination of metal ion impurities, prevention of trivalent $\mathrm{Cr}$ oxidization near the anode, and fabrication of functional thick coatings with acceptable quality.

\subsubsection{The existence form of trivalent chromium ion in simple aqueous solution [3]}

In aqueous solution, $\mathrm{Cr}^{3+}$ ion won't exist independently but form an inner orbital coordination complexing compound $\mathrm{Cr}\left(\mathrm{H}_{2} \mathrm{O}\right)_{6}{ }^{3+}[4] . \mathrm{Cr}^{3+}$ ion is in the center of the octahedron[5] (Figure 1.1a), it can hardly get contact with the cathode to get electrons. Therefore, the inert $\mathrm{Cr}\left(\mathrm{H}_{2} \mathrm{O}\right)_{6}{ }^{3+}$ needs more negative potential for discharging. 
Hydrogen generation happens at the same time. The reduction reaction of $\mathrm{Cr}^{3+}$ to $\mathrm{Cr}^{0}$ is characterized by a standard reduction potential $\left(E^{\circ}=-0.74 \mathrm{~V}\right.$ vS $S H E$ ) more negative than the reduction potential of hydrogen in water:

$2 \mathrm{H}_{2} \mathrm{O}+2 e^{-} \rightarrow \mathrm{H}_{2}(g)+2 \mathrm{OH}^{-}$

$E^{\circ}=-0.12 \mathrm{~V}($ vs. SHE, $\mathrm{pH}=2)$

That means that the minimum polarization required to activate the reduction process of trivalent chromium will produce a considerable hydrogen evolution, which leads to poor-quality coatings with low current efficiency.

Moreover, the hydrogen evolution occurs at the cathode and causes a significant $\mathrm{pH}$ increase near the electrode surface. When the $\mathrm{pH}$ value is higher than 4.5 , the olation reaction[6] and formation of Cr olation products (high molecular weight polymers where the various $\mathrm{Cr}^{3+}$ ions are linked by hydroxyl bridges $[7,8]$ ) will occur as a result. Once the polymers formed during the olation process reach high values of molecular weight, they precipitate near the cathode surface limiting the availability of $\mathrm{Cr}^{3+}$.

It is mentioned in a review literature that [9], thick chrome coating can be deposited in ion electrolyte, current efficiency can be $30 \% \sim 40 \%$, by using the current density up to 15 A/dm² with deposit rate $8 \sim 1.0 \mu \mathrm{m} / \mathrm{min}$.

For the first time, the positive effect of some polybasic organic acid as ligands on the current efficiency and physical properties of chromium electrochemically deposited from diluted $\mathrm{Cr}(\mathrm{III})$ solution was noted[10]. 
a
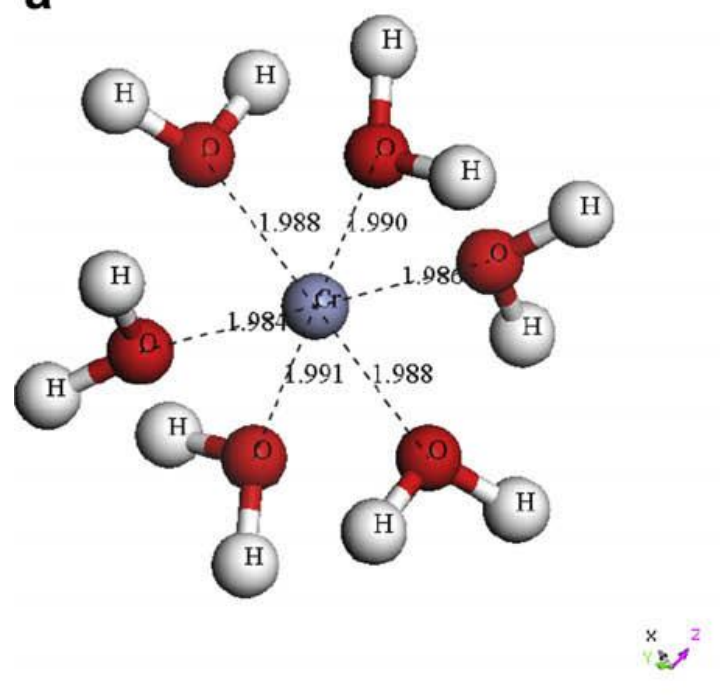

C

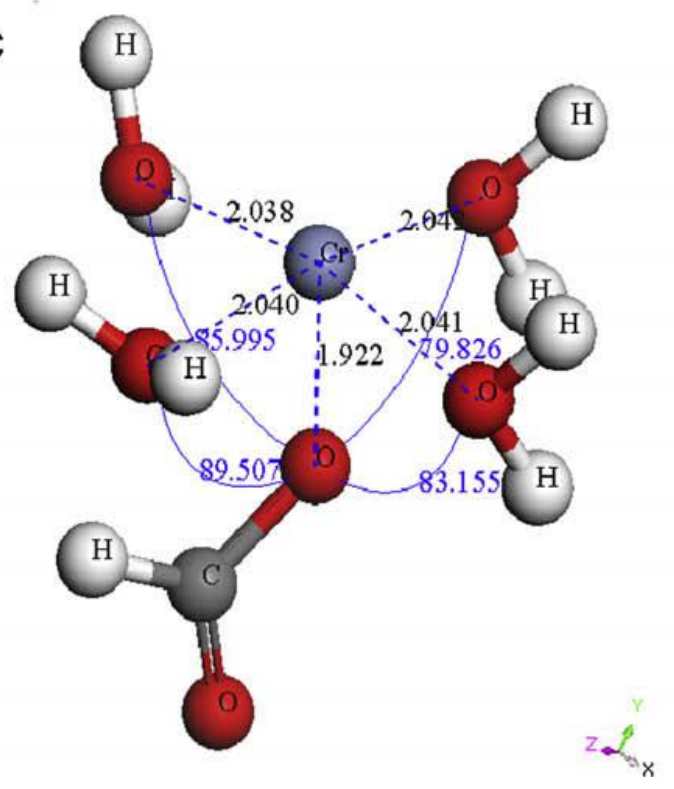

b
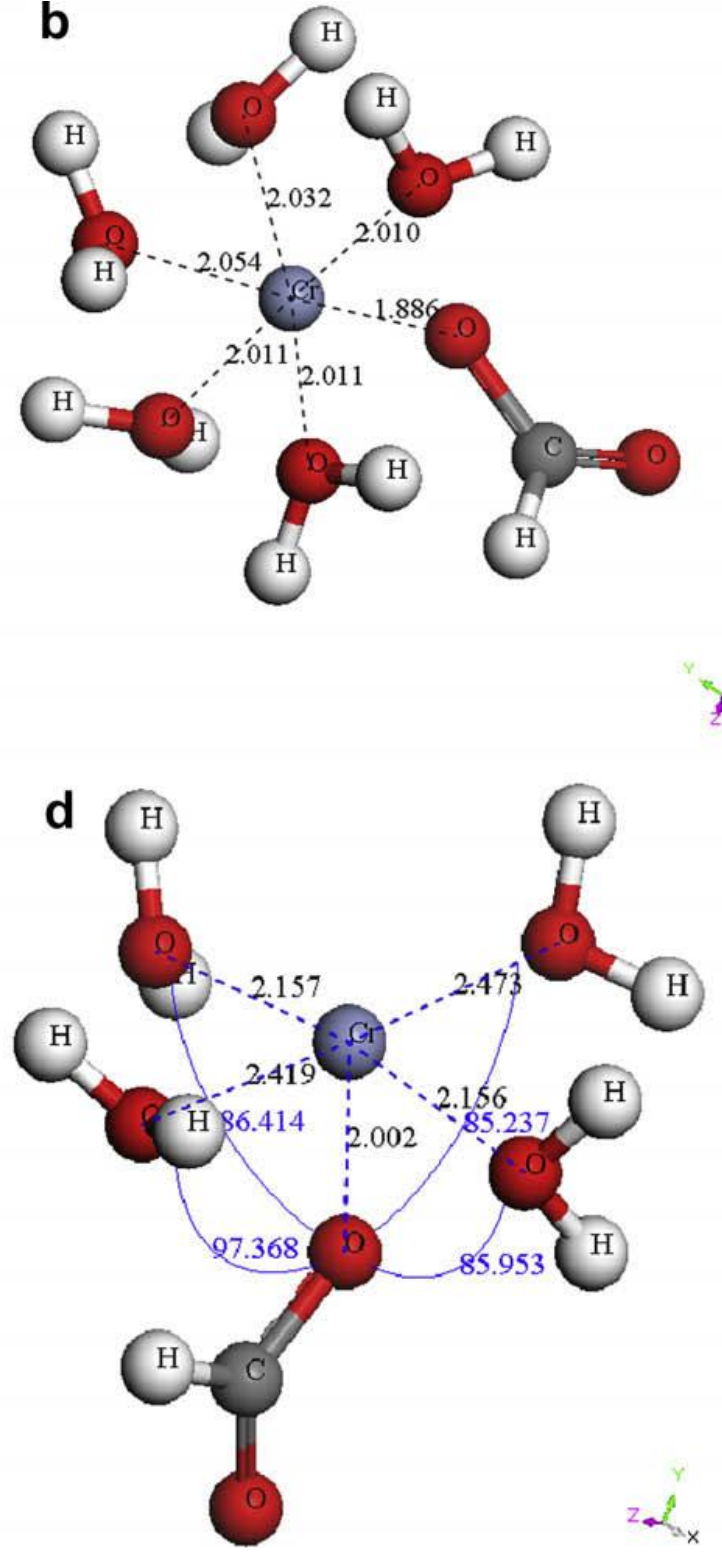

Figure 1.1 Equilibrium geometric structures of $(\mathrm{a})\left[\mathrm{Cr}\left(\mathrm{H}_{2} \mathrm{O}\right)_{6}\right]^{3+}$, (b) $\left[\mathrm{Cr}\left(\mathrm{H}_{2} \mathrm{O}\right)_{5} \mathrm{CHOO}\right]^{2+}$, (c) $\left[\mathrm{Cr}\left(\mathrm{H}_{2} \mathrm{O}\right)_{4} \mathrm{CHOO}\right]^{2+}$ and (d) $\left[\mathrm{Cr}\left(\mathrm{H}_{2} \mathrm{O}\right)_{4} \mathrm{CHOO}\right]^{+[5]}$.

\subsubsection{Discharge mechanism of tricalent $\mathrm{Cr}$}

It is difficult to electroplate trivalent chromium from aqueous solutions because aquachromium complexes have a low thermodynamic stability and a high kinetic inertness[11]. Whereas previous plating workers found that the high-quality coatings with excellent corrosion resistance and brightness can be electrodeposited from 
electrolytes containing a complex ion constituted by trivalent $\mathrm{Cr}$ and at least one weak complex agent such as oxalate and glycine[12], formic Acid[5] and oxalic acid[13]. The organic acid has less than six atoms of carbon and the amine has at most six atoms of carbon[14].

The electrolyte Giovanardi[15] used consist of $\mathrm{CrCl}_{3}$, Sulfate acid and formate. They found that formate could replace the water molecular in the $\left[\mathrm{Cr}\left(\mathrm{H}_{2} \mathrm{O}\right)_{6}\right]^{3+}$ forming an complex, which promote the discharge of $\mathrm{Cr}^{3+}$. The current efficiency can be up to $22.2 \%$.

Also, by using formate and urea as complex agents in the sulfate bath, nanocrystalline deposit was obtained with low $\mathrm{pH}$ value and high current density[16], with high corrosion resistance and hardness.

Zeng Zhixiang[13] studied the electrochemical reduction process of trivalent $\mathrm{Cr}$ in the presence of formic acid, and gave the optimized geometric structures of the original and transition state ions during the electroreduction process. According to Zeng, in the $\mathrm{Cr}-$ formic acid solution, the complexing ability of formate ion to $\mathrm{Cr}$ ion is stronger than that of $\mathrm{H}_{2} \mathrm{O}$, so a $\mathrm{H}_{2} \mathrm{O}$ molecule in $\left[\mathrm{Cr}\left(\mathrm{H}_{2} \mathrm{O}\right)_{6}\right]^{3+}$ will be replaced firstly by formate ion to produce $\left[\mathrm{Cr}\left(\mathrm{H}_{2} \mathrm{O}\right)_{5} \mathrm{CHOO}\right]^{2+}$. Figure $1.1(\mathrm{~b})$ is the equilibrium geometric structure of $\left[\mathrm{Cr}\left(\mathrm{H}_{2} \mathrm{O}\right)_{5} \mathrm{CHOO}\right]^{2+}$. Formate ion expands the distance between $\mathrm{Cr}^{3+}$ and $\mathrm{H}_{2} \mathrm{O}$ molecules. Thus this $\mathrm{H}_{2} \mathrm{O}$ molecule is easy to depart from central $\mathrm{Cr}^{3+}$, which results in the formation of $\left[\mathrm{Cr}\left(\mathrm{H}_{2} \mathrm{O}\right)_{4} \mathrm{CHOO}\right]^{2+} .\left[\mathrm{Cr}\left(\mathrm{H}_{2} \mathrm{O}\right)_{4} \mathrm{CHOO}\right]^{2+}$ is shown in Figure $1.1(\mathrm{c})$ which exhibits irregular octahedron structure with $\mathrm{Cr}^{3+}$ ion as a top. Due to the exposure of $\mathrm{Cr}^{3+}$ ion, $\mathrm{Cr}^{3+}$ ion can contact the cathode easily and obtain electrons. Figure 1.1(d) shows the equilibrium geometric structure of $\left[\mathrm{Cr}\left(\mathrm{H}_{2} \mathrm{O}\right)_{4} \mathrm{CHOO}\right]^{+}$. The introduction of an electron significantly weakens the forces between $\mathrm{Cr}$ and ligands. In this case, all $\mathrm{H}_{2} \mathrm{O}$ molecules are easy to depart from central $\mathrm{Cr}^{2+}$, which is favorable for the further quick reduction of $\mathrm{Cr}^{2+}$ to metallic $\mathrm{Cr}$ on the cathode.

However, it is reported that the $\mathrm{pH}$ value increased with long time electrodeposition. When it is more than 8[17], $\mathrm{Cr}(\mathrm{OH})_{3}$ formed on the surface of cathode, which decreased the quality of the coating and acted as a barrier for further deposition. This is one of 
main reasons for the difficulty of getting thick coating deposit from trivalent $\mathrm{Cr}$ bath. Rousseau[18] discovered which mechanism was the major cause of the decrease of the chromium deposition rate in a trivalent chromium bath from an electrochemical point of view.

It was pointed out[19-21] that electroreduction of $\mathrm{Cr}(\mathrm{II})$ is a rate-limiting stage in chromium electrodeposition. By establishing a mathematics model to testify the relationship s between $\mathrm{Cr}^{3+}$ ions concentration, diffusion intensity, temperature and the deposition rate of $\mathrm{Cr}^{3+}$ by mathematic methods. $\mathrm{Li}[19]$ find that even though the limited current density of the reaction $\mathrm{Cr}^{3+}+e \rightarrow \mathrm{Cr}^{2+}$ is controlled by diffusion step, the reaction of $\mathrm{Cr}^{2+}+e \rightarrow \mathrm{Cr}^{0}$ is the rate control step of the whole trivalent chromium electrodeposition, and the limited current density is independent of the diffusion condition.

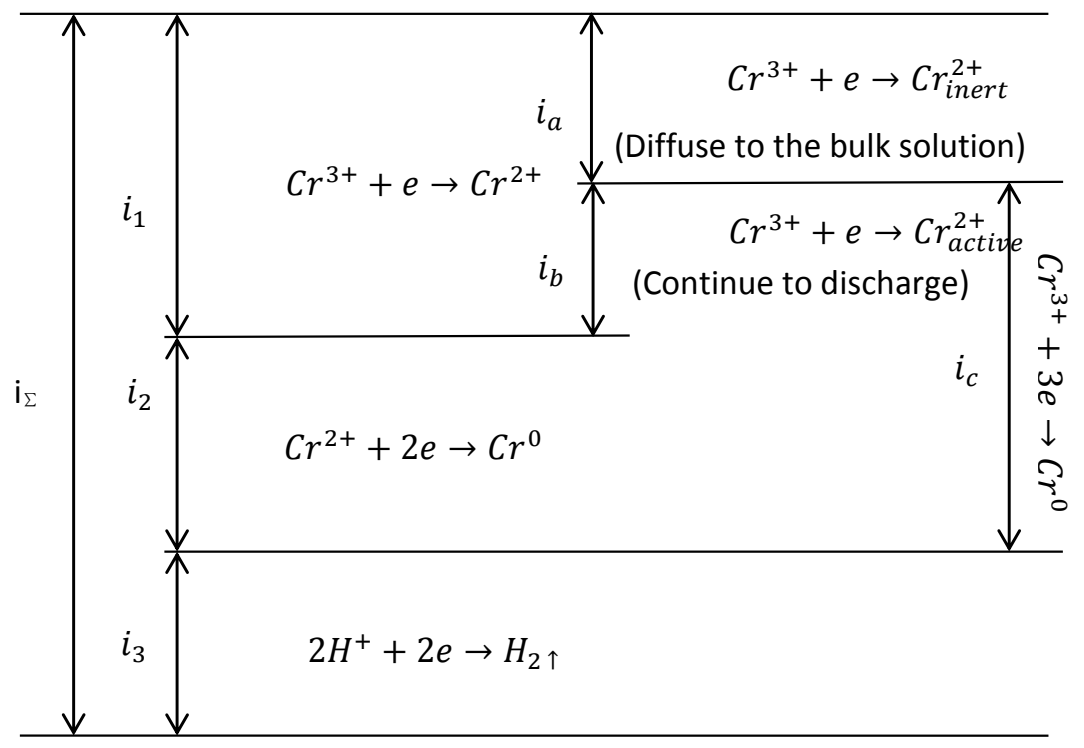

Figure $1.2 \mathrm{The}^{3+}$ discharging steps 


\subsubsection{Electrode reaction}

1) Cathode reactions

According to Song[2], the chromium electroplating proceeded in two steps:

In the first step, $\mathrm{Cr}$ (III) compounds were the reduced to $\mathrm{Cr}$ ( II ) compounds, $\mathrm{E}=-0.42 \mathrm{~V}$ (vs. SHE):

$\left[\mathrm{Cr}\left(\mathrm{H}_{2} \mathrm{O}\right)_{5} \mathrm{~L}\right]^{2+}+e^{-} \rightarrow\left[\mathrm{Cr}\left(\mathrm{H}_{2} \mathrm{O}\right)_{5} L\right]^{+}$where $\mathrm{L}^{-}$represents the ligand

In the second step, $\mathrm{Cr}$ (II) compounds were reduced to metallic chrome, E=-0.90V(vs. SHE):

$\left[\mathrm{Cr}\left(\mathrm{H}_{2} \mathrm{O}\right)_{5} L\right]^{+}+2 e^{-} \rightarrow \mathrm{Cr}(\mathrm{s})+5 \mathrm{H}_{2} \mathrm{O}+\mathrm{L}^{-}$

In $\mathrm{Cr}$ (III) based aqueous bath, the development of hydrogen happened at the cathode side as well, $\mathrm{E}=-0.12 \mathrm{~V}$ (vs. $\mathrm{SHE}, \mathrm{pH}=2$ ):

$2 \mathrm{H}_{2} \mathrm{O}+2 e^{-} \rightarrow \mathrm{H}_{2}(g)+2 \mathrm{OH}^{-}$

2) Anode reactions

Oxygen evolution $2 \mathrm{H}_{2} \mathrm{O}-2 e^{-} \rightarrow 2 \mathrm{H}^{+}+\mathrm{O}_{2}(g)$

Chlorine evolution (side reaction) $2 \mathrm{Cl}^{-}-2 e^{-} \rightarrow \mathrm{Cl}_{2}(g)$

Trivalent chromium was oxidized to hexavalent chrome (side reaction)

$C r^{3+}-3 e^{-} \rightarrow C r^{6+}$

\subsubsection{Internal stress in the deposits}

A general review of the causes of internal stresses in electrodeposits given by Weil summarizes five possible theories[22]: crystallite joining, hydrogen incorporation, changes in foreign substances, excess energy, and lattice effects.

When considering amorphous deposits, crystallite joining should be modified to nodule joining, which is taken into account in this study. Hydrogen incorporation can result in 
both compressive and tensile stresses; when hydrogen stays in the deposits after electroplating, a compressive stress is induced; on the other hand, once the incorporated hydrogen releases from the deposit, a tensile stress occurs resulting from the decrease in the volume of the deposit. Owing to the low current efficiency of trivalent $\mathrm{Cr}$ reduction, hydrogen incorporation plays an important role in this study and should be mainly discussed. Moreover, incorporated $\mathrm{C}$ originating from complex agents, is regarded as the foreign substances and can apparently influence the internal stress of the $\mathrm{Cr}-\mathrm{C}$ deposits. Consequently, the internal stress of the deposit plated in trivalent $\mathrm{Cr}$ baths seems to be related to crystallite/nodule joining, hydrogen incorporation, and $\mathrm{C}$ incorporation. Nodule joining can be the main source leading to tensile stresses in the amorphous $\mathrm{Cr}-\mathrm{C}$ deposits, according to Chien[23].

\subsubsection{Carbon in the coating}

As mentioned in 1.2.1.2, organic complex agents containing less than 6 carbons were needed to help trivalent $\mathrm{Cr}$ to be reduced to metallic $\mathrm{Cr}$. Inevitably, the final $\mathrm{Cr}$ coatings electrodeposited from these baths contain considerable carbon content due to the reduction of the carboxylic acids.

Moreover, the $\mathrm{Cr}-\mathrm{C}$ deposit can have extremely high electrocatalytic activity for the reduction of formic or oxalic acid[24]. It is generally recognized that $C$ incorporated in the interstitial sites of $\mathrm{Cr}$ results in lattice distortion. The extent of lattice distortion always increases as more $\mathrm{C}$ is incorporated in the $\mathrm{Cr}$ deposit. It is thus understandable that the $\mathrm{Cr}$ deposit plated in the bath displays an amorphous structure, as shown by both the XRD and TEM characterizations.

Edigaryan[25] assumed that the formation of these carbide compounds during the cathodic deposition of chromium electroplates from sulfuric acid $\mathrm{Cr}$ (III) solutions in the presence of sodium oxalate is a result of electrocatalytic activity of metal chromium. They confirmed this assumption by XPS analysis of surface layers formed during the exposure of chromium to sulfuric acid solutions containing organic substances. 
By calculation the separation factor for chromium and carbon deposition process, Protsenko[26] found that the rate of carbon co-deposition process is entirely determined by the rate of chromium electroplating reaction. He suggested that part of active chromium as-atoms generated as a result of $\mathrm{Cr}(\mathrm{II})$ ions discharge may interact with the carbon of organic bath constituent which is adsorbed on electrode surface:

$2 C r_{a d}^{0}+C(\mathrm{IV}) \rightarrow 2 C r(\mathrm{II})+C(0)$

Thus, the process of carbon co-deposition in $\mathrm{Cr}-\mathrm{C}$ electroplating from trivalent chromium bath under consideration does not occur as a "pure" electrochemical reduction. Active chromium ad-atoms seem to react with adsorbed organic molecules forming chromium carbon compounds by "chemical" mechanism.

\subsubsection{Hydrogen in the coating}

Hydrogen is present in chromium deposits in two forms. There is a mobile hydrogen that is removed from the deposits at $110-120^{\circ} \mathrm{C}$ and a more strongly bonded hydrogen the desorption of which finishes around $200^{\circ} \mathrm{C}[27]$.

\subsection{Multilayer coatings}

Multilayer films or compositionally modulated multilayers (CMM) consist of alternating layers of two different metals or alloys. It is found that multilayers can combine the properties of the constituent materials and have improved properties when compared to the individual single layer films. Furthermore, it has been observed that materials exhibit enhanced properties when their critical dimension is in the nano regime $(<100 \mathrm{~nm})$. Multilayered thin films have been shown to exhibit extremely high hardness and a low friction coefficient, making them useful as abrasion-resistant coatings[28].

Multilayered films introduce a large number of interfaces parallel to the substrate surface, which can deflect micro cracks and provide barriers to dislocation motion, increasing the strength and fracture toughness of the films[29]. When layers have small dimensions, dislocation blocking occurs when two phases of the multilayered film have different shear moduli, and therefore different dislocation-line energies. In this case, 
dislocations prefer to pile up at the interface within the layer with the lower shear modulus. An additional stress is required to move the dislocations into the layer with the higher shear modulus compared to that required in a homogeneous film.

\subsubsection{Electroplating of Multilayers}

Multilayers may be developed by a range of techniques, which include physical vapor deposition (PVD), chemical vapor deposition (CVD), their derivatives and sputtering Recently, electroplating has been employed for fabricating multilayers, because of its low cost and convenience in operation. For example, multilayers of $\mathrm{NiFe} / \mathrm{Cu}[30], \mathrm{Co}-$ $\mathrm{Cu} / \mathrm{Cu}[31]$ and $\mathrm{Co}-\mathrm{Ni} / \mathrm{Cu}[32]$ have been successfully deposited by means of electroplating.

There are mainly two techniques used for electrodeposition of multilayers - dual bath and single bath. The dual bath involves the use of two different plating baths. The substrate is successively transferred between separate plating baths to get different compositional layers. The main advantage of dual bath is that it could make sure each layer consist of pure metal. However, this process has some important draw backs: (1) it is often accompanied by different phenomena, such as dissolution and reaction displacement; (2) there may be contaminated or form an oxide layer on the substrate or former layer during the transfer between baths. Such an oxide layer will have a negative impact on the quality of multilayers. When it comes to $\mathrm{Ni} / \mathrm{Cr}$ multilayer, the oxide layer of chrome has no bonding with the following deposited layer. In SBT, an electrolyte containing two or more metal ions may be used. A deposition of multilayers from a single bath is normally carried out by periodically varying the current density or the potential owing to the difference in reduction potential for metals in electrolyte. This

process presents electrochemical limitations for two metals choice. The deposition current density or potential of both components must be sufficiently different to allow separate electrodeposition. Alloying of the less noble metal with the other is almost inevitable. Pure layers of the more noble metal can be deposited, while the less noble 
metal layers will always contain a certain amount of the other. In fact, this situation can increase the bonding of interfaces.

The Ni-Cr multilayers should exhibit improved characteristics compared with chromium without nickel deposits, such as corrosion and wear resistance[33]. In order to deposit $\mathrm{Ni}-\mathrm{Cr}$ multilayers in single bath, limit the amount of the noble metal (easy to be reduced) in the coating by mass transfer is needed. In my electrolyte, nickel is the noble material and $\mathrm{Cr}$ is the less noble one, because their reduction potentials.

The Ni-Cr multilayer coating in this study was deposited at room temperature, which obviated the problems associated with element diffusion and ensured a good interface structure.

\section{Chapter 2 Experimental Method}

\subsection{Electroplating Set-up}

The electroplating process was carried out by using Dynatronix DRP 20-10-30 shown in Figure 2.1 as the power supply. This is a pulse generator, and can provide voltage up to $20 \mathrm{~V}$ and peak current up to $30 \mathrm{~A}$. Especially, it has a recipe control function and the minimum recipe step transition time is 100 milliseconds, which makes the nano multilayer coating deposition possible. The schematic picture of electroplating process setup is shown in Figure 2.2. 


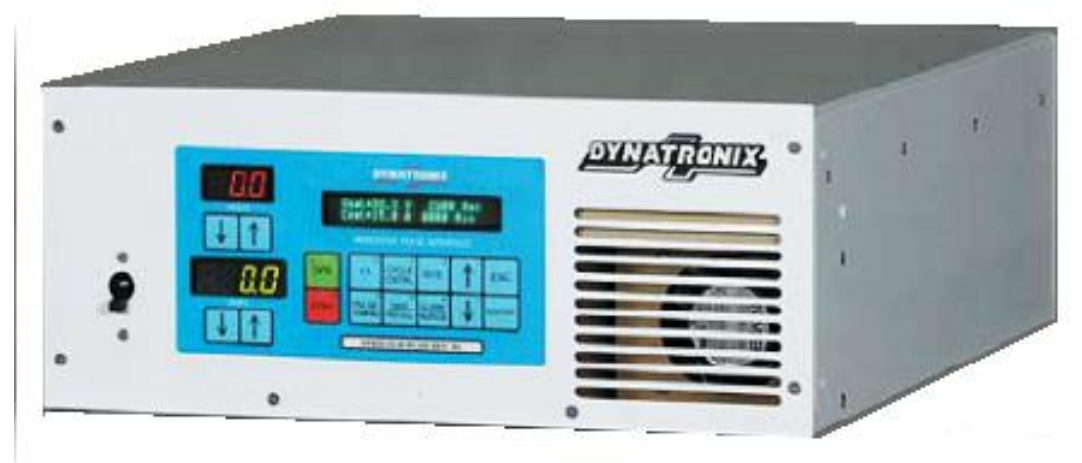

Figure 2.1 Electroplating power supply-Dynatronix DRP 20-10-30

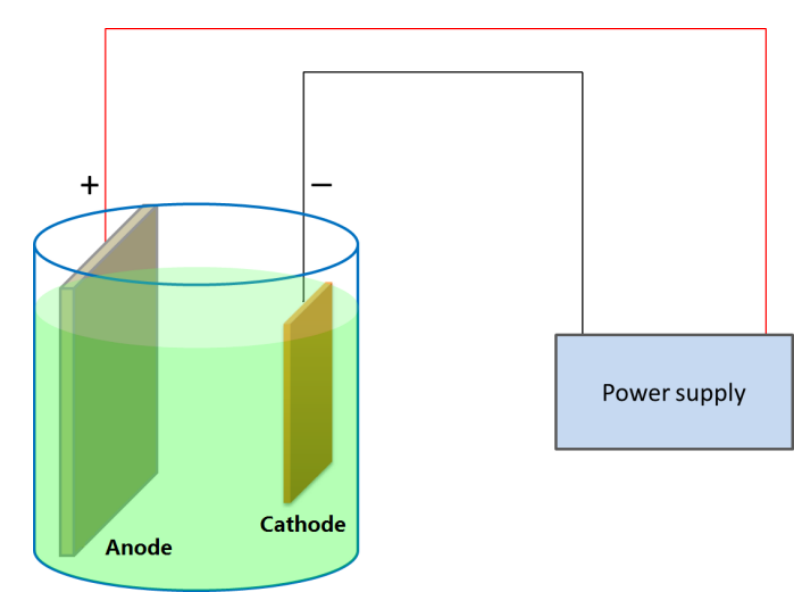

Figure 2.2 schematic of the electrolytic cell

\subsection{Electrolyte}

\subsubsection{Formula of Electrolyte}

The plating solution components were ascertained by groping experiments. 
Table 2.1 The composition of plating solution used to deposit the $\mathrm{Cr}$-Ni coatings at $25^{\circ} \mathrm{C}$

\begin{tabular}{ccc}
\hline Constituent & Concentration $(\mathrm{g} / \mathrm{L})$ & Function \\
\hline $\mathrm{CrCl}_{3} \cdot 6 \mathrm{H}_{2} \mathrm{O}$ & 128 & Source of $\mathrm{Cr}^{3+}$ \\
$\mathrm{NiCl}_{2} \cdot 6 \mathrm{H}_{2} \mathrm{O}$ & 25 & Source of $\mathrm{Ni}^{2+}$ \\
$\mathrm{CHOONa}$ & 40.8 & Organic complexing agent \\
$\mathrm{urea}$ & 36 & Organic complexing agent \\
$\mathrm{NaBr}$ & 18.5 & Antioxidizing agent \\
$\left(\mathrm{NH}_{4}\right)_{2} \mathrm{SO}_{4}$ & 20 & Electrolyte support \\
$\mathrm{H}_{3} \mathrm{BO}_{3}$ & 24 & Buffer agent \\
$\mathrm{SDS}$ & 0.2 & Wetting agent \\
$\mathrm{pH}$ & 2.0 & \\
\hline
\end{tabular}

\subsubsection{Preparation of the electrolyte for deposition}

All of the electrodeposition experiments were carried out in $500 \mathrm{~mL}$ electrolytes prepared with deionized water. All chemicals used were of laboratory reagent grade from Alfa Aesar. The $\mathrm{pH}$ of electrolytes was adjusted to a required value by addition of $\mathrm{HCl}$ or $\mathrm{NaOH}$. The electrolyte used in the initial electrodeposition trials was based on a simple solution from references $[15,17,34-36]$ and the concentration was ascertained by groping experiments. The $\mathrm{pH}$ was adjusted to 2 . After each electrodeposition, the $\mathrm{pH}$ was measured and readjusted to the original value.

Chromium chloride and sodium bromide were first added into DI water with magnetic stirrer agitation and heat at $80^{\circ} \mathrm{C}$, to promote the ions reach thermodynamic equilibrium state[5]. After at least $12 \mathrm{~h}$, sodium formate was added slowly with continued agitation for $1 \sim 2 h$ or saw the color of the solution change from dark green to bluish green, then add urea and other component separately with agitation until all the chemical dissolved. The solution was then kept standing for $12 \mathrm{~h}$ to approach equilibrium. The $\mathrm{pH}$ of the solution was then measured and adjusted to the values specified. Finally the solution was topped up to the correct working volume.

All the electrochemical measurements were carried out in a conventional threeelectrode cell at room temperature. A platinum plate ( $1 * 1 \mathrm{inch})$ was used as the counter electrode and a saturated $\mathrm{Ag} / \mathrm{AgCl}$ electrode served as a reference. 


\subsubsection{Influence of the components}

\subsubsection{Buffer agent:}

As mentioned in 1.2.1.3, at high current density, chrome electroplating accompanied by the hydrogen evolution requires a high buffer capacity of the solution. Accordingly, attention was mainly paid to choosing the buffer agent. For chrome electroplating bath, one typically uses boric acid[34] or aluminum sulfate[5] as buffer agents.

Boric acid is the most common buffer agent in the electroplating field. It also acts as a brightening agent for trivalent $\mathrm{Cr}$ electroplating[37].

While, the effect of $\mathrm{Al}^{3+}$ is controversial: the results from Roberti[15] show that the $\mathrm{Al}^{3+}$ ion is able to influence the deposition mechanism favoring a nucleation and growth process which ensures brightest deposits; at the same time $\mathrm{Al}^{3+}$ promotes the hydrogen reduction reaction, resulting in low current efficiency and defects, such as porosity and fractures, caused by excessive hydrogen evolution. The effect of $\mathrm{Al}^{3+}$ ion can be explained by considering, once again, its properties of Lewis acid and the fact that, being positively charged, it is located near the cathode surface: this ion is able to stabilize the $\mathrm{pH}$ at low values in proximity of the cathode surface even after the consumption of $\mathrm{Cr}^{3+}$ and $\mathrm{H}^{+}$. This phenomenon prevents the olation reaction from taking place, but simultaneously increases the amount of $\mathrm{H}^{+}$available for the hydrogen reduction reaction. El-Sharif[38] believed that the role of aluminum chloride was to improve bath stability and quality of chromium deposits.

Ward[39] indicated that Aqueous solutions of chromic salts are themselves acids. The simple hexaquo chromium (III) cation is capable of auto-ionization in proton accepting solvents to yield solvated hydrogen ions:

$$
\left[\mathrm{Cr}\left(\mathrm{H}_{2} \mathrm{O}\right)_{6}\right]^{3+} \leftrightarrow\left[\mathrm{Cr}(\mathrm{OH})\left(\mathrm{H}_{2} \mathrm{O}\right)_{5}\right]^{2+}+\mathrm{H}_{3} \mathrm{O}^{+}
$$

He pointed out that the buffer is agent must itself not be able to auto-ionize as an acid to yield the solvated proton. A range of organic liquids possess this property and are themselves good ionizing solvents. They are the dimethylated amides. 


\subsubsection{2 $\mathrm{Br}^{-}:$}

It was claimed in the patent[40] that the addition of sodium halide, particularly in a concentration of at least $0.8 \mathrm{M}$, not only increases the plating range and current efficiency, but also has a beneficial effect in enhancing covering power.

Help to suppress chlorine evolution

$$
2 \mathrm{Br}^{-}+\mathrm{Cl}_{2} \rightarrow \mathrm{Br}_{2}+2 \mathrm{Cl}^{-}
$$

Act as stabilizer, it was used to prevent the oxidation of $\mathrm{Cr}(\mathrm{III})$ into $\mathrm{Cr}(\mathrm{VI})$ at the anode $[41,42]:$

$$
\mathrm{Cr}^{6+}+3 \mathrm{Br}^{-} \rightarrow \mathrm{Cr}^{3+}+3 \mathrm{Br}
$$

\subsubsection{3 $\mathrm{NH}^{4+}$ :}

The addition of an ammonium salt according to the invention improves the stability of the solution and reduces the tendency to hydrogen evolution at higher water contents (the use of high water contents is desirable, other things being equal, from an economic viewpoint). Furthermore, the addition of an ammonium salt markedly reduces the effect of a change in $\mathrm{pH}$ on the lower limiting plating current density.

The ammonium should be present a $\mathrm{t}$ a concentration of at least $0.2 \mathrm{M}$, and preferably from $0.6 \mathrm{M}$ to $1.0 \mathrm{M}$. Solutions containing over $80 \%$ by volume of DMF, however, dissolve only traces of ammonium chloride due to its limited solubility in DMF. It is, therefore, necessary to provide sufficient water for the solution to be able to dissolve the required amount of ammonium salt.

The mixed solvent system could be stabilized by the addition of ammonium ions as ammonium chloride. In addition, the dissolved chlorine gas is involved in a further reaction with the ammonium chloride[41]:

$2 \mathrm{NH}_{4} \mathrm{Cl}+3 \mathrm{Cl}_{2} \rightarrow 2 \mathrm{~N}_{2}+8 \mathrm{HCl}$ 
This contributes to a gradual acidification of the bath, and helps to decrease the chlorine evolution.

\subsubsection{4 $\mathrm{Cr}^{6+}$}

When chromium VI was added to these baths in the form of sodium chromate, it was found to produce a mottled pattern of dark and light spots on the surface of the deposit about $1 \mu \mathrm{m}$ in size at a chromium VI level above 1200ppm. Increasing the level above this cased a marked deterioration of the alloy deposits[41].

\subsection{Substrate preparation}

The electrodeposition was conducted on copper sheet, with surface area1.5 $\times 3 \mathrm{~mm}^{2}$ expose to the electrolyte. Before electroplating, the substrates were first mechanically polished with various grades of Silicon carbide papers up to 1200 grit, rinsed with deionized water and then dried with a cold air blaster. The current density for electroplating was varied from 3 to $15 \mathrm{~A} \mathrm{dm}^{2}$ for DMF mixture electrolyte and 5-35 $\mathrm{A} / \mathrm{dm}^{2}$ for aqueous electrolyte. At the end of electroplating, the sample was cleaned in ethanol, dried with a hot air blaster and then prepared for microstructure characterization.

\subsection{The choose of anode}

The choice of anode material plays an important role in $\mathrm{Cr}$ or Ni/Cr electroplating, since an appropriate oxygen evolution potential is required at the anode side. As mentioned in 1.2.1.3, there are three possible reactions at the anode side. The lower the potential is, the more likely for oxygen evolution; conversely, if the potential is too high, $\mathrm{Cr}^{3+}$ is likely to be oxidized to $\mathrm{Cr}^{6+}$, and $\mathrm{Cr}^{6+}$ will poison the plating bath. However, if the potential is too high, the severe reaction will lead to sharp $\mathrm{pH}$ value change and the instability of the bath. Separation of the anode is one way to solve this problem.

To maintain the stability of the electrolyte for $\mathrm{Ni}$ and $\mathrm{Cr}$ co-deposition, it is preferred that the anode be made of inert material, like high-density graphite and DSA. Table 2.2 is a brief comparison among them. 
Table 2.2 The merits and demerits of anode type

\begin{tabular}{cccc}
\hline Type & high-density graphite & DSA & Separation of anode \\
\hline Strength & $\begin{array}{c}\text { Cheap, good conductivity, } \\
\text { good corrosive resistance }\end{array}$ & $\begin{array}{c}\text { Convenient, good Low } \\
\text { oxygen evolution potential, } \\
\text { corrosive resistance, long } \\
\text { life time, cheaper than } \\
\text { platinum }\end{array}$ & $\begin{array}{c}\text { Solve the } \mathrm{Cr}^{6+} \\
\text { poisoning problem }\end{array}$ \\
\hline Drawback & $\begin{array}{c}\text { Fail to prevent } \mathrm{Cr}^{6+} \\
\text { formation, likely to be } \\
\text { oxidized, and the fall down } \\
\text { particle will contaminate } \\
\text { the bath }\end{array}$ & $\begin{array}{c}\text { Current efficiency a little } \\
\text { lower than that of graphite }\end{array}$ & $\begin{array}{c}\text { Complex structure, } \\
\text { high cost(ion exchange } \\
\text { membrane), and } \\
\text { limited life time }\end{array}$ \\
\hline
\end{tabular}

\subsubsection{Dimensionally stable anodes (DSA)}

Dimensionally stable anodes were developed in the 1965 by Beer[43], and were first applied in the chloralkali industry. Basically, they use precious metal $\mathrm{RuO}_{2}$ and $\mathrm{TiO}_{2}$ mixture coated on titanium. $\mathrm{TiO}_{2}$ served as a matrix contribute to improve the mechanical and chemical stability[44], and $\mathrm{RuO}_{2}$ attribute to big decrease of the over potential for chlorine or oxygen evolution. Moreover, DSA have good corrosion resistance in chlorine generating environment and do not contaminate the electrolyte because of their remarkable stability unlike the graphite anodes they replaced. In this research, DSA was chosen to be used as anode.

\subsection{Characterization of coatings}

\subsubsection{Scanning Electron Microscopy (SEM)}

The surface morphology of the deposit and the cross section were observed using a scanning electron microscope (JEOL JSM-7600F), and the average composition of the deposit was measured with an Oxford Inca energy-dispersive X-ray spectrometry (EDS) system equipped with SEM. LEI mode was used to observe the morphology, and COMPO mode was used to reflect more information about the multilayer structure. 
Cross-sectional specimens mounted in epoxy or fixed in the clamp were mechanically ground using a series of abrasive SiC grit size papers, from 120 to 1200 grit, followed with final polishing using $3 \mu \mathrm{m}$ and $1 \mu \mathrm{m}$ diamond suspension.

\subsubsection{Transmission Electron Microscopy (TEM)}

The microstructure of multilayered thin films was examined by TEM. Specimens for TEM were prepared with a special process to an ultrathin thickness that allows electrons to transmit through the sample. Cross-sectional TEM samples were prepared by mechanical thinning, polishing, followed by $\mathrm{Ar}^{+}$ion milling with $5 \mathrm{keV}$ beam energy with an incident beam angles of $6^{\circ}, 4^{\circ}$, and $2^{\circ}$ using a Gatan precision ion polishing system. All TEM images of the films were obtained using FEI Tecnai T12 and FEI Tecnai F20.

\subsubsection{X-ray photoelectron spectroscopy (XPS)}

X-ray photoelectron spectroscopy (XPS) analysis was carried out using a PHI 5000 VersaProbe System, utilizing monochromatic AlKa radiation to examine the passive film formed on the surface and the chemical state in the deeper layer of specimens. The C1s peak from carbon contamination at $284.8 \mathrm{eV}$ was used as a reference to correct for charging shifts. After a background subtraction according to Shirley, the quantification of the species in the passive film was processed with XPSpeak 4.1 peak fitting software.

\subsubsection{Electrochemical Measurements}

All the electrochemical measurements were set up with a three electrode cell in a $500 \mathrm{ml}$ glass container. A potentiostat/galvanostat (EG\&G 263A) controlled by a computer was used for all the electrochemical measurements. The three electrode cell setup consisting of a pair of graphite counter electrodes (CE), an $\mathrm{Ag} / \mathrm{AgCl}$ reference electrode (RE) immersed in a saturated potassium chloride $(\mathrm{KCl})$ solution and the specimen as the working electrode (WE) was employed. Potentials cited in this thesis are all referred to $\mathrm{Ag} / \mathrm{AgCl}$. 


\subsubsection{Cathodic polarization curve measurement}

$1.0 \mathrm{~cm} \times 1.0 \mathrm{~cm}$ specimens were cut from the copper sheet by using diamond saw. All cathodic polarization curve measurements were performed at room temperature using different electrolytes, prepared with deionized water. All specimens were mounted using epoxy, ground with silicon carbide (SiC) papers starting from 120-grit and finishing with 800 -grit, rinsed with distilled water, dried with a cold air blaster and then transferred to the test electrolyte.

\subsubsection{Corrosion resistance measurement}

$1.0 \mathrm{~cm} \times 1.0 \mathrm{~cm}$ specimens were cut from the coating samples by using diamond saw. All electrochemical measurements were performed at room temperatures using a $3.5 \mathrm{wt}$. \% $\mathrm{NaCl}$ solution, prepared with deionized water. All specimens were mounted using epoxy, ground with silicon carbide (SiC) papers starting from 120-grit and finishing with 800-grit, rinsed with distilled water, dried with a cold air blaster and then transferred to the test solution.

\subsubsection{Nano-indentation}

Nanoindentation has been recently rekindled because of a need for techniques to study the mechanical properties of thin films. Nanoindentation is similar to conventional hardness testing but performed on a much smaller scale. The depth resolution is on the scale of nanometers. Thus, it is possible to conduct indentation experiments on thin films $[45,46]$. Nanohardness $(\mathrm{NH})$ is defined as the indentation load divided by the projected contact area, and it can be obtained using the relationship $\mathrm{NH}=\mathrm{P}_{\max } / \mathrm{A}$, where $\mathrm{P}$ max is the maximum load applied during the indentation, and $\mathrm{A}$ is the contact area between the indenter and specimen, projected into the plane of the surface. Nano indentation was performed with a Nano-Indentation Tester (NHT2) by CSM Instruments and the experiments were conducted using a spherical indenter was loaded to normal loads up to $1 \mathrm{mN}$ with a pause of 10 seconds. 


\subsubsection{Mircoscratch test}

Mircoscratch as well as friction and wear tests were carried out using a CETR microtribometer (CETR Inc.). In the microscratch tests, a conical diamond indenter having a tip radius of $1.5 \mu \mathrm{m}$ and an included angle of $60^{\circ}$ was drawn over the sample surface, and the load was ramped up until substantial damage occurred. An acoustic emission sensor was used to detect crack formation during scratching. The $0.5-\mathrm{mm}$ long scratches were made by translating the sample while ramping the loads on the conical tip over different loads ranging from $6 \mathrm{mN}$ to $50 \mathrm{mN}$. The coefficient of friction, friction force, normal load, and acoustic emission signal were detected in situ during scratching. Scanning electron microscopy (SEM; Zeiss Ultra plus Field Emission Gun (FEG)-SEM) was used to examine the scratch tracks for all samples.

\section{Chapter 3 Electroplating of Nickel-Chrome alloys in aqueous solution}

\subsection{Hull cell study}

The Hull cell is an economical and powerful screening device to estimate the effects of electrolyte compositions and concentrations, and applied working conditions (e.g.: temperature, $\mathrm{pH}$ value, and stirring) on the deposit surface appearance, composition and crystal structure.

Normally, the Hull cell gives information about the deposits features over a wide range of current densities and various experimental results on a single cathode. For its high efficiency, Hull cell technology was chosen to initial study the influence of some key parameters (e.g.: main salts concentration and current density) on Cr deposit content in the electroplating of $\mathrm{Ni}-\mathrm{Cr}$ alloys.

As mentioned in 1.2 , the difference between the deposition potential of individual chromium and nickel is large, and the co-deposition of them only happened in a narrow 
range of the current density. Therefore, to increase the range of current density for $\mathrm{Ni}$ $\mathrm{Cr}$ alloy formation was the initial goal of this research.

\subsubsection{Experimental set-up and design}

Hull cell tests were used to study the effect of main salts concentration on the coatings.

The setup for Hull cell electroplating is shown in Figure 3.1. Dynatronix DRP 20-10-30 worked as power source to supply current needed for DC electroplating. Masked copper sheet $(100 \times 70 \mathrm{~mm})$ with exposed $1230 \mathrm{~mm}^{2}(100 \times 12.3 \mathrm{~mm})$ deposit area for DC electroplating and DSA sheet $(63 \times 70 \mathrm{~mm})$ was served as the anode.

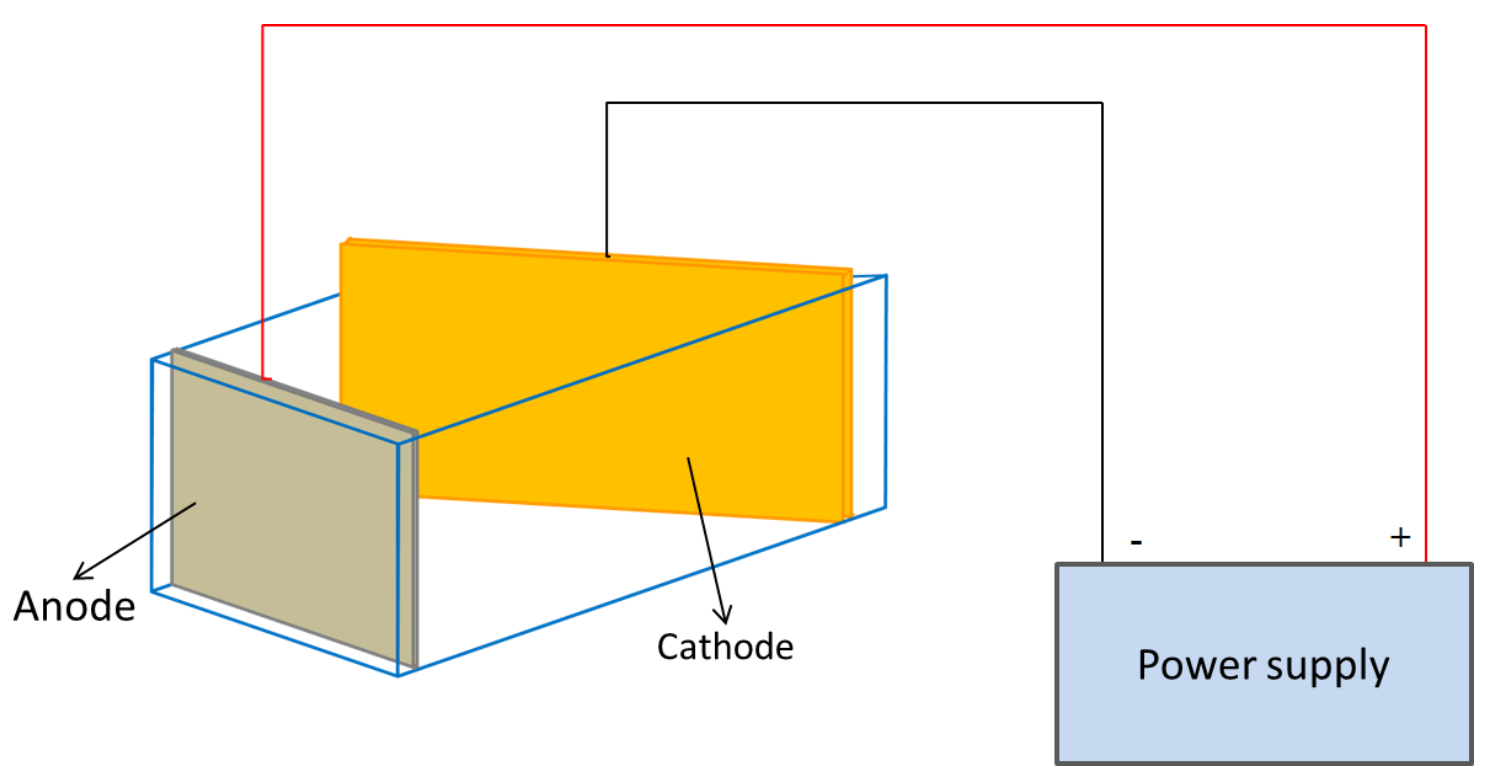

Figure 3.1 Schematic diagram for the Hull cell electroplating setup

\subsubsection{The effect of the concentrations for main salts}

The tests were conducted in a $267 \mathrm{ml}$ Hull cell filled with the baths as shown in Table 3.1. In order to develop $\mathrm{Cr}-\mathrm{Ni}$ alloy plating with different $\mathrm{Cr}$ and $\mathrm{Ni}$ contents, the concentration of the two main salts are variable, and that of other salts are fixed. 
Table 3.1 Component of electrolytes used in Hull cell studies $\left(25^{\circ} \mathrm{C}\right)$

\begin{tabular}{ccccccc}
\hline & Solution & Solution & Solution & Solution & Solution & Solution \\
& 1 & 2 & 3 & 4 & 5 & 6 \\
\hline $\mathrm{CrCl}_{3} \cdot 6 \mathrm{H}_{2} \mathrm{O}$ & $0.4 \mathrm{M}$ & $0.4 \mathrm{M}$ & $0.4 \mathrm{M}$ & $0.6 \mathrm{M}$ & $0.6 \mathrm{M}$ & $0.6 \mathrm{M}$ \\
$\mathrm{CHOO}^{-}$ & $0.8 \mathrm{M}$ & $0.8 \mathrm{M}$ & $0.8 \mathrm{M}$ & $0.8 \mathrm{M}$ & $0.8 \mathrm{M}$ & $0.8 \mathrm{M}$ \\
$\mathrm{Br}^{-}$ & $0.1 \mathrm{M}$ & $0.1 \mathrm{M}$ & $0.1 \mathrm{M}$ & $0.1 \mathrm{M}$ & $0.1 \mathrm{M}$ & $0.1 \mathrm{M}$ \\
$\mathrm{NH}_{4}^{+}$ & $0.2 \mathrm{M}$ & $0.2 \mathrm{M}$ & $0.2 \mathrm{M}$ & $0.2 \mathrm{M}$ & $0.2 \mathrm{M}$ & $0.2 \mathrm{M}$ \\
$\mathrm{H}_{3} \mathrm{BO}_{3}$ & $0.6 \mathrm{M}$ & $0.6 \mathrm{M}$ & $0.6 \mathrm{M}$ & $0.6 \mathrm{M}$ & $0.6 \mathrm{M}$ & $0.6 \mathrm{M}$ \\
$\mathrm{urea}_{\mathrm{NiCl}} \cdot 6 \mathrm{H}_{2} \mathrm{O}$ & $0.8 \mathrm{M}$ & $0.8 \mathrm{M}$ & $0.8 \mathrm{M}$ & $0.8 \mathrm{M}$ & $0.8 \mathrm{M}$ & $0.8 \mathrm{M}$ \\
$\mathrm{pH}$ & $0.1 \mathrm{M}$ & $0.2 \mathrm{M}$ & $0.3 \mathrm{M}$ & $0.1 \mathrm{M}$ & $0.2 \mathrm{M}$ & $0.3 \mathrm{M}$ \\
\hline
\end{tabular}

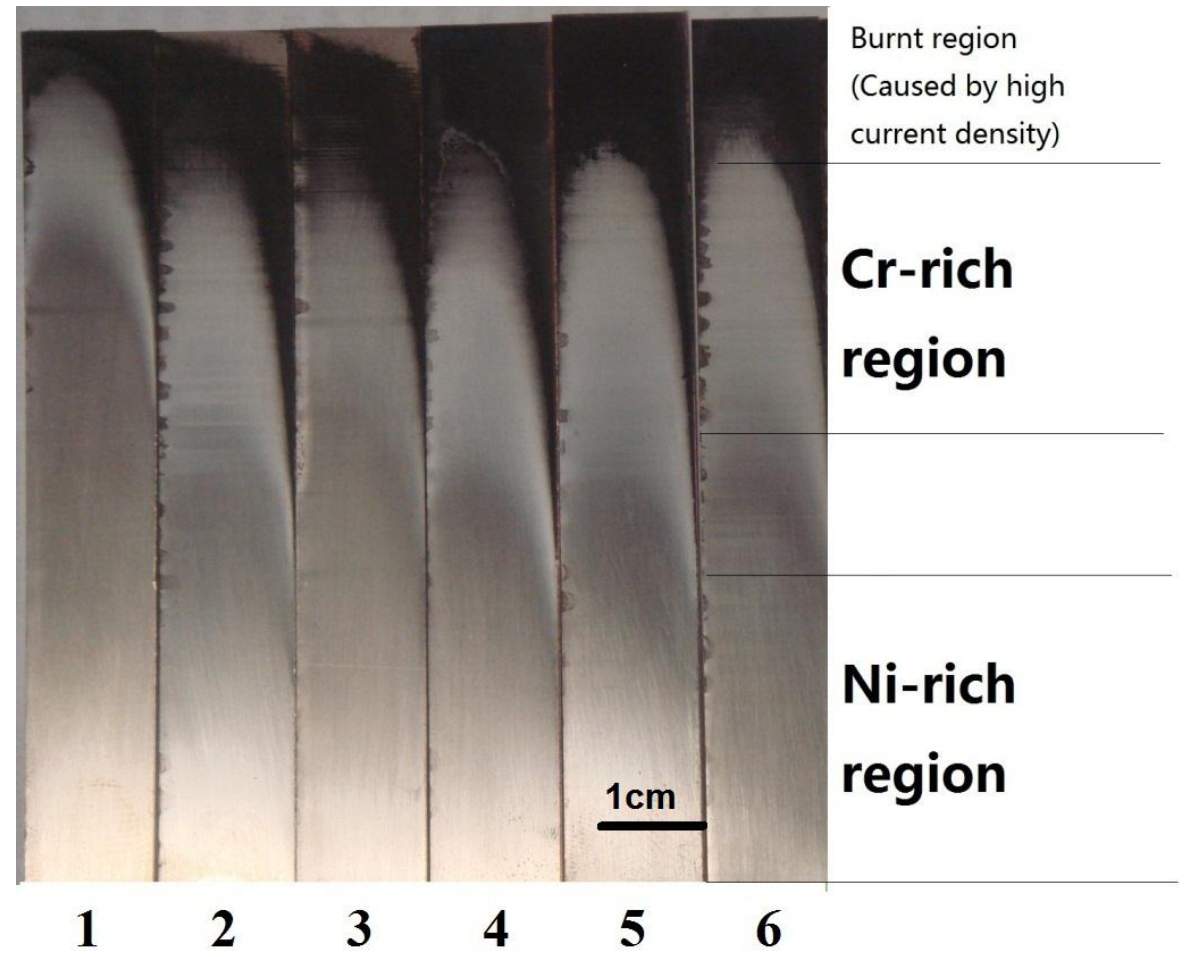

Figure 3.2 Deposits obtained from solution 1,2,3,4,5, and 6 in Hull cell tests

The results of Hull Cell tests showed in Figure 3.2. According to the Hull cell experiments, bright $\mathrm{Cr}-\mathrm{Ni}$ alloy coatings are obtained in the range $5-40 \mathrm{~A} / \mathrm{dm}^{2}$. It should be pointed out 
that the bright range is silvery white with slightly golden tinge to silvery white in appearance, which may be associated with $\mathrm{Ni}$ rich and $\mathrm{Cr}$ rich coating. The silvery white with slightly golden tinge color may be associated with the Ni rich coating, whereas the silvery white color with the $\mathrm{Cr}$ rich coating. The black part was caused by high current density.

The current density range of $\mathrm{Cr}$-rich coating is very narrow in solution 1 , at a very wide range of current densities, only Ni-rich layer can be deposited. With the increase of $\mathrm{Cr}^{3+}$ concentration in the solution, the current density range for $\mathrm{Cr}$-rich layer increase. The $\mathrm{Ni}-\mathrm{Cr}$ alloy range of solution 5 and 6 seem the same, but the range for $\mathrm{Cr}$-rich coating of solution 5 is larger. Since a decent wide range of current densities for alloy and $\mathrm{Cr}$-rich deposits were the initial goal, the composites and concentration of solution 5 was good for further study.

\subsubsection{Cathode polarization curve}

Cathodic potentiodynamic behavior of the various electrolytes was determined using linear sweep voltammetry.

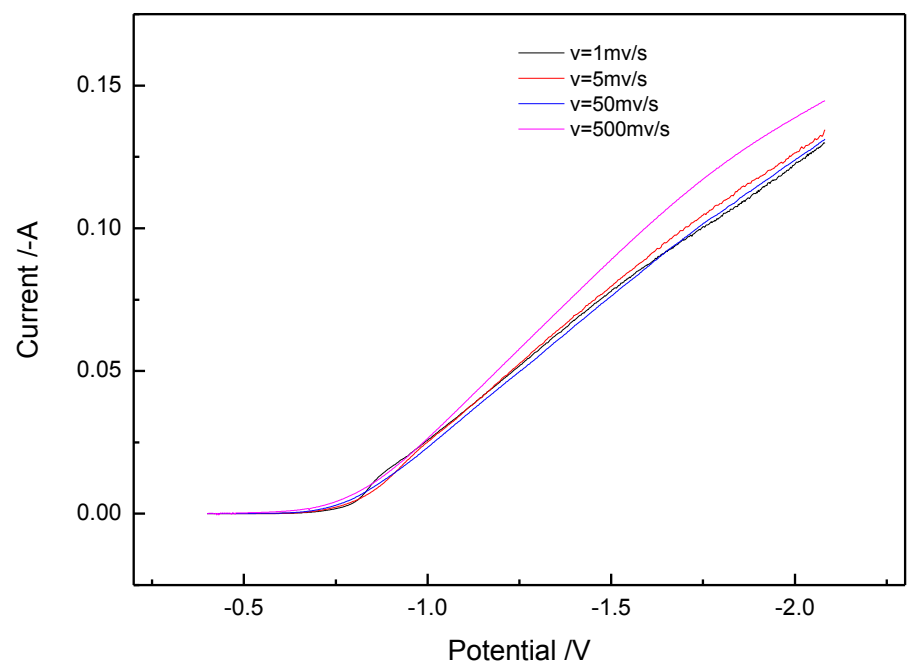

Figure 3.3 Cathodic polarization curves recorded in basic solution 5 with different scan rates 
They were measured in basic solution 5 (without main salts) with different scan rates in a potential range from $-0.4 \mathrm{~V}$ to $-2.0 \mathrm{~V}$ to determine the suitable scan rate. From Figure 3.3 , the curves scanned by $1 \mathrm{mv} / \mathrm{s}, 5 \mathrm{mv} / \mathrm{s}$ and $50 \mathrm{mv} / \mathrm{s}$ were almost the same. Based on the need of efficiency and accuracy, $5 \mathrm{mv} / \mathrm{s}$ was chosen for future study.

Electrodeposition of $\mathrm{Cr}$-Ni alloy coatings was carried out in $\mathrm{Cr}$ (III) baths, using the nominal compositions of baths, which are presented in Table 3.2.

Table 3.2 Constituent of electrolytes for cathodic polarization curves measurement

\begin{tabular}{|c|c|c|c|c|c|}
\hline \multirow{2}{*}{$\begin{array}{l}\left(25^{\circ} \mathrm{C}\right) \\
\text { Constituent }\end{array}$} & \multicolumn{5}{|l|}{ Solution } \\
\hline & 1 & 2 & 3 & 4 & 5 \\
\hline $\mathrm{CrCl}_{3} \cdot 6 \mathrm{H}_{2} \mathrm{O}$ & $0.48 \mathrm{M} / \mathrm{L}$ & $0.48 \mathrm{M} / \mathrm{L}$ & $0.48 \mathrm{M} / \mathrm{L}$ & & \\
\hline $\mathrm{NiCl}_{2} \cdot 6 \mathrm{H}_{2} \mathrm{O}$ & & & $0.12 \mathrm{M} / \mathrm{L}$ & $0.12 \mathrm{M} / \mathrm{L}$ & $0.12 \mathrm{M} / \mathrm{L}$ \\
\hline CHOONa & & $0.6 \mathrm{M} / \mathrm{L}$ & $0.6 \mathrm{M} / \mathrm{L}$ & & $0.6 \mathrm{M} / \mathrm{L}$ \\
\hline urea & & $0.6 \mathrm{M} / \mathrm{L}$ & $0.6 \mathrm{M} / \mathrm{L}$ & & $0.6 \mathrm{M} / \mathrm{L}$ \\
\hline $\mathrm{NaBr}$ & $0.18 \mathrm{M} / \mathrm{L}$ & $0.18 \mathrm{M} / \mathrm{L}$ & $0.18 \mathrm{M} / \mathrm{L}$ & $0.18 \mathrm{M} / \mathrm{L}$ & $0.18 \mathrm{M} / \mathrm{L}$ \\
\hline$\left(\mathrm{NH}_{4}\right)_{2} \mathrm{SO}_{4}$ & $0.18 \mathrm{M} / \mathrm{L}$ & $0.18 \mathrm{M} / \mathrm{L}$ & $0.18 \mathrm{M} / \mathrm{L}$ & $0.18 \mathrm{M} / \mathrm{L}$ & $0.18 \mathrm{M} / \mathrm{L}$ \\
\hline $\mathrm{H}_{3} \mathrm{BO}_{3}$ & $0.43 \mathrm{M} / \mathrm{L}$ & $0.43 \mathrm{M} / \mathrm{L}$ & $0.43 \mathrm{M} / \mathrm{L}$ & $0.43 \mathrm{M} / \mathrm{L}$ & $0.43 \mathrm{M} / \mathrm{L}$ \\
\hline solvent & DI water & DI water & DI water & DI water & DI water \\
\hline pH before & 2 & 2 & 2 & 2 & 2 \\
\hline pH after & 2 & 2 & 2 & 2 & 2 \\
\hline Coating quality & Black & $\begin{array}{l}\text { Shining } \\
\text { sliver } \\
\text { white color }\end{array}$ & $\begin{array}{l}\text { Shining } \\
\text { sliver } \\
\text { white color }\end{array}$ & Black & $\begin{array}{l}\text { Shining sliver white } \\
\text { color with slightly } \\
\text { golden tinge }\end{array}$ \\
\hline
\end{tabular}




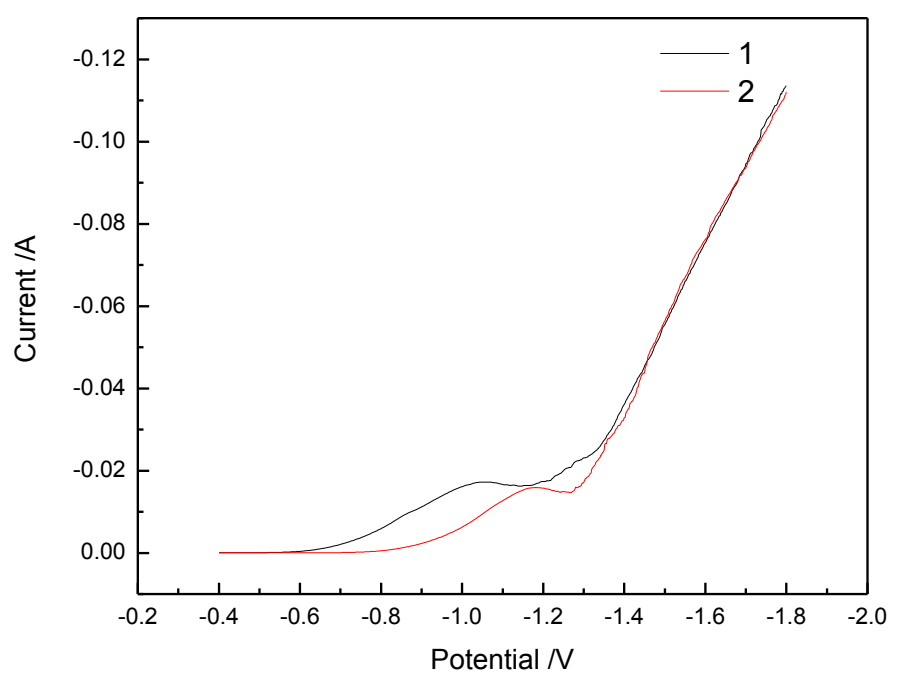

Figure 3.4 Cathodic polarization curves recorded in solution 1 and 2 with $5 \mathrm{mv} / \mathrm{s}$ scan rate

Figure 3.4 shows the current potential curves for bath 1 and 2 as previously described in Table 3.2. Curve 2 for chromium with complex agents divides into two main parts separated by a short plateau region at $-1.15 \mathrm{~V}$ to $-1.3 \mathrm{~V}$. There are no current until the electrode potential reaches $-0.8 \mathrm{~V}$, then the current increases with the potential sweep. This wave $(-0.8 \mathrm{~V}$ to $-1.15 \mathrm{~V})$ is due to the reduction of $\mathrm{Cr}(\mathrm{III})$ to $\mathrm{Cr}(\mathrm{II})[17,41]$. The $\mathrm{Cr}(\mathrm{II})$ which diffuses back into the bath is highly unstable and will react with the hydrogen ion or water to form hydrogen gas and return to $\mathrm{Cr}(\mathrm{III})$. At the potential more negative than $-1.3 \mathrm{~V}$ the deposition of chromium metal begins and the current rises rapidly. Inspection of the data reveals the discharge of hydrogen occurs within the current plateau region, as can be observed visually. 


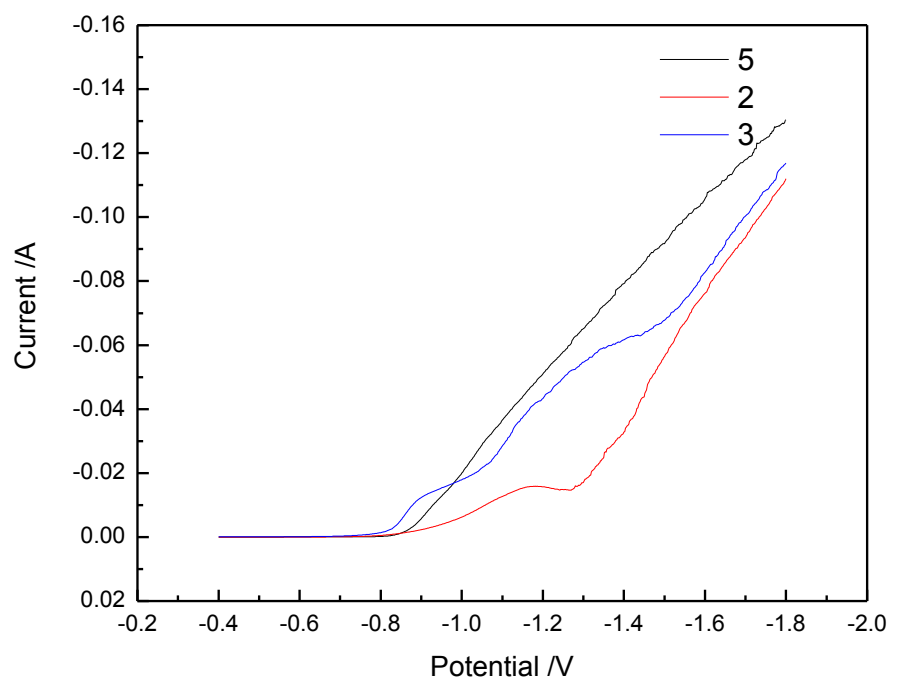

Figure 3.5 Cathodic polarization curves recorded in solution 2, 4, and 6 with $5 \mathrm{mv} / \mathrm{s}$ scan rate

Figure 3.5 show the cathodic polarization curves recorded in bath 2, 3 and 5 respectively. The curves were swept from $-0.2 \mathrm{~V}$ in the negative direction. These curves are characterized by an initial rapid potential shift to more negative values followed by a gradual increase in the current density. Simultaneous discharge of hydrogen ions was observed during the electrodeposition of $\mathrm{Cr}$ or $\mathrm{Ni}$ or $\mathrm{Cr}-\mathrm{Ni}$ alloy. The potential at which the current rises sharply could be considered as the deposition potential for chromium. However, it is known that the standard reduction potential for chromium from $\mathrm{Cr}(\mathrm{III})$ solution is less negative, about $-740 \mathrm{mV}(\mathrm{SHE})$, indicating that $\mathrm{Cr}$ deposition is accompanied by polarization. The curve 5 for nickel (bath 5 ) with complex agents shows nickel deposition from - $0.85 \mathrm{~V}$. No separate wave is seen due to the hydrogen evolution at a lower over-potential. It has been found experimentally that the formation of $\mathrm{Cr}-\mathrm{Ni}$ alloy begins at a less negative potential $(-0.9 \mathrm{~V})$ than that of pure $\mathrm{Cr}(-1.15 \mathrm{~V})$ in the bath without of $\mathrm{Ni}(\mathrm{II})$ ions. 


\subsection{The Effect of current density}

\subsubsection{Morphology}

Figure 3.6 shows the SEM pictures of $\mathrm{Ni}-\mathrm{Cr}$ coatings deposited from solution 5 using different current densities. The deposition parameters show in Table 3.3.
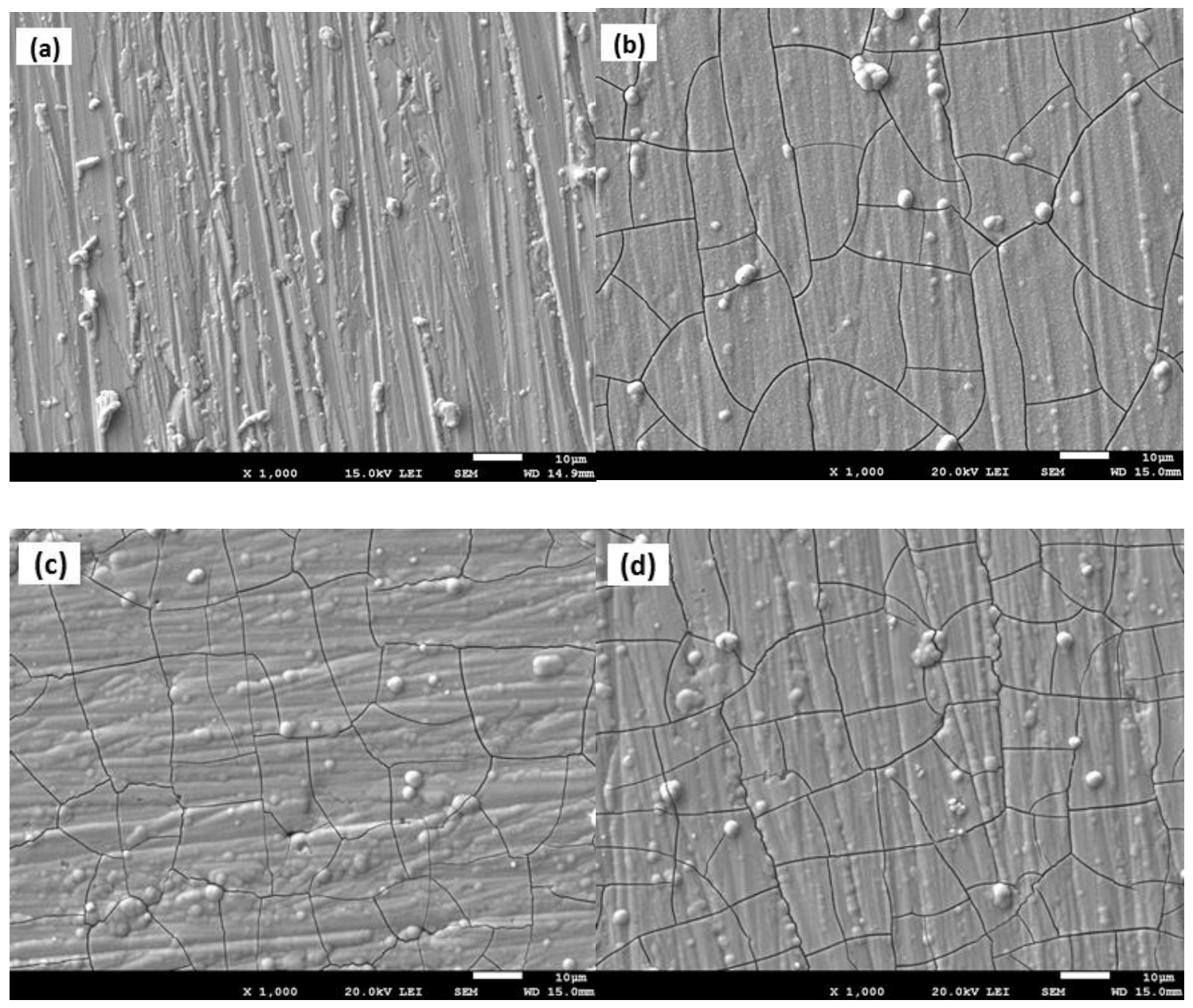


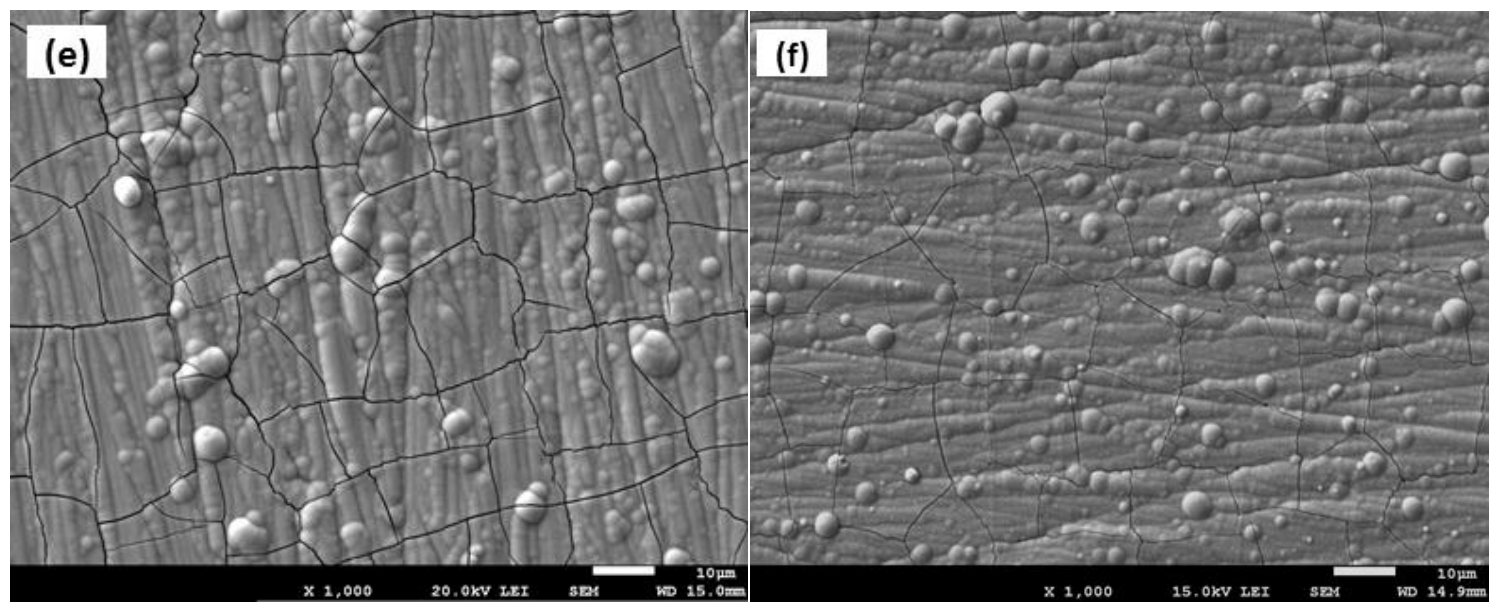

Figure 3.6 SEM imaging of coatings deposit from solution 5 using different current densities at 1,000x magnification

All the coatings deposited from solution 5 had cracks on the surface, expect for Figure 3.6 (a). With the increase of current density applied, the density of cracks increased. The microstructures show a smooth surface containing some nodules on top and some microcracks on the coating. It was generally believed that the cracks were attributed to the reduction of hydrogen ions during the electrodeposition process results in hydrogen evolution. At lower $\mathrm{pH}$, the reduction of hydrogen ions during the electrodeposition is more pronounced due to higher concentration of hydrogen ions, thus higher tendency for microcracks formation is expected by applying a high cathodic current density.

Table 3.3 Composition of deposits from baths 1

\begin{tabular}{ccccc}
\hline Picture & Atomic\% Cr & Atomic\% Ni & $\begin{array}{c}\text { Current Density } \\
\left(\mathrm{A} / \mathrm{dm}^{2}\right)\end{array}$ & Time (min) \\
\hline (a) & 0 & 100 & 5 & $10 \mathrm{~min}$ \\
(b) & 14.48 & 85.52 & 10 & $10 \mathrm{~min}$ \\
(c) & 22.51 & 77.49 & 15 & $10 \mathrm{~min}$ \\
(d) & 50.41 & 49.59 & 20 & $10 \mathrm{~min}$ \\
(e) & 79.04 & 20.96 & 25 & $10 \mathrm{~min}$ \\
(f) & 87.51 & 12.49 & 30 & $10 \mathrm{~min}$ \\
\hline
\end{tabular}



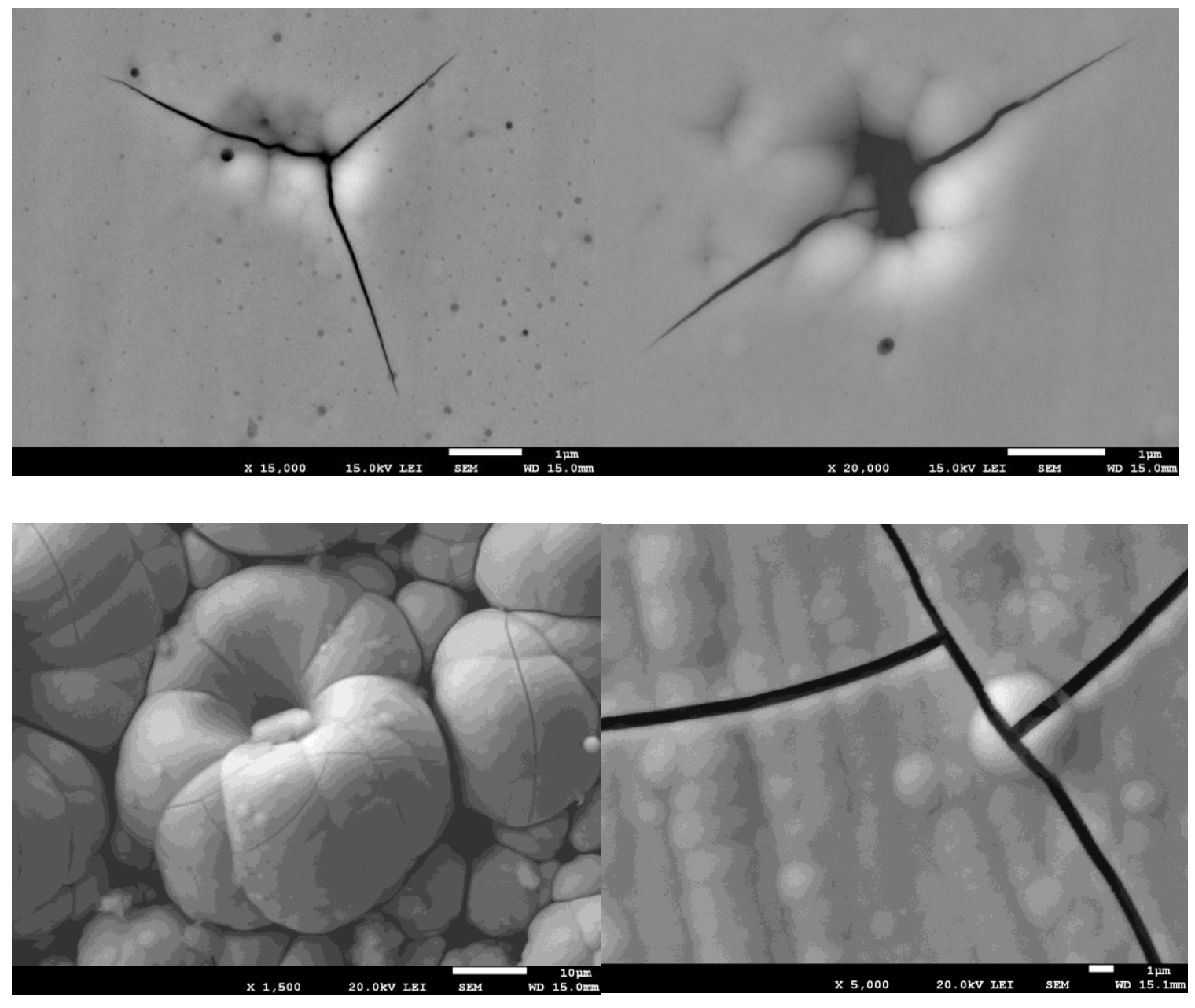

Figure 3.7 Cracks on the $\mathrm{Ni}-\mathrm{Cr}$ alloy coatings

Some researchers [47] believed the crack formed on and along the boundaries of the nodular grains formed. Conversely, this assumption was not consistent with the SEM observation result of our samples. Obviously, the cracks went through the pinhole or the nodular grains directly, which indicated that the cracks formation time was after the deposition finished. However, when exactly the cracks formed was still unknown.

\subsubsection{Composition}




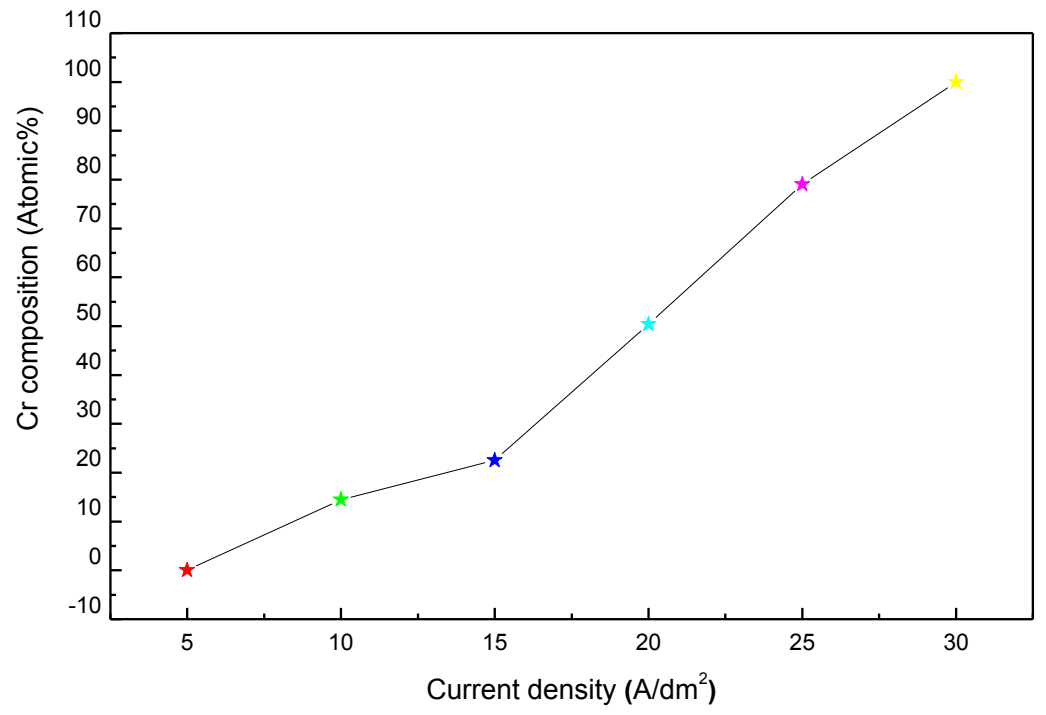

Figure 3.8 Effect of current density on the composition of $\mathrm{Cr}-\mathrm{Ni}$ coatings electroplated from the $\mathrm{Cr}(\mathrm{III})$ and $\mathrm{Ni}(I I)$ bath using DC current.

It can be seen from Figure 3.8 that the influence of current density on $\mathrm{Cr}$ content of the deposits is great. With the increase of current density, the $\mathrm{Cr}$ content increases continuously. Coatings of $\mathrm{Cr}$ content from $0 \%$ to $87.51 \%$ were achieved.

From the result of Figure 3.8, Cr-rich and Ni-rich deposits were achieved individually by regulating the current density: lower current densities or less negative reduction potentials for Ni-rich deposits, and higher plating current densities or higher reduction potentials for $\mathrm{Cr}$-rich deposits. Hence, a multilayer structure with a modulation of $\mathrm{Cr}$ rich and $\mathrm{Ni}$-rich deposits can be expected to be deposited by means of pulse plating with the current densities.

\subsection{Crack-proposed solution}

It is pointed out by some researchers $[48,49]$ that the surface cracks created in $\mathrm{Cr}$ deposits or $\mathrm{Cr}$ alloys are difficult to avoid by using direct current electroplating in aqueous solution, because of the high residual stresses in the $\mathrm{Cr}$ deposit and the 
creation of hydrogen bubbles during electroplating. According, $\mathrm{Ni}-\mathrm{Cr}$ alloy electroplating also encountered the same problem.

Three directions were proposed to eliminate the cracks involving the release of residual stress, suppression of hydrogen evolution and the introduction of sublayer to prevent the crack from propagate the coating.

It is reported that crack free $\mathrm{Cr}$ or $\mathrm{Ni} / \mathrm{Cr}$ alloy coating could be realized by pulse current density $[50,51]$. The effect of pulse plating on crack elimination was explained through the earlier release of hydrogen and stress during the off-period. However, the goal was achieved at the expense of $\mathrm{Cr}$ content, since the chromium deposit would also redissolve during off period at the same time.

During the late 1960s, using organic solvents (or mixed with water) were proposed[40], in particular one consisting of dimethylformamide (DMF) as a polar aprotic solvent which decreases the $\mathrm{H}_{2}$ gas evolution. Mixture of different dipolar organic compounds may be employed. In order to minimize the tendency of hydrogen to be evolved at the cathode, it is preferred that the dipolar organic compound be aprotic.

For optimal hardness and corrosion resistance, Huang[52] recommend a sequential twostep electrodeposition with Ni-rich alloy electroplating followed by Cr-rich alloy electroplating, or $\mathrm{Cr} / \mathrm{Ni}$ alloy electrodeposition, to create a protective coating.

As an alternative, Etminanfar[53] showed that the optimized $20 \mathrm{nmCr} / 50 \mathrm{nmNi}$ multilayer coating have great corrosion resistance due to its crack free surface and layered structure.

Wang[54] found that the microcracks formed during electroplating were closed after plasma nitriding at higher temperature as the result of nitride and carbide layer formation and nitrogen and carbon went into the cracks. Moreover, there is a slight increase in the surface hardness of nitrided specimen compared to hard chromium plating. 


\section{Chapter 4 Electroplating of Nickel-Chrome alloys in DMF- Mixture Solution}

It is generally believed[55] that surface cracking in the $\mathrm{Cr}$ deposit can reduce its residual stress developed during the electrocrystallization of metallic chromium, suggesting that the higher surface-crack density of the $\mathrm{Cr}$-deposit is, the lower the residual stress would be. However, from the perspective of corrosion resistance mechanism, it has been accepted by many researchers that surface cracks of the $\mathrm{Cr}$ deposit would be the active path in certain corrosive environment due to crevice corrosion within the crack and exposing especially in the relatively active substrate. Therefore, attempts to develop a plating technology for a crack-free $\mathrm{Cr}$ or $\mathrm{Cr}$ alloy deposits are very important.

The use of a dipolar organic compound in place of a substantial proportion of the water of an aqueous plating bath has the advantage of reducing the tendency of hydrogen to be evolved at the cathode.

If the complexes formed are excessively stable, then electrodeposition may be difficult. It is believed[40] that the highly electronegative oxygen atoms which characterize the dipolar organic compounds of this invention may act as covalent links in the formation of complexes between the chromic ions and the organic molecules.

In 1969, Bharucha[40] and Ward of the British Non-Ferrous Metals Research Association (BNFMRA) published information on a trivalent chromium plating process using an unusual solution with 50 percent by volume dimethylformamide (DMF) as the solvent for chromic chloride.

\subsection{Introduction of DMF}

Dimethylformamide (DMF) is a dipolar aprotic solvent with the formula $\left(\mathrm{CH}_{3}\right)_{2} \mathrm{NC}(\mathrm{O}) \mathrm{H}$, which is miscible with water in all proportion and the majority of organic liquids. It contains no labile hydrogen atoms and therefore does not have the ionizing ability to provide solvated hydrogen ions. 
DMF[40], in addition to possessing the best balance of physical, chemical, toxicological and economic properties, has good electroplating properties. DMF has a wide liquid range (B.P. $150^{\circ} \mathrm{C}$ ), high dielectric constant (37.5), low Vapor pressure at ordinary temperature $\left(3.6 \mathrm{~mm}\right.$ mercury at $\left.25{ }^{\circ} \mathrm{C}\right)$ and is completely miscible with water in all proportions. The chromic salt $\mathrm{CrCl}_{3} \cdot 6 \mathrm{H}_{2} \mathrm{O}$ has very high solubility (450g/L) in DMF, the interaction with the solvent resulting in stable complexes of the type $\mathrm{CrCl}_{3} \cdot 6 \mathrm{DMF}$ and $\mathrm{CrCl}_{3} \cdot 4 \mathrm{DMF}$.

DMF was used as complex agent for trivalent chromium [7, 56, 57]. Wald pointed out in the patent[58] that DMF could be treated as "a weak complexing agent for trivalent chromium ions" which is used and defined herein as meaning a complexing agent for trivalent chromium ions which does not bind trivalent chromium so strongly as to prevent electrodeposition of chromium from aqueous trivalent chromium solutions containing it. DMF was also tried in our laboratory at various concentrations as complex agents but had negative effects.

Additionally, DMF was also used as butter agent[59]. These was consistent with our experimental findings that it consumed more analytical pure $\mathrm{HCl}$ to adjust to the target $\mathrm{pH}$ value of DMF mixture electrolyte compared to aqueous solution. However, for this study, the DMF was only served as part of the solvent.

Fawcett[60] reported a study of the electroreduction of $\operatorname{Cr}(\mathrm{DMF})_{6}^{3+}$ in $\mathrm{DMF}$, and they concluded that the electroreduction of $\mathrm{Cr}(\mathrm{DMF})_{6}^{3+}$ in $\mathrm{DMF}$ is in many ways similar to the reaction in water, while the rate of the reaction in DMF is approximately 30 times faster than in water under equivalent conditions.

\subsection{DMF mixture electrolyte}

Because the limitation of solubility and conductivity of DMF will lead to low current efficiency and bad coating quality, the content of DMF needed to be controlled within a certain range. To get the optimized DMF content range, different volume ratio of DMF 
in the solvent were studied; details were showed in Table 4.1. All the components were dissolved in the mixture of DI water and DMF.

Table 4.1 Constituent of electrolytes with different volume ratio of DMF $\left(25^{\circ} \mathrm{C}\right)$

\begin{tabular}{|c|c|c|c|c|c|}
\hline $\begin{array}{l}\text { Bath No. } \\
\text { Constituent }\end{array}$ & 1 & 2 & 3 & 4 & 5 \\
\hline $\mathrm{CrCl}_{3} \cdot 6 \mathrm{H}_{2} \mathrm{O}$ & $0.48 \mathrm{M}$ & $0.48 \mathrm{M}$ & $0.48 \mathrm{M}$ & $0.48 \mathrm{M}$ & $0.48 \mathrm{M}$ \\
\hline $\mathrm{NiCl}_{2} \cdot 6 \mathrm{H}_{2} \mathrm{O}$ & $0.12 \mathrm{M}$ & $0.12 \mathrm{M}$ & $0.12 \mathrm{M}$ & $0.12 \mathrm{M}$ & $0.12 \mathrm{M}$ \\
\hline CHOONa & $0.6 \mathrm{M}$ & $0.6 \mathrm{M}$ & $0.6 \mathrm{M}$ & $0.6 \mathrm{M}$ & $0.6 \mathrm{M}$ \\
\hline Urea & $0.6 \mathrm{M}$ & $0.6 \mathrm{M}$ & $0.6 \mathrm{M}$ & $0.6 \mathrm{M}$ & $0.6 \mathrm{M}$ \\
\hline $\mathrm{NaBr}$ & $0.18 \mathrm{M}$ & $0.18 \mathrm{M}$ & $0.18 \mathrm{M}$ & $0.18 \mathrm{M}$ & $0.18 \mathrm{M}$ \\
\hline$\left(\mathrm{NH}_{4}\right)_{2} \mathrm{SO}_{4}$ & $0.18 \mathrm{M}$ & $0.18 \mathrm{M}$ & $0.18 \mathrm{M}$ & $0.18 \mathrm{M}$ & $0.18 \mathrm{M}$ \\
\hline $\mathrm{H}_{3} \mathrm{BO}_{3}$ & $0.43 \mathrm{M}$ & $0.43 \mathrm{M}$ & $0.43 \mathrm{M}$ & $0.43 \mathrm{M}$ & $0.43 \mathrm{M}$ \\
\hline \multirow{2}{*}{ Solvent } & \multirow[t]{2}{*}{$100 \%$ DI water } & $80 \%$ DI water & $70 \%$ DI water & $60 \%$ DI water & $50 \%$ DI water \\
\hline & & $+20 \% \mathrm{DMF}$ & $+30 \% \mathrm{DMF}$ & $+40 \% \mathrm{DMF}$ & $+50 \% \mathrm{DMF}$ \\
\hline $\mathrm{pH}$ & 2.0 & 2.0 & 2.0 & 2.0 & 2.0 \\
\hline
\end{tabular}

\subsection{The effect of DMF on morphology}

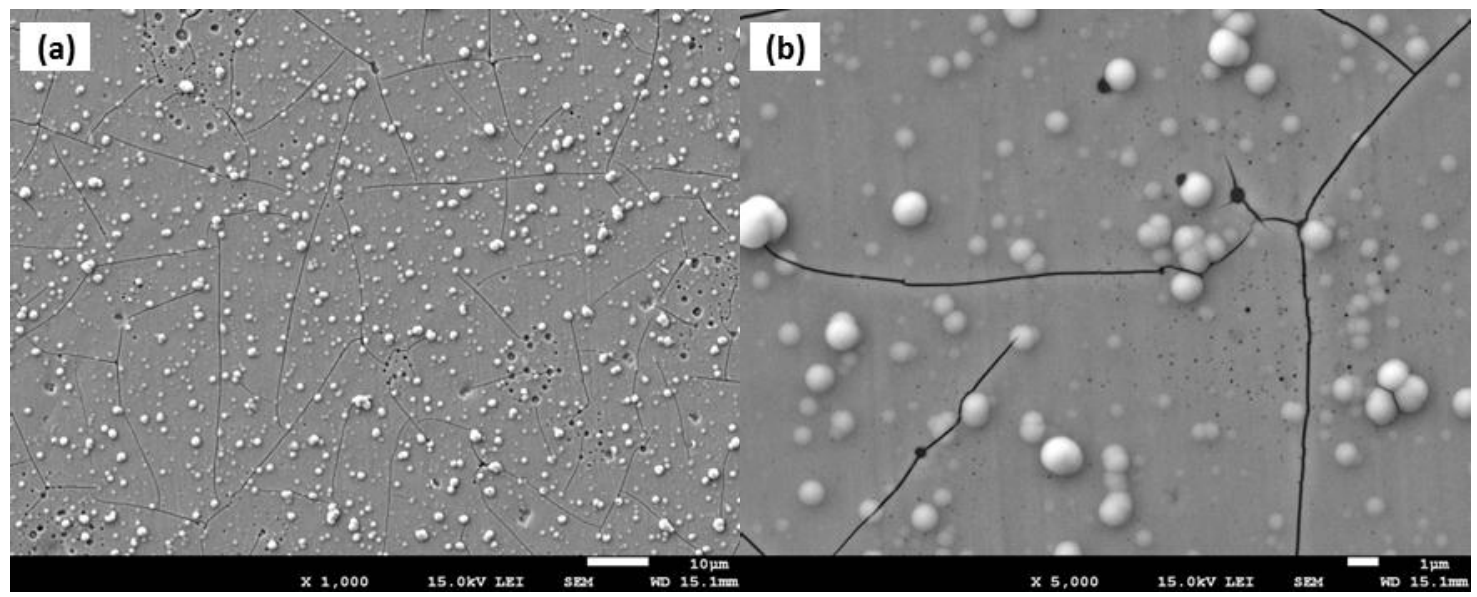



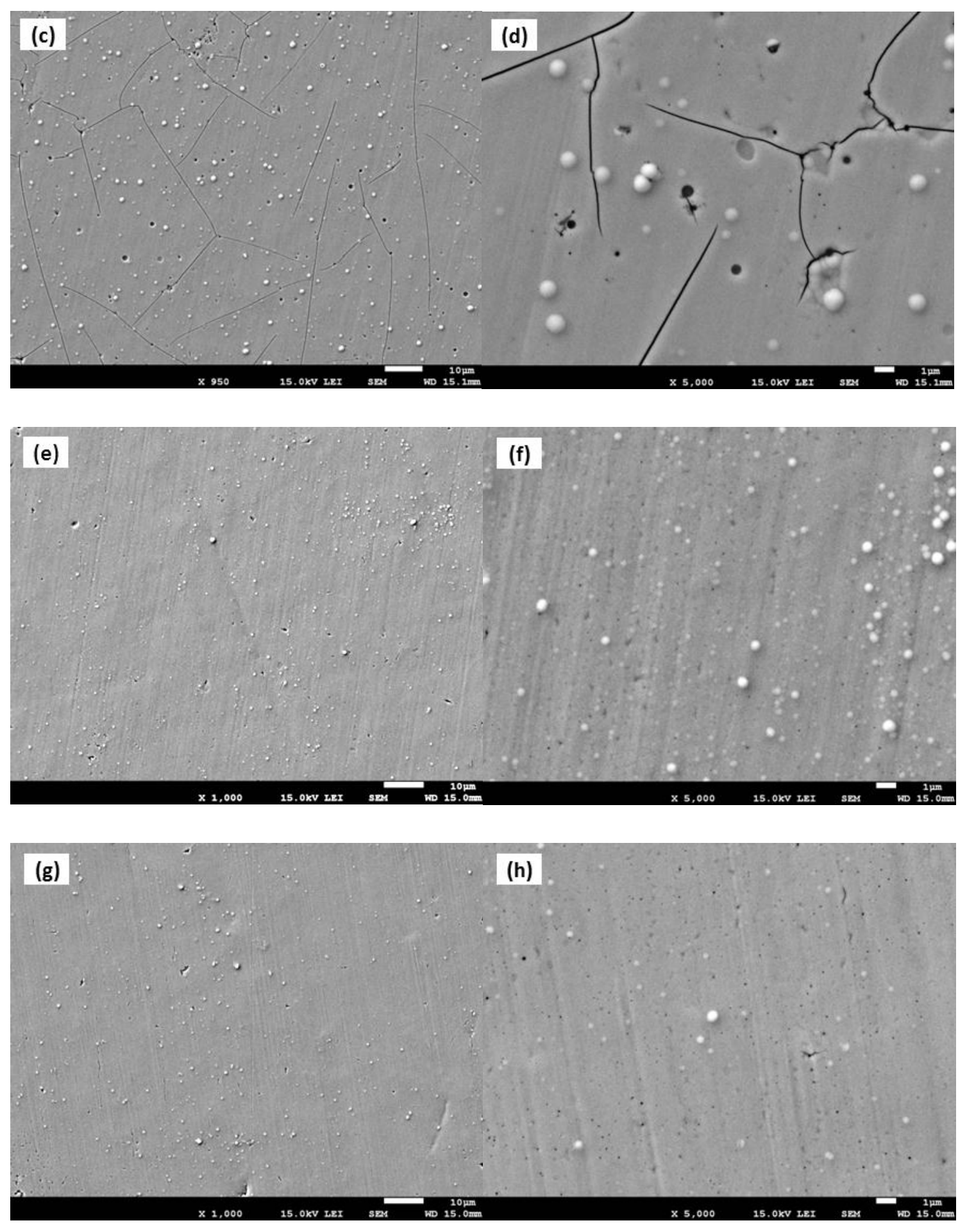


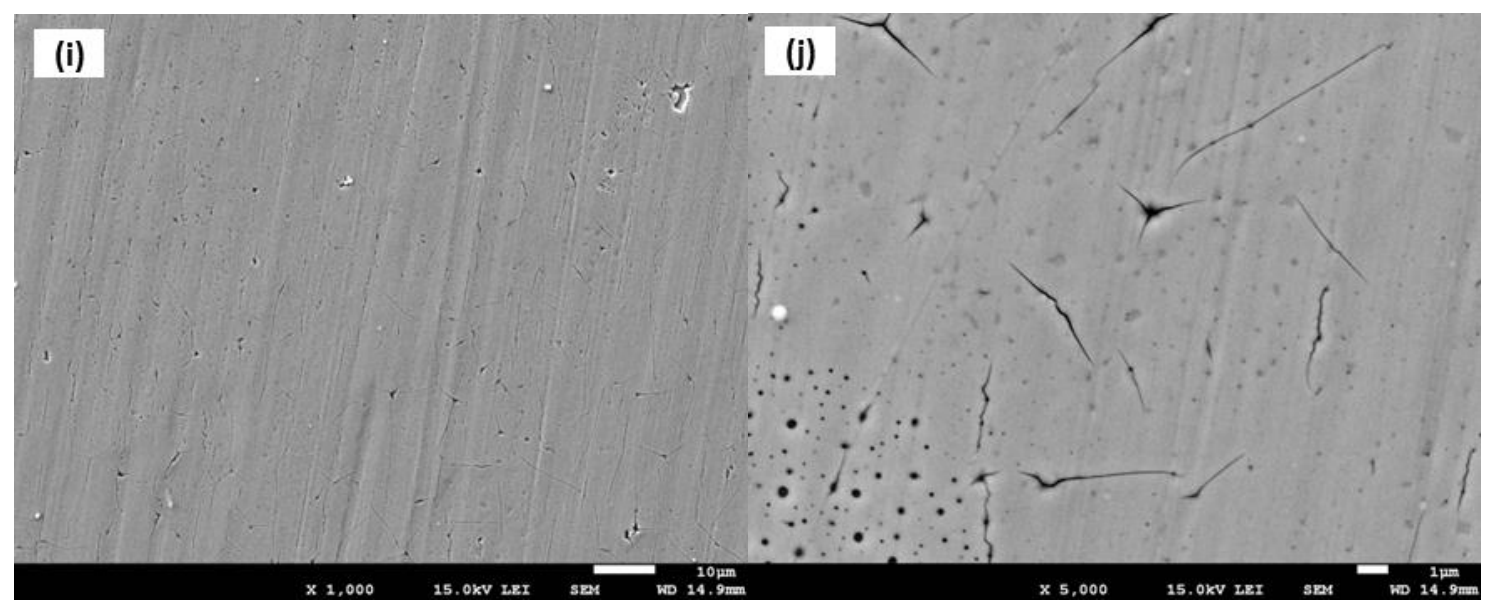

Figure 4.1 SEM imaging of coatings deposit from bath 2 to bath 4 at $(a)(c)(e)(g)(i) 1,000 \times$ and $(b)(d)(f)(h)(j)$ $5,000 \times$ magnification

The solubility of the components in DMF, especially that of $\mathrm{NH}_{4}^{+}[40]$ and $\mathrm{H}_{3} \mathrm{BO}_{3}$ is very low, there is no SEM imaging recorded for the coating deposited from bath 5 , because not all the salts could be dissolved.

Table 4.2 Composition of deposits from baths 2.3.4

\begin{tabular}{ccccccc}
\hline $\begin{array}{c}\text { Sample } \\
\text { No. }\end{array}$ & Bath No. & Picture & Atomic\% Cr & Atomic\% Ni & $\begin{array}{c}\text { Current Density } \\
\left(\mathrm{A} / \mathrm{dm}^{2}\right)\end{array}$ & Time (min) \\
\hline 1 & 2 & (a).(b) & 30.55 & 69.45 & 5 & $10 \mathrm{~min}$ \\
2 & 3 & (c).(d) & 33.80 & 66.20 & 5 & $10 \mathrm{~min}$ \\
3 & & (e).(f) & 33.92 & 66.08 & 5 & $10 \mathrm{~min}$ \\
4 & 4 & (g).(h) & 41.29 & 58.71 & 6 & $10 \mathrm{~min}$ \\
5 & & (i).(j) & 52.53 & 47.47 & 7 & $10 \mathrm{~min}$ \\
\hline
\end{tabular}

The $\mathrm{Cr} \%$ in the coating corresponding to the SEM pictures shows in Table 4.2. With the increased of DMF amount in the electrolyte, the number and the width of cracks was decreased a lot. Especially, the coatings deposited from bath 4, there were no cracks on sample 3 and 4 , and the $\mathrm{Cr} \%$ can be up to $41 \%$. When the current density increased to 
$7 \mathrm{~A} / \mathrm{dm}^{2}$, though the Cr\% was increased to $52 \%$, discontinuous cracks were observed on the coating.

\subsection{Hydrogen evolution}

To study the influence of DMF on hydrogen evolution, cathodic polarization curves were measured in the basic electrolyte of bath 1 and bath4, shown in Figure 4.2. As there were no metal ions in the basic electrolytes, the curve only reflect the reaction of $\mathrm{H}^{+}$ reduction.

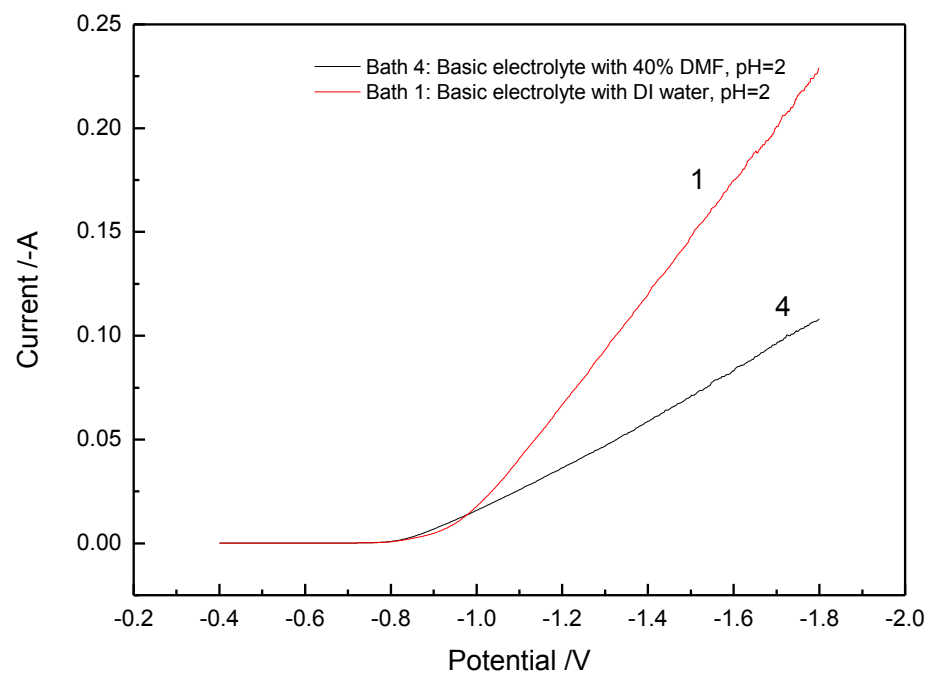

Figure 4.2 Cathodic polarization curves for electrodes recorded in the basic electrolyte ( bath 4 and bath 1 without main salts) $\mathrm{pH} 2.0$, temperature $20{ }^{\circ} \mathrm{C}$, potential scan rate $5 \mathrm{mV} / \mathrm{s}$

From curve 1 , the hydrogen evolution reaction was very severely when the potential the more negative than -1.0V (the slope of the curve increased a lot), while the reaction current of $\mathrm{H}^{+}$reduction for curve 4 is small compared to that of curve 1 . This can be attributing to the factor that DMF is a dipolar aprotic solvent, and contains no labile hydrogen atoms and therefore does not have the ionizing ability to provide solvated hydrogen ions, so the $\mathrm{H}^{+}$concentration in DMF mixture is smaller than that in pure 
aqueous electrolyte. Therefore, the $\mathrm{H}^{+}$reduction rate in DMF mixture electrolyte is lower.

Adding DFM as part of the solvent could suppress hydrogen evolution and decrease the density of cracks on coatings effectively. Additionally, $\mathrm{Ni}-\mathrm{Cr}$ coatings could be acquired at much lower current density from DMF mixture electrolyte compared with aqueous electrolyte. That could be another reason account for the decrease of crack density, because the relative low deposition rate benefits the stress release of the deposit, which has similar function like low duty circle Cr electroplating for crack free coatings[51].

Hoare[61] provided a theoretical background about why pure chrome can be deposited easily from $\mathrm{Cr}^{6+}$ and cannot be easily deposited from $\mathrm{Cr}^{3+}$. He argued that $\mathrm{Cr}^{3+}$ can easily complex with water to form $\mathrm{Cr}\left(\mathrm{H}_{2} \mathrm{O}\right)_{6}{ }^{3+}$ which he claims, is inactive. The continuous complexation process accounts for the decay of the $\mathrm{CrCl}_{3}$ bath. Contrary to the trivalent chromium, $\mathrm{CrO}_{3}$ can polymerize to a trichromate species which accumulate near the interface, accept electrons on by one and finally reduce to chrome metal. In this way, there is no naked $\mathrm{Cr}^{3+}$ exposed to the attack of $\mathrm{H}_{2} \mathrm{O}$. The theory also explains the critical ratio of sulfate to $\mathrm{CrO}_{3}$ (1 to 100). At this ratio, most trichromate ions are blocked at one end so that electron transfer takes place only at the other end. Hoare's results seem to support indirectly Ward and Christie's results[39], because the DMF could contain $\mathrm{Cr}^{3+}$ so that $\mathrm{Cr}^{3+}$ would be immune from water complexation.

\subsection{The Effect of surfactant}

\subsubsection{Introduction of surfactant}

From Figure 4.1, even though DMF helped to reduce the cracks on the coating, however, the existence of pinhole is not desirable. Pitting is caused by adhesion of air or hydrogen bubbles to the parts being plated. As chromium deposition need very low $\mathrm{pH}$ value, so $\mathrm{H}_{2}$ bubble cannot be avoided. Stirring the plating solution or rotating objects being plated can lessen the problem but cannot provide a satisfactory resolution for the problem. 
Incorporation of the surface-active compounds with suitable structures into a plating bath appears to be a promising remedy to diminish surface pinholes. The function of wetting agents or surfactants is to lower the surface tension of the plating solution so that air and hydrogen bubbles do not cling to the cathode surface. In principle, the surfactant molecules play a role in the removal of tiny hydrogen bubbles from the surface of the substrate through adsorption at the $\mathrm{H}_{2}$-liquid interface as illustrated in Figure 4.3.

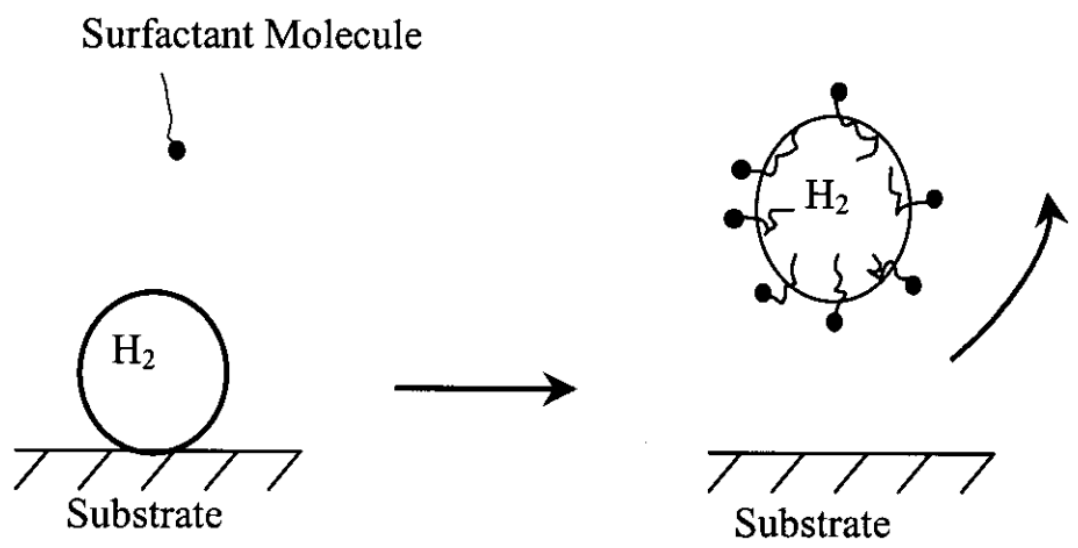

Figure 4.3 Schematic diagram showing the adsorption of surfactant molecules on the hydrogen bubble[62]

Sodium dodecyl sulfate (SDS) is one of the most common surfactants for plating field. So it was chosen as surfactant in this study. The concentration of SDS should be controlled between $0.05 \mathrm{~g} / \mathrm{L}$ to $0.2 \mathrm{~g} / \mathrm{L}$. The amount of SDS used in this plating bath was determined by groping experiments, which was $0.2 \mathrm{~g} / \mathrm{L}$.

\subsubsection{Morphology}

Figure 4.4 shows the SEM imaging of $\mathrm{Ni}-\mathrm{Cr}$ coating deposited from bath 4 with $0.2 \mathrm{~g} / \mathrm{L}$ SDS, the diminishment of pitting observed on the deposits. According to the EDS result, the $\mathrm{Cr} \%$ was around $58 \%$. 


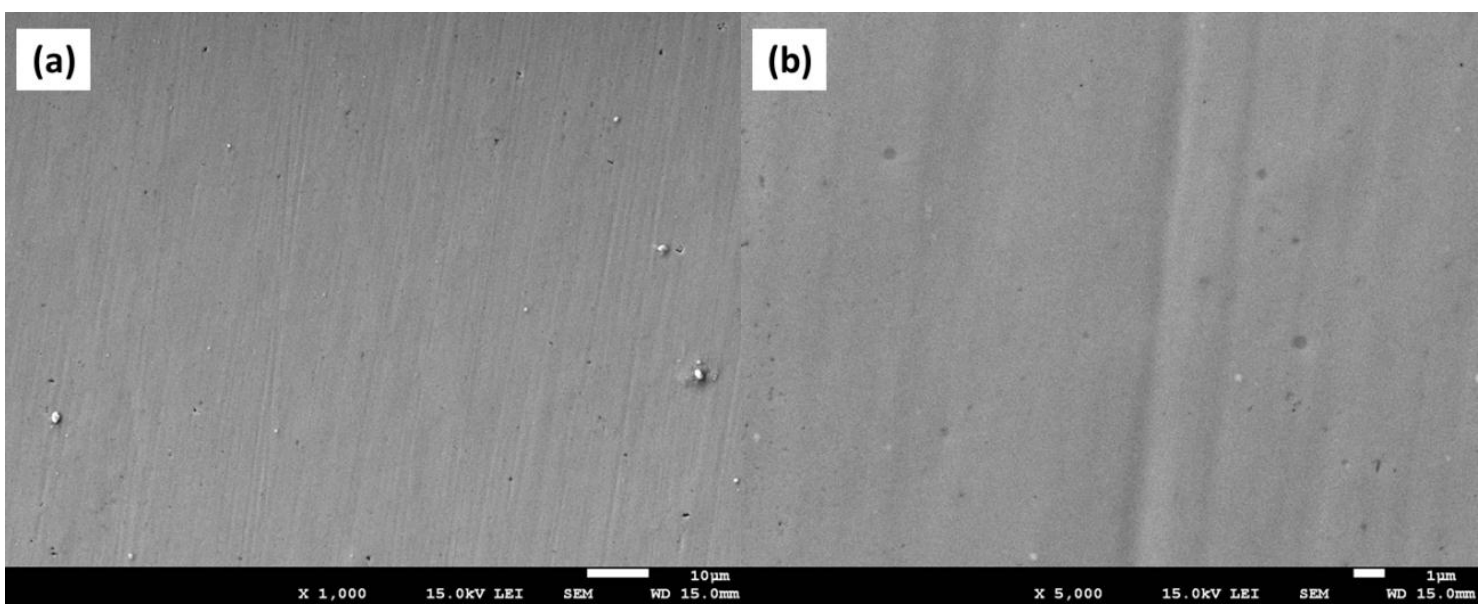

Figure 4.4 SEM imaging of Ni-Cr coating deposited from bath 4 at (a) 1,000× and (b) 5,000× magnification

\subsection{Chemical state analysis}

In order to obtain the chemical information about the Ni-Cr coating, XPS analysis is carried out. Figure 4.5 shows survey scan of the deposit. It can be observed that besides chromium and nickel, carbon, oxygen and small amount of nitrogen are also present.

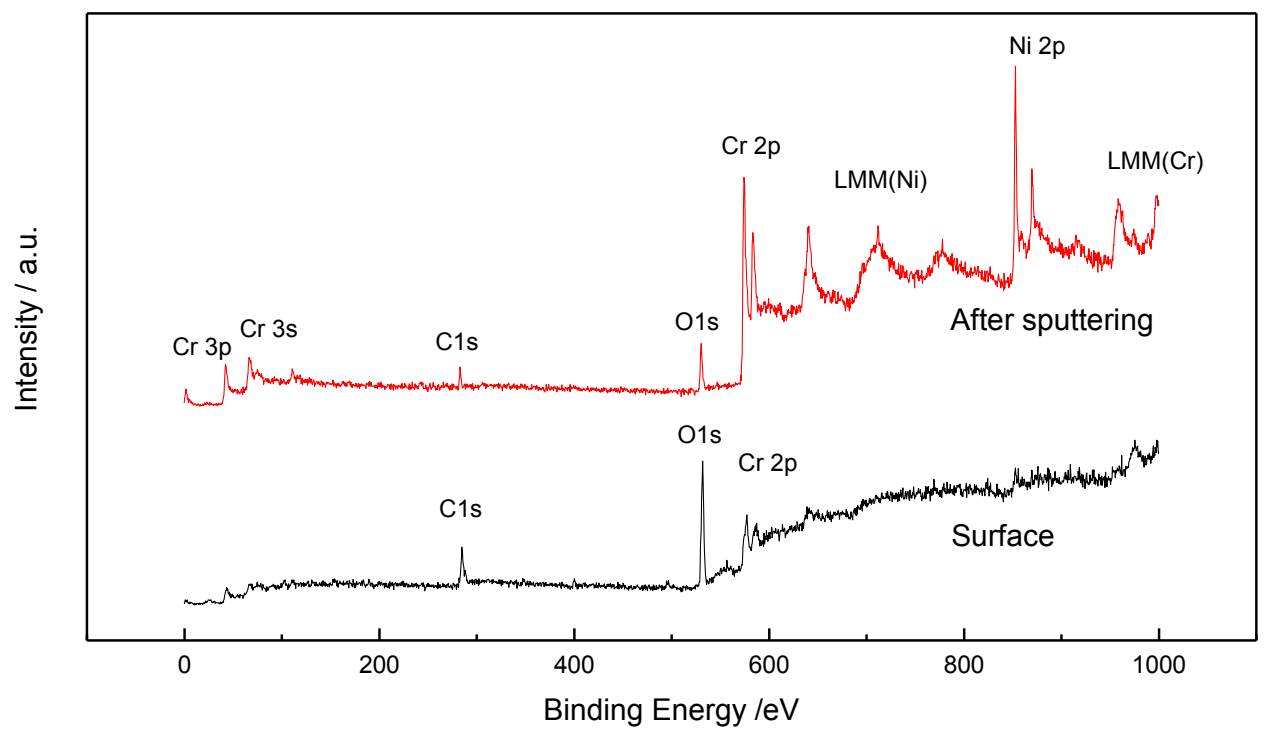

Figure 4.5 XPS survey spectra for Ni-Cr coating from bath 4 before and after sputtering for one minute 

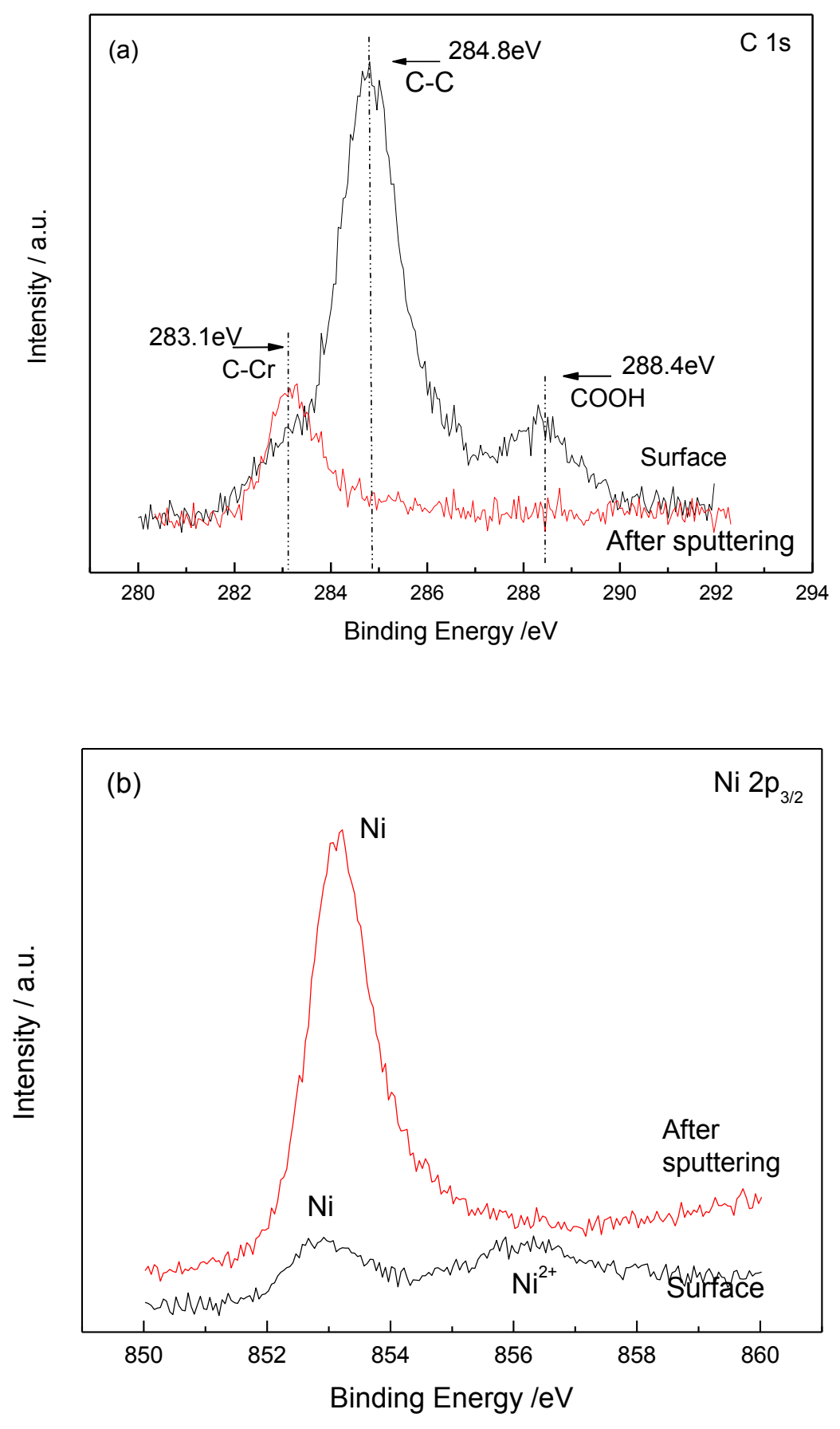


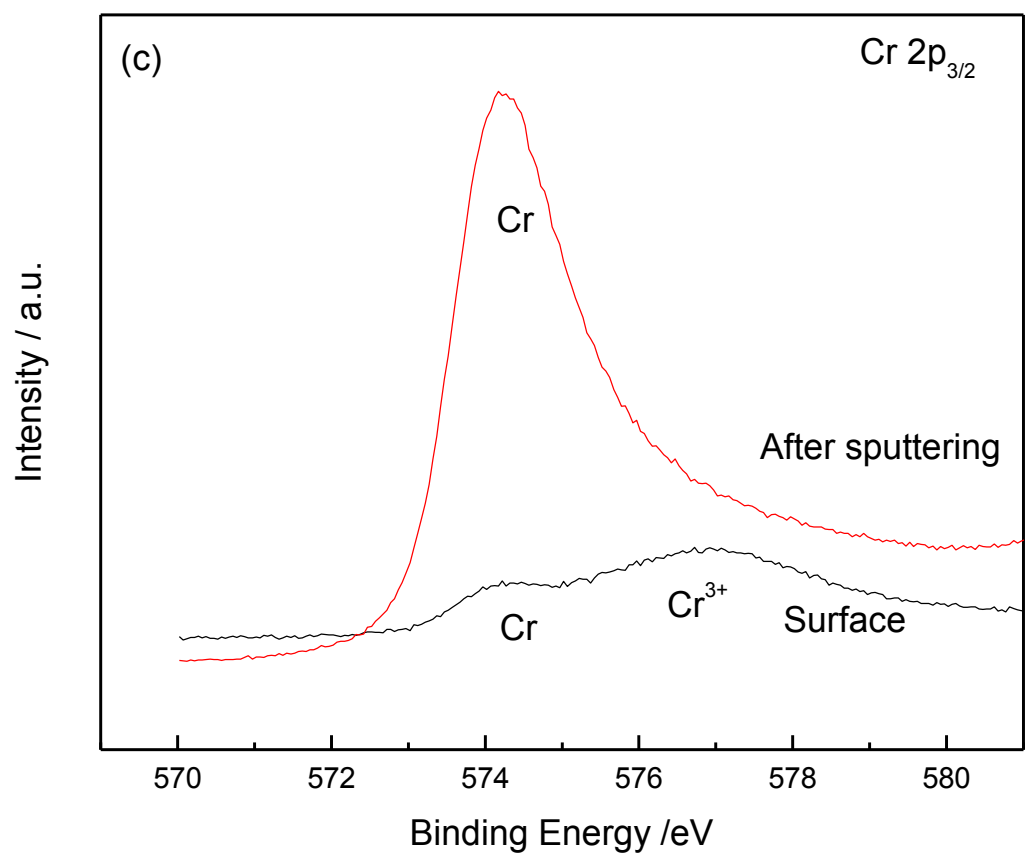

Figure 4.6 XPS spectra for (a) $\mathrm{C} 1 \mathrm{~s}$ (b) $\mathrm{Ni} 2 \mathrm{p}_{3 / 2}$ (c) $\mathrm{Cr} 2 \mathrm{p}_{3 / 2}$ recorded respectively for $\mathrm{Ni}-\mathrm{Cr}$ coating from bath 4 before and after sputtering for one minute

Specific functional organic groups can be distinguished from C1s band with binding energies above $285.0 \mathrm{eV}$. For carbon-containing molecules coordinated on the metal surface, the carbon-metal interaction is revealed in the spectrum by the appearance of a low energy line as compared with the binding energy of 285.0eV. Edigaryan [25] believed that, for this case, the values of negative shifts can vary from 1.5 to $0.2 \mathrm{eV}$. Reduced shift value points to a decrease in the electronic density on carbon and a weakening of metal-carbon interaction.

The XPS spectrum recorded in the depth of Ni-Cr coating deposited from bath 4 (Figure 4.6 (a)) shows three $C$ 1s peaks for the original surface layer (at 283.1, 284.8, and $288.4 \mathrm{eV}$ ) The peak at $283.1 \mathrm{eV}$ corresponds to metal-carbon bond[17, 63], the peak at $284.8 \mathrm{eV}$ can be assigned to $\mathrm{C}-\mathrm{C}$ bond $[17,63,64]$ and the third peak may be attributed to organic ligands adsorbed on the coating surface[63]. 
It seems there is only one peak (Figure 4.6 (a)) in the deep layer (sputtering for one minutes, $20 \mathrm{~nm}$ in depth), however, the $C 1 \mathrm{~s}$ is actually an envelope of the spectral lines (Figure 4.8 (b)), which covers not only the peak (at 283.1eV) of a carbide constituent, but also the peak (at $284.8 \mathrm{eV}$ ) of graphite-like carbon[63]. This result agree with Huang[65], who extracted carbon-based membranes from as-deposit $\mathrm{Cr}$ coatings by etching in a solution of 33 vol. $\% \mathrm{HNO}_{3}+67$ vol. $\% \mathrm{HCl}$.

XPS of the Ni 2p core level of Ni-Cr coating from bath 4 are shown in Figure 4.6 (b). The spectrum for surface layer shows the presence of pure $\mathrm{Ni}$ metal as well as $\mathrm{Ni}^{2+}$. Ni $2 \mathrm{p}_{3 / 2}$ peak at $853.0 \mathrm{eV}$ can be assigned to metallic nickel, whereas the peak at $856.6 \mathrm{eV}$ could be assigned to $\mathrm{Ni}^{2+}$ in the form of hydroxide or oxide, instead of $\mathrm{Ni}^{3+}$ like Tharamani[66] claimed. The spectrum for the inner layer indicates the presence of pure nickel.

Similarly, XPS of the $\mathrm{Cr} 2 \mathrm{p}$ core level of Ni-Cr coating from bath 4 are shown in Figure 4.6 (b). The spectrum for surface layer shows the presence of pure $\mathrm{Cr}$ metal as well as $\mathrm{Cr}^{3+}$. $\mathrm{Cr} 2 \mathrm{p}_{3 / 2}$ peak at $574.3 \mathrm{eV}$ can be assigned to metallic chromium. The peak at 577.0eV could be assigned to $\mathrm{Cr}^{3+}$ in the form of oxide or hydroxide as $\mathrm{Cr}(\mathrm{OH})_{3}$ or $\mathrm{CrOOH}[66]$. And this oxyhydroxide passive film could enhance the corrosion resistance of the $\mathrm{Ni}-\mathrm{Cr}$ alloy[66]. For the XPS spectrum of deep layer, the detailed analysis result (Figure 4.8 (b)) indicates the presence of $\mathrm{Cr}$ metal and $\mathrm{Cr}^{3+}$. Chromium carbide peak cannot be observed distinctly as the binding energies for metallic chromium and chromium carbide are very close to each other $[63,67,68]$. 

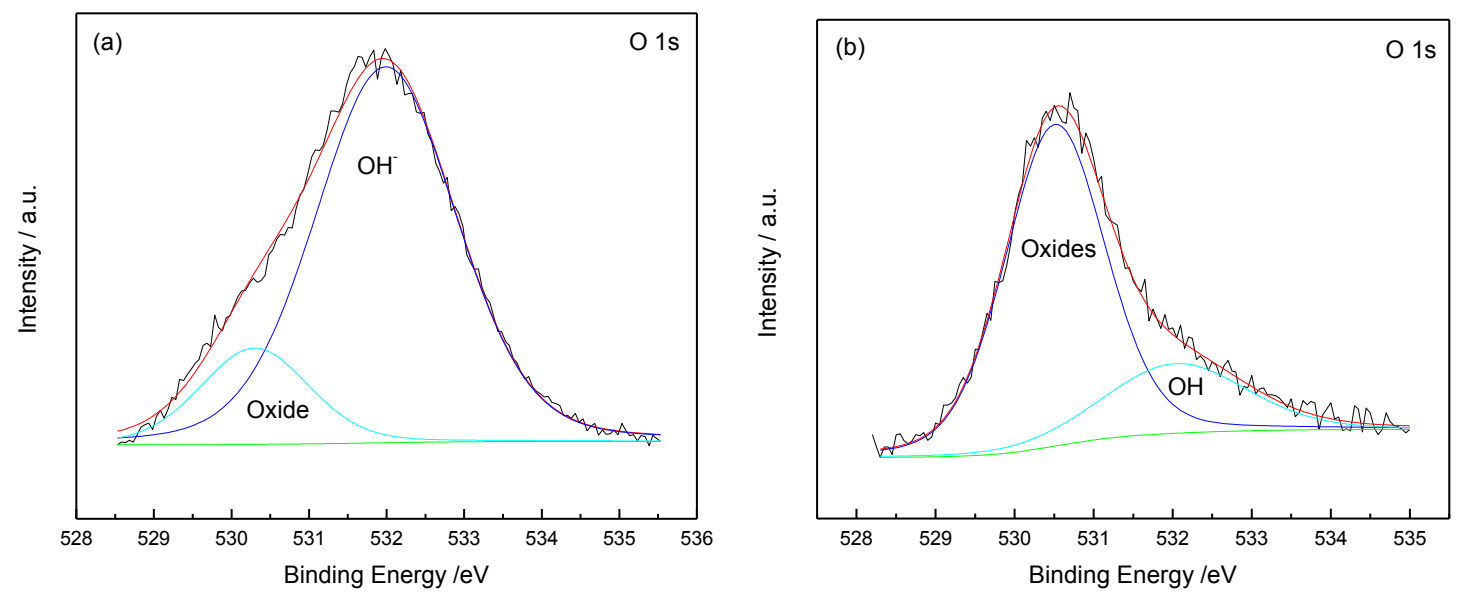

Figure 4.7 Fitting result of XPS spectra for $\mathrm{O} 1 \mathrm{~s}$ recorded for $\mathrm{Ni}$-Cr coating from bath 4 (a) before and (b) after sputtering for one minute

Figure 4.7 present the XPS spectrum of $\mathrm{O}$ 1s core level for the Ni-Cr coating from bath 4. In the surface layer, the high intensity peak at $532.0 \mathrm{eV}$ could be assigned to hydroxide, and weak peak at $530.4 \mathrm{eV}$ could be assigned to oxide. In the deep layer, the intensity peak at $530.4 \mathrm{eV}$ increases, while that at $532.0 \mathrm{eV}$ decreases to a weak peak. The presence of hydroxide in the inner layer agrees with the assignment of $\mathrm{Ni} 2 \mathrm{p}_{3 / 2}$ peak at $856.6 \mathrm{eV}$ in Figure 4.6 (b). 

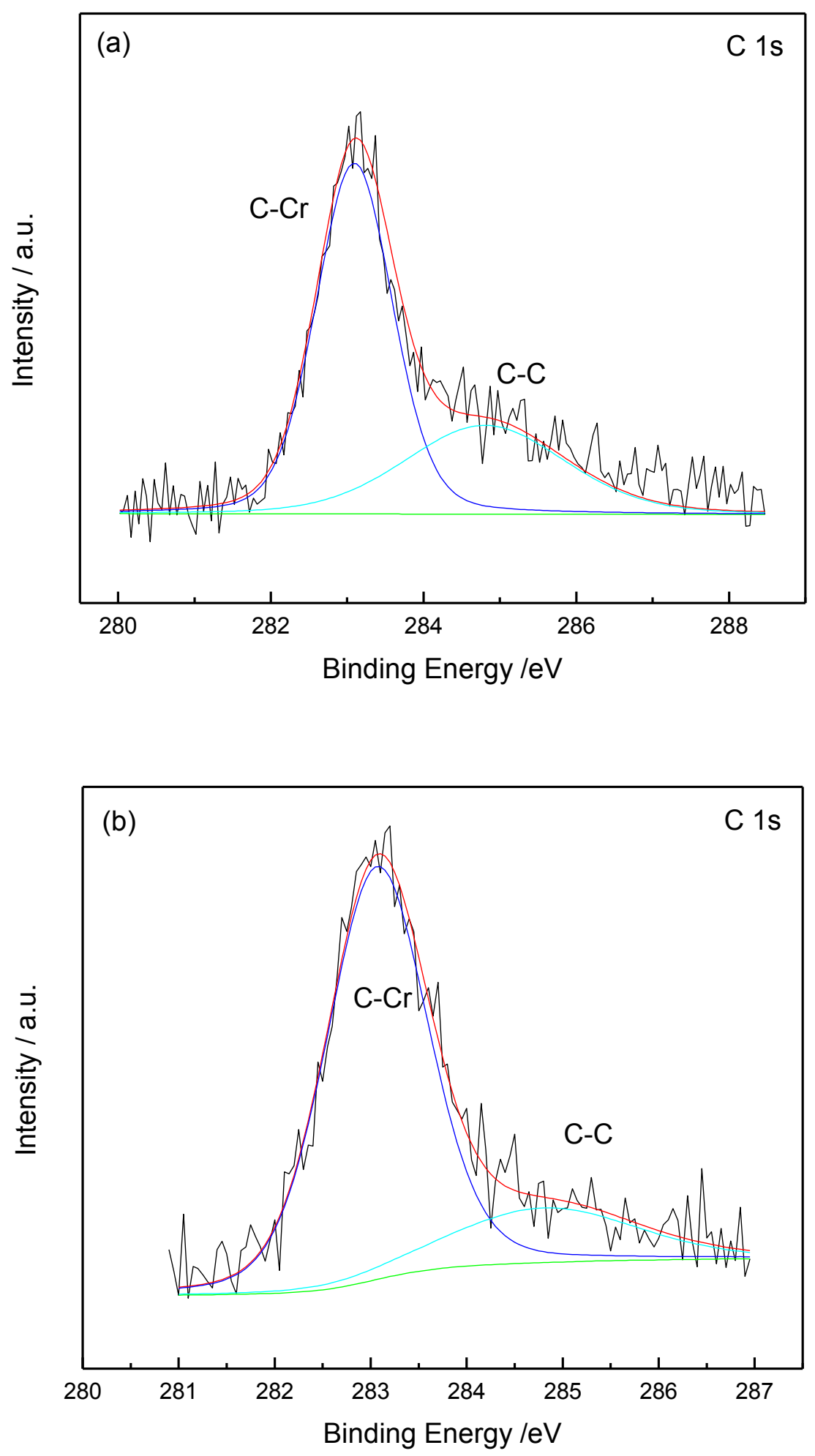

Figure 4.8 Fitting result of XPS spectra for $\mathrm{C} 1 \mathrm{~s}$ recorded for $\mathrm{Ni}-\mathrm{Cr}$ coating from (a) bath 1 and (b) bath 4 after sputtering for one minute 

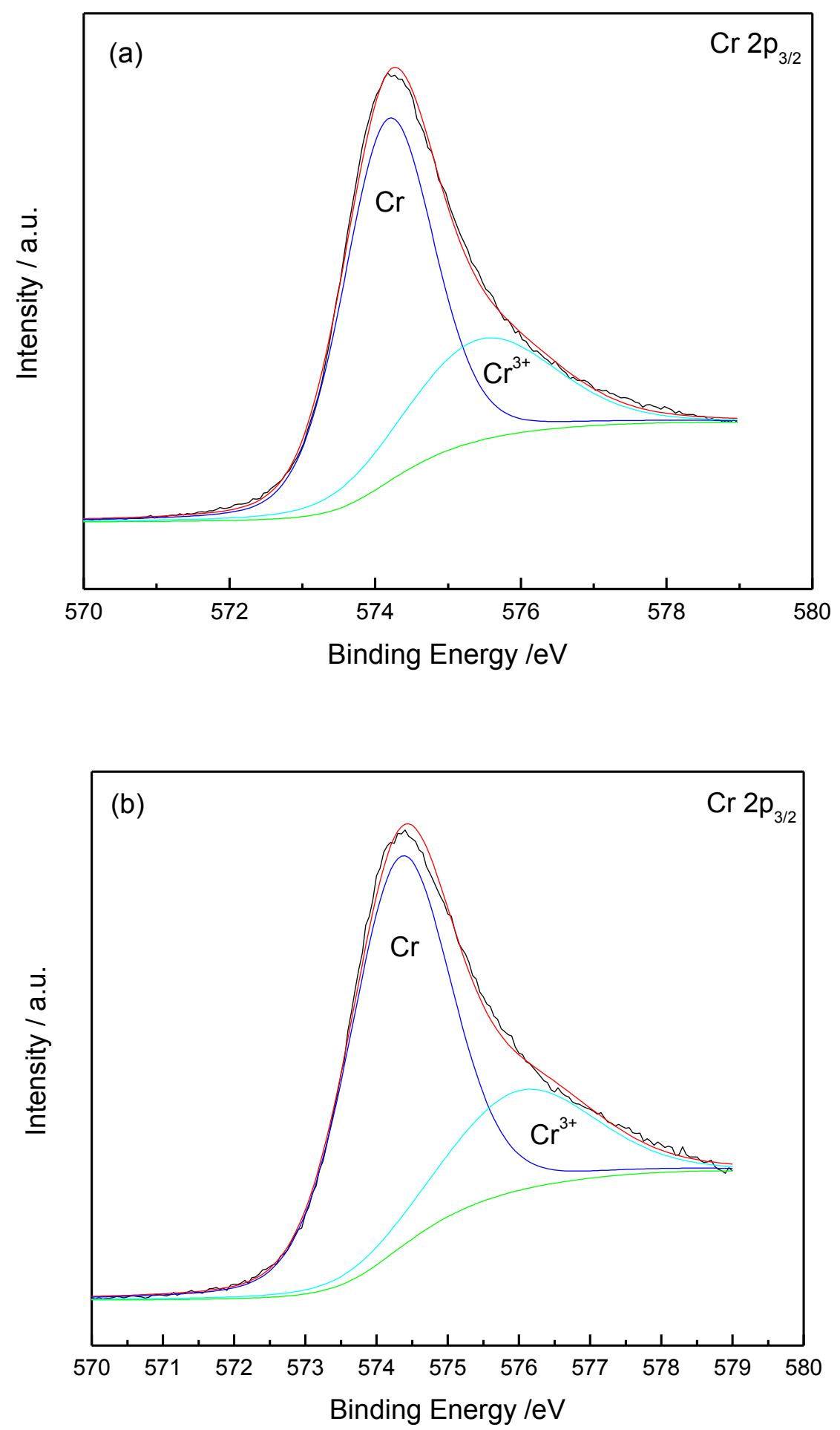

Figure 4.9 Fitting result of XPS spectra for $\mathrm{Cr}_{2} \mathrm{p}_{3 / 2}$ recorded for $\mathrm{Ni}$-Cr coating from (a) bath 1 and (b) bath 4 after sputtering for one minute 
Table 4.3 Parameters of the photoelectron spectra of C1s of chromium deposits from bath 1 and 4

\begin{tabular}{lllll}
\hline No. of bath & Chemical state & Binging energy $(\mathrm{eV})$ & Area & FWHM $(\mathrm{eV})$ \\
\hline \multirow{4}{*}{1} & $\mathrm{Cr}-\mathrm{C}$ & 283.1 & 1640.3 & 1.2 \\
& $\mathrm{C}-\mathrm{C}$ & 284.8 & 867.6 & 2.5 \\
& $\mathrm{Cr}^{0}$ & 574.2 & 37608.6 & 1.5 \\
& $\mathrm{Cr}^{3+}$ & 575.4 & 17098.8 & 2.4 \\
& $\mathrm{Cr}-\mathrm{C}$ & 283.1 & 2056.9 & 1.2 \\
& $\mathrm{C}-\mathrm{C}$ & 284.8 & 502.6 & 2.3 \\
& $\mathrm{Cr}$ & 574.3 & 26823.4 & 1.7 \\
& $\mathrm{Cr}^{3+}$ & 576.0 & 9947.7 & 2.4 \\
\hline
\end{tabular}

The detailed analysis of XPS result of coatings obtained from bath 1 and bath 4 shows in Figure 4.8, Figure 4.9 and Table 4.3.

\subsection{Corrosion resistance}

The potentiodynamic polarization curves of the $\mathrm{Ni}-\mathrm{Cr}$ coating electrodeposited on copper in 3.5 wt. \% NaCl solutions are shown in Figure 4.10.

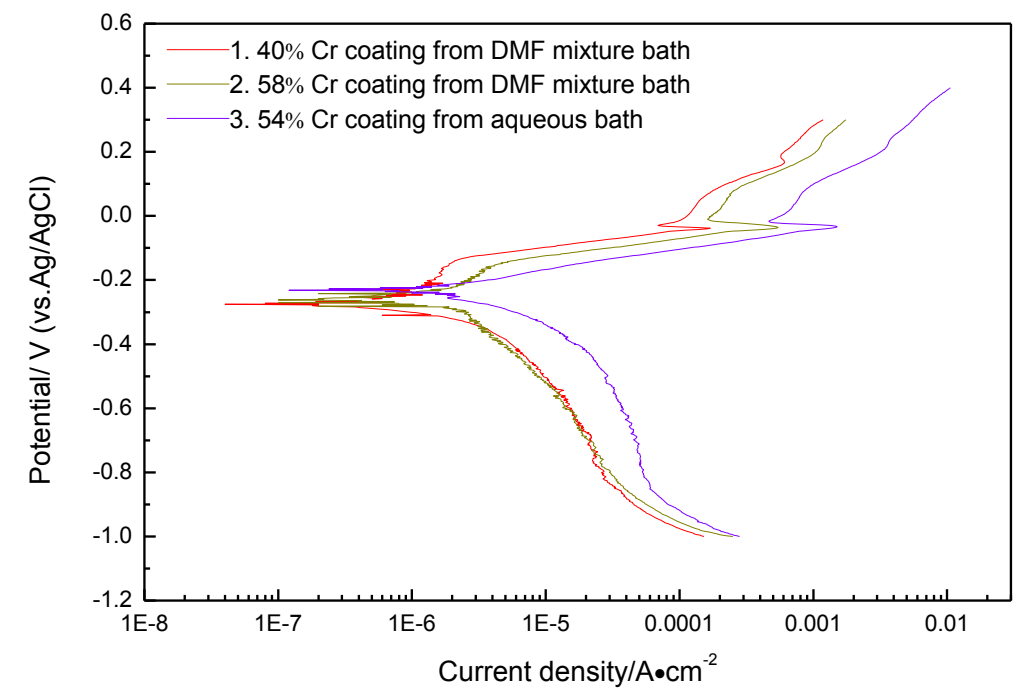

Figure 4.10 Potentiodynamic polarization curves for different specimens in $3.5 \mathrm{wt} \% \mathrm{HCl}$ solutions 
Table 4.4 The electrochemical parameters of potentiodynamic polarization curves in $3.5 \mathrm{wt} \% \mathrm{HCl}$

\begin{tabular}{llllllll}
\hline Curve No. & $\mathrm{E}_{\text {corr }}(\mathrm{mV})$ & $\mathrm{i}_{\text {corr }}\left(\mathrm{Acm}^{-2}\right)$ & $\mathrm{E}_{\text {pass }}(\mathrm{mV})$ & $\mathrm{i}_{\text {pass }}\left(\mathrm{Acm}^{-2}\right)$ & $\mathrm{b}_{+}(\mathrm{V})$ & $\mathrm{b}_{-}(\mathrm{V})$ & $\mathrm{OCP}(\mathrm{mV})$ \\
\hline 1 & -149 & $1.116 \mathrm{E}-6$ & -29.9 & $6.906 \mathrm{E}-5$ & 0.053 & -0.362 & -276 \\
2 & -186 & $9.751 \mathrm{E}-7$ & -9.8 & $1.648 \mathrm{E}-4$ & 0.057 & -0.313 & -261 \\
3 & -195 & $3.042 \mathrm{E}-6$ & -15.8 & $4.706 \mathrm{E}-4$ & 0.060 & -0.27415 & -232 \\
\hline
\end{tabular}

The corrosion potential $\left(\mathrm{E}_{\text {corr }}\right)$ and corrosion current density $\left(\mathrm{i}_{\text {corr }}\right)$ were calculated using the Tafel extrapolation and summarized in Table 4.4. Obvious passivation following active dissolution during anodic scan was observed for samples studied. Passivation potential $\left(E_{\text {pass }}\right)$ and passivation current density $\left(\mathrm{i}_{\text {pass }}\right)$ were thus measured. It can be seen in Table 4.4 that the $\mathrm{i}_{\text {pass }}$ was larger than the $\mathrm{i}_{\text {corr }}$. This is different from the metallurgical high-purity $\mathrm{Cr}$, which displays an $\mathrm{i}_{\text {pass }}$ markedly lower than the $\mathrm{i}_{\text {corr }}[69]$.

Generally, the increase in the current density in the passive region was attributed to the insufficient continuity of coatings, as mentioned in the literature[25]. Moreover, according to Zeng[70], $\mathrm{Cr}$ carbides are also responsible for the increase in the current density because the interfaces between $\mathrm{Cr}$ carbides and $\mathrm{Cr}$ can act as channels for chlorine ions penetrating the passive film to erode the bulk of the coatings or the $\mathrm{Cu}$ support. This could explain the higher $\mathrm{i}_{\text {pass }}$ of all the curves, and that of the coatings deposited from DMF mixture electrolyte is lower than that from aqueous electrolyte which has much higher crack density.

For the coating from aqueous electrolyte, because the deposits contain cracks or pinholes, the relatively large current density in the passivity region is due to dissolution of the copper substrate rather than to dissolution of the deposits[23].

It was reported[70] that $\mathrm{Cr}-\mathrm{P}$ coatings exhibit better corrosion resistance than traditional $\mathrm{Cr}$ and $\mathrm{Cr}-\mathrm{C}$ coatings the formation of a phosphide passive film, which has high stability and self-repairing ability, and can act as a "buffer" to reject the penetration of chloride ions. $\mathrm{Cr}$-P would be a promising direction instead of $\mathrm{Cr}$ - $\mathrm{C}$ for this co-deposition system. 


\subsection{Nano indentation test}

Table 4.5 Elastic modulus and hardness

\begin{tabular}{ccccc}
\hline Sample No. & Bath & Cr content & HV (Vickers) & E (GPa) \\
\hline 1 & Aqueous electrolyte & $80 \%$ & 1743.613 & 283.900 \\
2 & DMF mixture electrolyte & $80 \%$ & 948.79 & 141.067 \\
\hline
\end{tabular}

The elastic modulus and hardness test result is shown in Table 4.5. What could be account for the big hardness difference between coating deposited from aqueous and DMF mixture electrolytes was unknown. Unfortunately, the machine was down, further tests were no longer available.

\section{Chapter 5 Electroplating of Ni-Cr Multilayers in Single Bath}

\subsection{Six multilayer coatings}

The multilayer coatings were deposited from DMF electrolyte with composition shown in Table 5.1. And Figure 5.1 shows the deposition parameters for six multilayers from DMF mixture electrolyte. Since the thickness of each layer is proportional to the current density and deposition time. The current density was switched between $4 A / \mathrm{dm}^{2}$ to $7 \mathrm{~A} / \mathrm{dm}^{2}$ alternatively with circle of 3 , to prepare Ni-rich layers and $\mathrm{Cr}$-rich layers. 
Table 5.1 Constituent of electrolytes for 6 multilayer coatings $\left(25^{\circ} \mathrm{C}\right)$

\begin{tabular}{lll}
\hline Constituent & Function & Concentration \\
\hline $\mathrm{CrCl}_{3} \cdot 6 \mathrm{H}_{2} \mathrm{O}$ & Source of $\mathrm{Cr}^{3+}$ & $0.48 \mathrm{M}$ \\
$\mathrm{NiCl}_{2} \cdot 6 \mathrm{H}_{2} \mathrm{O}$ & Source of $\mathrm{Ni}^{2+}$ & $0.12 \mathrm{M}$ \\
$\mathrm{CHOONa}$ & Complex agent & $0.6 \mathrm{M}$ \\
urea & Complex agent & $0.6 \mathrm{M}$ \\
$\mathrm{NaBr}$ & Antioxidizing agent & $0.18 \mathrm{M}$ \\
$\left(\mathrm{NH}_{4}\right)_{2} \mathrm{SO}_{4}$ & Conducting salt & $0.18 \mathrm{M}$ \\
$\mathrm{H}_{3} \mathrm{BO}_{3}$ & Buffer agent & $0.43 \mathrm{M}$ \\
solvent & & DI water: DMF=6:4 \\
$\mathrm{SDS}$ & Wetting agent & $0.2 \mathrm{~g} / \mathrm{L}$ \\
$\mathrm{pH}$ & 2.0 & 2.0 \\
\hline
\end{tabular}

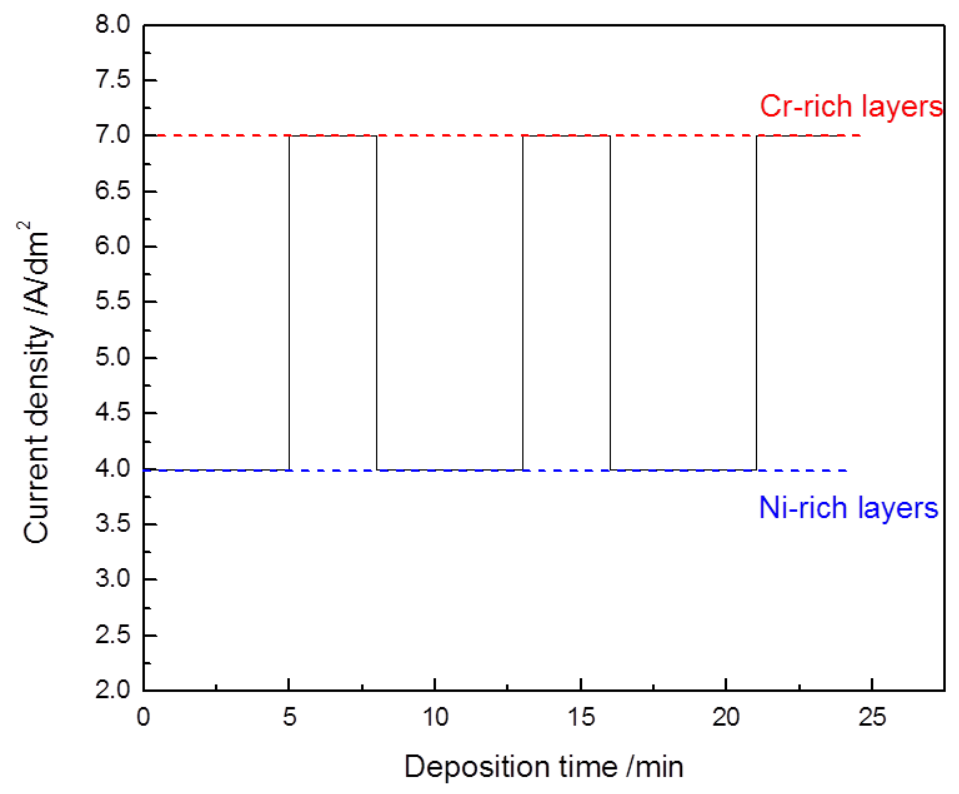

Figure 5.1 The current density waveform for 6 layers coating 


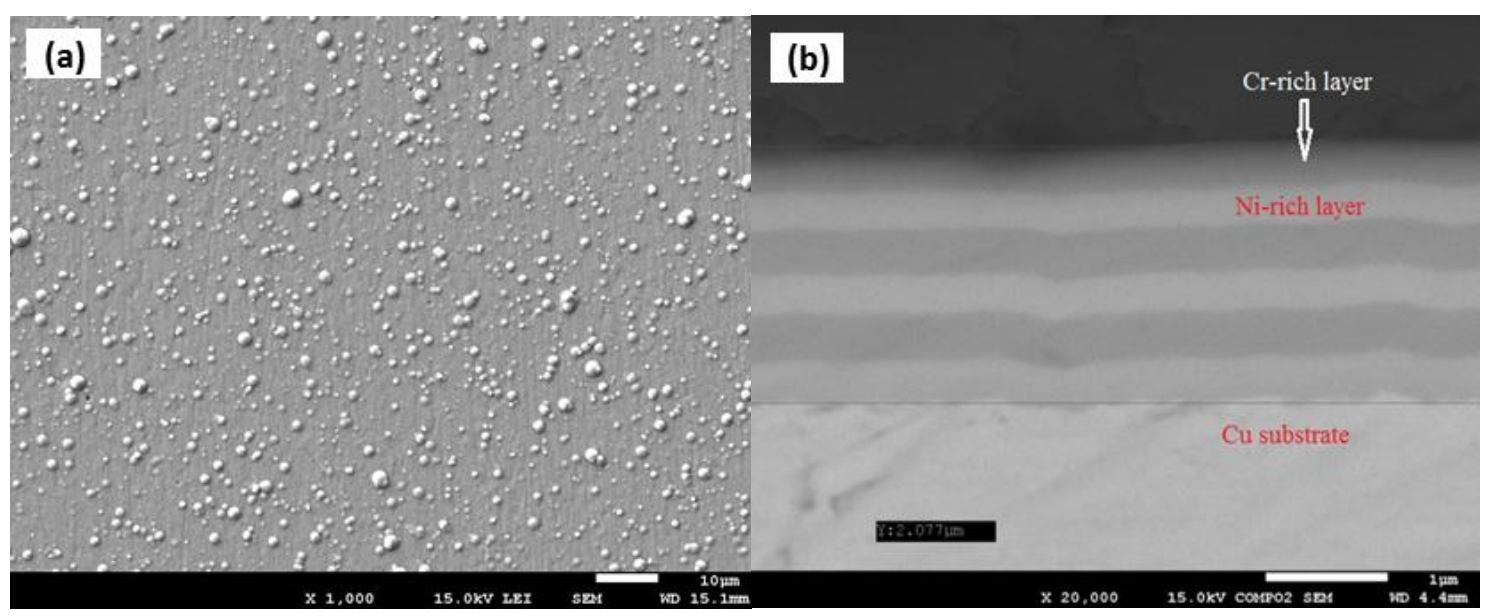

Figure 5.2 SEM imaging of 6 multilayer coatings (a) morphology, (b) cross section
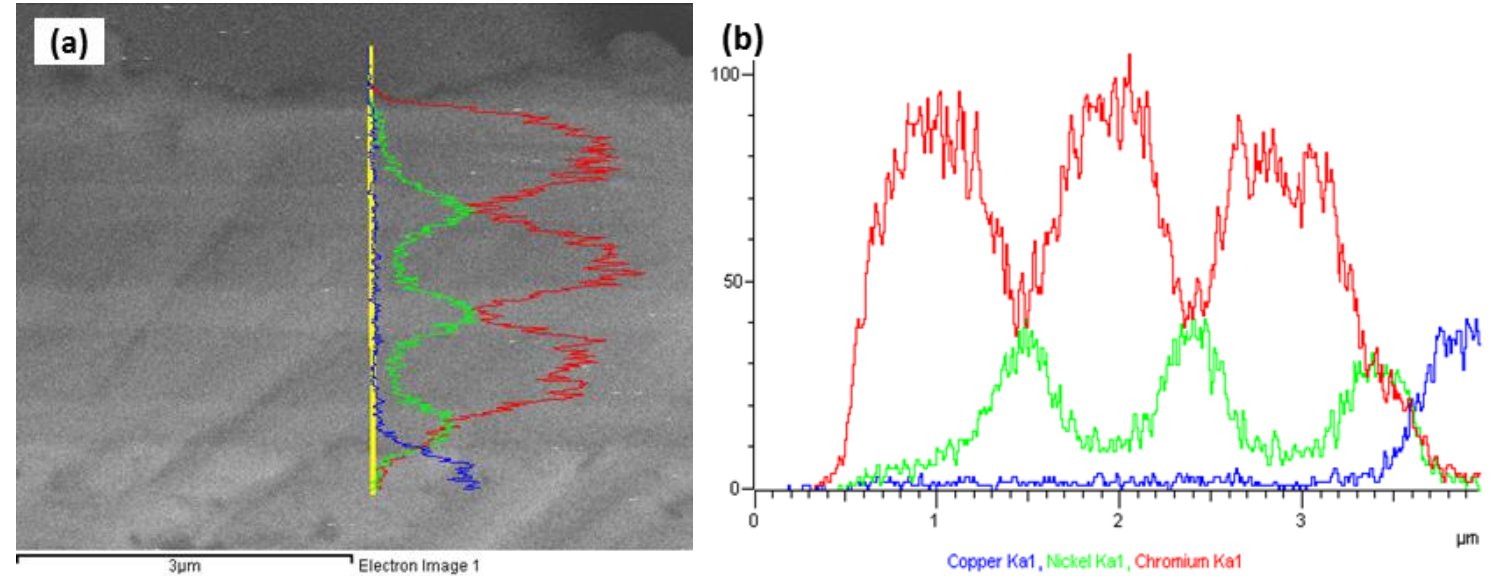

Figure 5.3 Cross section EDS line scan of 6 multilayer coating

As shown by Figure 5.2 and Figure 5.3, it is possible to reliably produce multilayered structures in wide intervals of changes in thicknesses. Table 5.2 shows the $\mathrm{Cr}$ content of each layer. 
Table 5.2 The quantitative chemical compositions in the $\mathrm{Cr}$-rich and Ni-rich layers

\begin{tabular}{lllll}
\hline \multirow{2}{*}{ Element } & Ni-rich layer & \multicolumn{3}{l}{ Cr-rich layer } \\
\cline { 2 - 5 } & Weight\% & Atomic\% & Weight\% & Atomic\% \\
\hline Cr K & 37.21 & 40.08 & 77.63 & 79.66 \\
Ni K & 62.79 & 59.92 & 22.37 & 20.34 \\
\hline
\end{tabular}

\subsection{Nano-multilayer coatings}

The multilayer deposition parameter was set by group experiments and shown in Table 5.3. As shown in Figure 5.4, a crack-free Ni-Cr multilayer was deposited from single bath successfully. The scratches came from copper substrate by polishing.

Table 5.3 Deposition parameters for nano-multilayers for TEM observation

\begin{tabular}{|c|c|c|c|c|c|}
\hline$S=1.5 * 3.5$ & $\begin{array}{l}\text { Current density } \\
\left(\mathrm{A} / \mathrm{dm}^{2}\right)\end{array}$ & $\begin{array}{l}\text { Deposition } \\
\text { time (s) }\end{array}$ & Cycles & $\begin{array}{l}\text { Thickness } \\
\text { (nm) }\end{array}$ & $\begin{array}{l}\text { Deposition } \\
\text { rate }(\mathrm{nm} / \mathrm{s})\end{array}$ \\
\hline Ni-rich layer & 3.5 & 18 & 40 & 16.5 & 0.91 \\
\hline Cr-rich layer & 8.5 & 10.5 & 40 & 23.5 & 2.23 \\
\hline
\end{tabular}

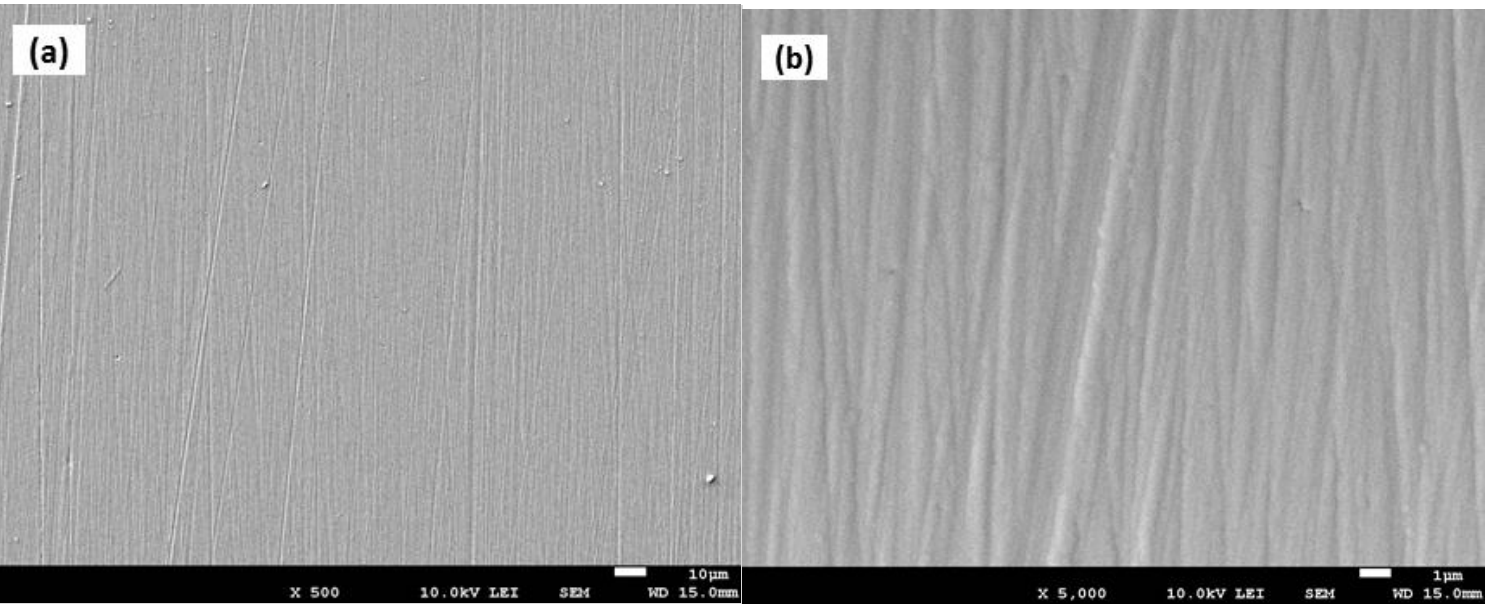

Figure 5.4 Morphologies of the nano-multilayers at (a) 500x and (b) 5,000× magnification 


\subsubsection{The preparation of cross section for thin film}

Since the thickness of each layer was down to tens nanometers, TEM observation was needed to exam the multilayered structure. Specimens for TEM were prepared with a special process to an ultrathin thickness that allows electrons to transmit through the sample.

The thinning procedure for cross section specimen including the pre-preparation of the specimen, it's fixing, the mechanical pre-thinning and the thinning by ion beam milling.

\section{1) Specimen pre-preparation}

At the beginning of the pre-preparation stage of coated specimens, small specimens $(2.5 \mathrm{~mm} \times 10 \mathrm{~mm})$ were cut from the specimen using a diamond saw. To ensure that the specimens could be bonded as closely as possible, deburring was carried out on the sharp edges produced by cutting. Then the specimens were cleaned in ethanol and acetone with ultrasonic for 2-3min, successively, to keep the surfaces very clean in order to achieve the high degree of bonding necessary.

\section{2) Bonding of the coated material specimens to a "sandwich"}

Based on the requirements of adhesives for bonding, Petropoxy 154 (Figure 5.5(a)) was chosen for the coated specimen. The cleaned specimens were applied to a thin layer of glue on their coated sides by a fine brush. The both part will be put one upon the other and pressed together firmly to ensure that the adhesive gap was kept as narrow as possible. The "sandwich" was then placed in the clamp (Figure 5.5(b)) with pressure, separated by two pieces of Teflon to prevent the specimen being glued to the clamp. And then put them on the heating plate $\left(130^{\circ} \mathrm{C}\right)$ for two hours for the curing of glue. 


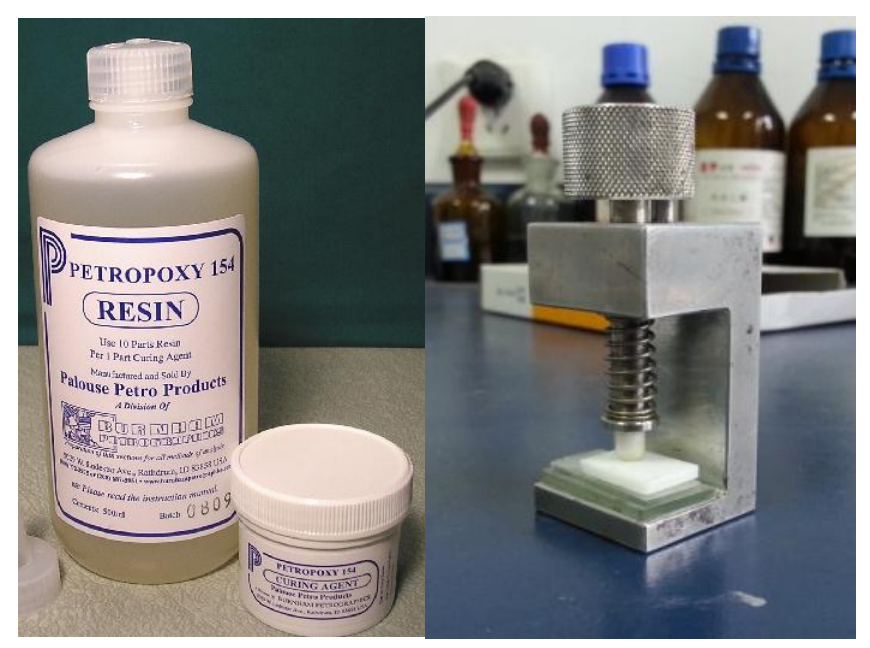

Figure 5.5 (a) Petropoxy 154, (b) clamp

\section{3) Mechanical pre-thinning}

The "sandwich" was cut by diamond saw to thin slice of about $0.5 \mathrm{~mm}$ thickness, polishes each cross section face, fixed on the $3 \mathrm{~mm}$ copper ring by $A B$ glue and then grinded and polishes to discs of at least $30 \mu \mathrm{m}$ thickness. Precision dimpler was not used in the mechanical pre-thinning method to protect the bonded specimens from breaking apart.

\section{4) Ion beam milling until perforation}

The ion beam thinning steps shows in Table 5.4

Table 5.4 lon beam thinning steps

\begin{tabular}{ccccc}
\hline Step & $\begin{array}{c}\text { Voltage } \\
(\mathrm{keV})\end{array}$ & $\begin{array}{c}\text { Degree } \\
\left({ }^{\circ}\right)\end{array}$ & $\begin{array}{c}\text { Time } \\
(\mathrm{min})\end{array}$ & Note \\
\hline 1 & 5 & 6 & $\begin{array}{c}\text { Until observed } \\
\text { the hole } \\
\text { Until the hole is } \\
\text { big enough }\end{array}$ & $\begin{array}{c}\text { Thinning the specimen quickly, but will damage } \\
\text { Continue to thinning the hole, and leads to } \\
\text { larger area of electron transparency in the } \\
\text { specimen }\end{array}$ \\
2 & 5 & 4 & $5-10 \mathrm{~min}$ & $\begin{array}{c}\text { Thinning rate is slow, but has lower material } \\
\text { damage and lower specimen heating which can } \\
\text { repair the surface of the specimen }\end{array}$ \\
\hline
\end{tabular}




\subsubsection{TEM observation}

Figure 5.6 (a) and (b) show the cross-sectional TEM images of multilayer coating under different magnifications. The thickness of $\mathrm{Cr}$-rich to $\mathrm{Ni}$-rich layers was shown in Table 5.3. Those pictures proved that a modulation $\mathrm{Ni}-\mathrm{Cr}$ multilayered coating can be successfully obtained from single bath, and the interfaces are very clear.
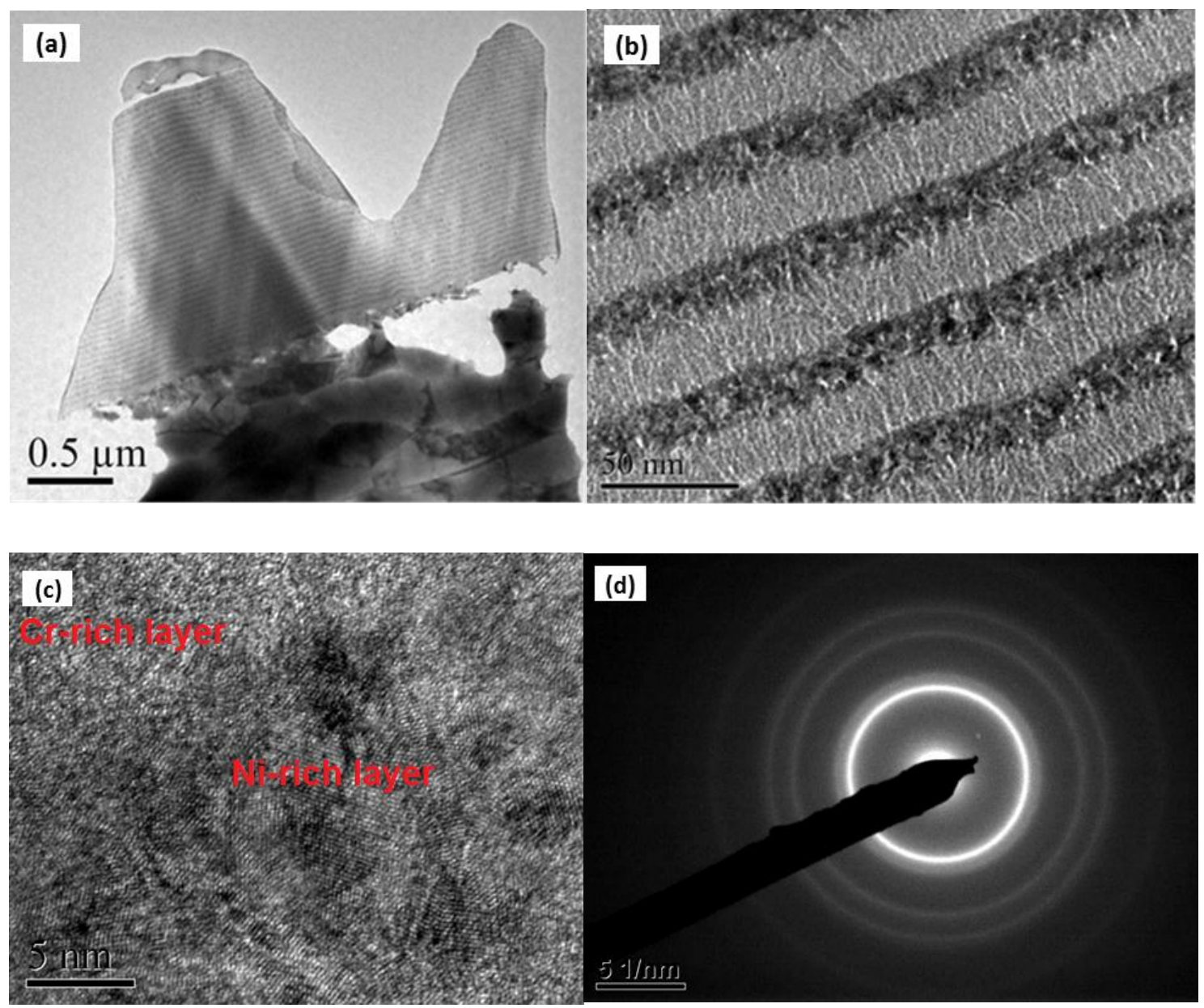

Figure 5.6 Cross-sectional TEM images of Cr-Ni multilayers (a), (b) under different magnification, (c) HRTEM micrograph, and (d) SAED pattern of the coating shown in (b)

HRTEM micrograph of the multilayer coating presents in Figure 5.6 (c). It showed that the Ni-rich layer consisted of nanocystalline with an average grain size of $5 \mathrm{~nm}$; while 
the structure of $\mathrm{Cr}$-rich layer is amorphous. Selected area electron diffraction (SAED) patterns of the multilayer are presented in Figure 5.6 (d). The continuous rings and diffuse halos in the SAED pattern indicated that the coating is constructed with modulated nanocystalline and amorphous structure. This conclusion was consistent with the HRTEM observation in Figure 5.6.
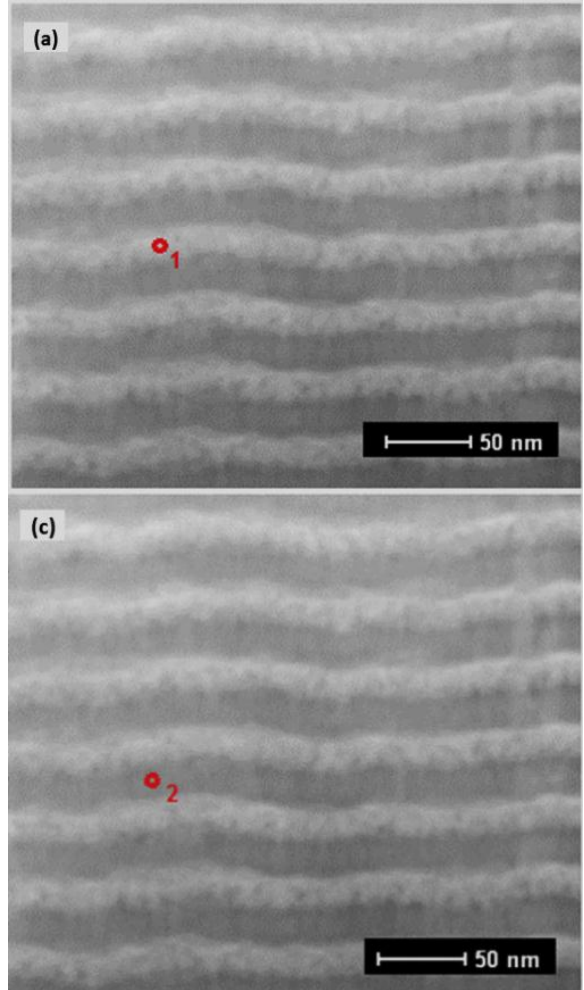

(e)

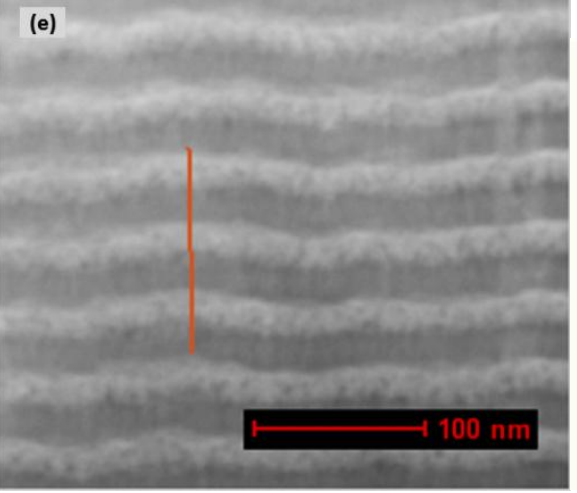

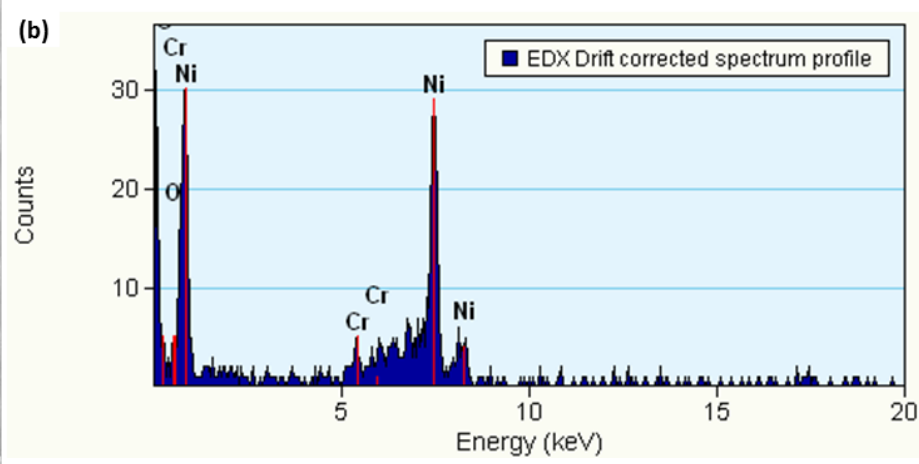
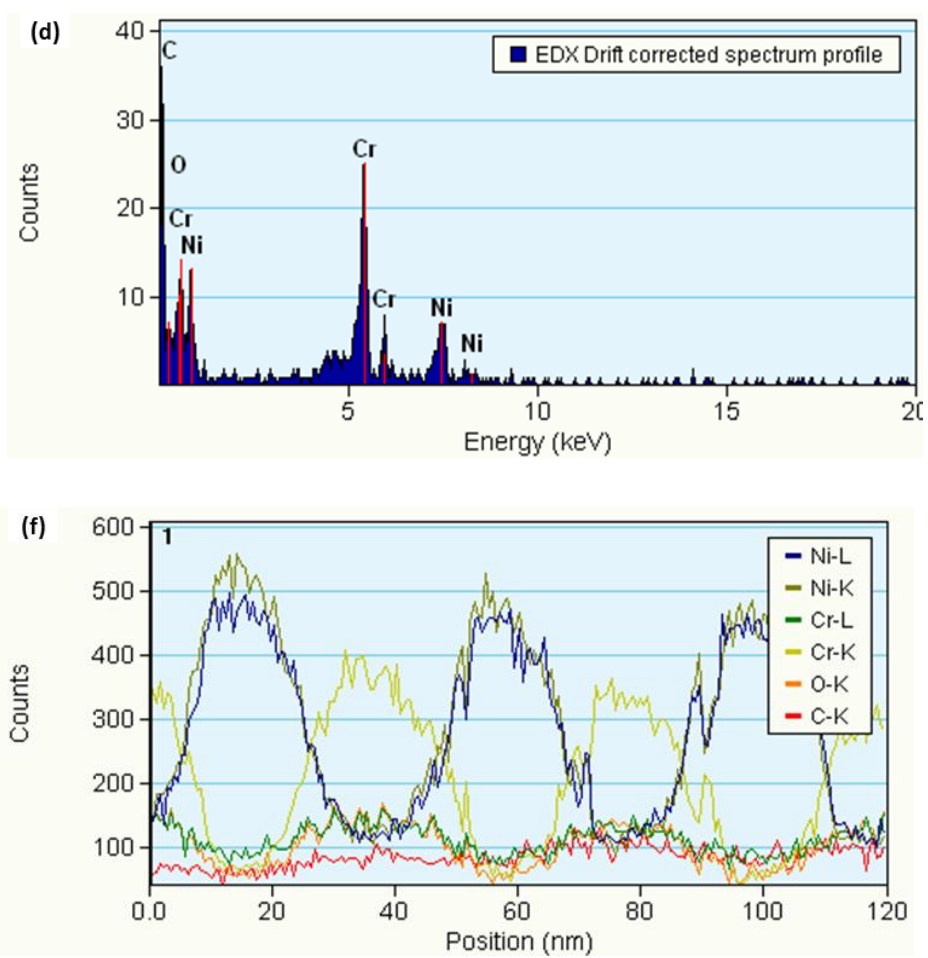

Figure 5.7 The EDS spectrum of (a) Ni-rich layer, (c) Cr-rich layer, and line scan result of (e) 
Table 5.5 The quantitative chemical compositions in the $\mathrm{Cr}$-rich and $\mathrm{Ni}$-rich layers

\begin{tabular}{lllll}
\hline & \multicolumn{3}{l}{ Ni-rich layer } & \multicolumn{3}{l}{ Cr-rich layer } \\
\cline { 2 - 5 } Element & Weight \% & Atomic \% & Weight \% & Atomic \% \\
\hline $\mathrm{Cr}(\mathrm{K})$ & 3.86 & 4.33 & 70.18 & 72.66 \\
$\mathrm{Ni}(\mathrm{K})$ & 96.13 & 95.66 & 29.81 & 27.33 \\
\hline
\end{tabular}

EDS spectrum result of the Ni-rich layer and Cr-rich layers are presented in Figure 5.7 (b) and (d), detected by electron probe. As shown in

Table 5.5, the Ni-rich layer consists of $95.66 \%$ nickel and $4.33 \%$ chromium, while there is $27.33 \%$ nickel and $72.66 \%$ chromium in the $\mathrm{Cr}$-rich layer.

\subsubsection{Scratch test}

In the microscratch tests, a conical diamond indenter having a tip radius of $1.5 \mu \mathrm{m}$ and an included angle of $60^{\circ}$ was drawn over the sample surface. The $0.5-\mathrm{mm}$ long scratches were made by translating the sample while the loads on the conical tip ramp up from 6 $\mathrm{mN}$ to $50 \mathrm{mN}$. Scanning electron microscopy (SEM; Zeiss Ultra plus Field Emission Gun (FEG)-SEM) was used to examine the scratch tracks for all samples. The microscratch test was repeated 5 times for each sample.

Table 5.6 Deposition parameters for nano-multilayers for hardness and wear resistance test

\begin{tabular}{ccccccccc}
\hline $\begin{array}{c}\text { No. of } \\
\text { sample }\end{array}$ & $\begin{array}{c}\text { Ni layer } \\
\text { Current } \\
(\mathrm{A})\end{array}$ & $\begin{array}{c}\text { Deposition } \\
\text { Time }(\mathrm{s})\end{array}$ & $\begin{array}{c}\text { Cr layer } \\
\text { Current } \\
(\mathrm{A})\end{array}$ & $\begin{array}{c}\text { Deposition } \\
\text { Time }(\mathrm{s})\end{array}$ & $\begin{array}{c}\text { Total } \\
\text { Thickness } \\
(\mu)\end{array}$ & $\begin{array}{c}\text { No. of } \\
\text { layers }\end{array}$ & $\begin{array}{c}\text { Thickness } \\
\text { of } \\
\text { each Ni } \\
\text { layer }(\mathrm{nm})\end{array}$ & $\begin{array}{c}\text { Thickness } \\
\text { of } \\
\text { each Cr } \\
\text { layer }(\mathrm{nm})\end{array}$ \\
\hline 1 & 0.3 & 6 & 0.63 & 2 & 1.7 & 80 & 21.25 & 21.25 \\
2 & 0.3 & 6 & 0.72 & 2 & 2 & 80 & 21.25 & 28.75 \\
3 & 0.3 & 4 & 0.63 & 1.5 & 1.2 & 80 & 15 & 15 \\
4 & 0.3 & 4 & 0.72 & 1.5 & $1.5-1.6$ & 80 & 15 & 22 \\
5 & 0.3 & 3 & 0.63 & 1 & 1.08 & 120 & 9 & 9 \\
6 & 0.3 & 3 & 0.72 & 1 & $1.5-1.6$ & 120 & 9 & 16 \\
\hline
\end{tabular}



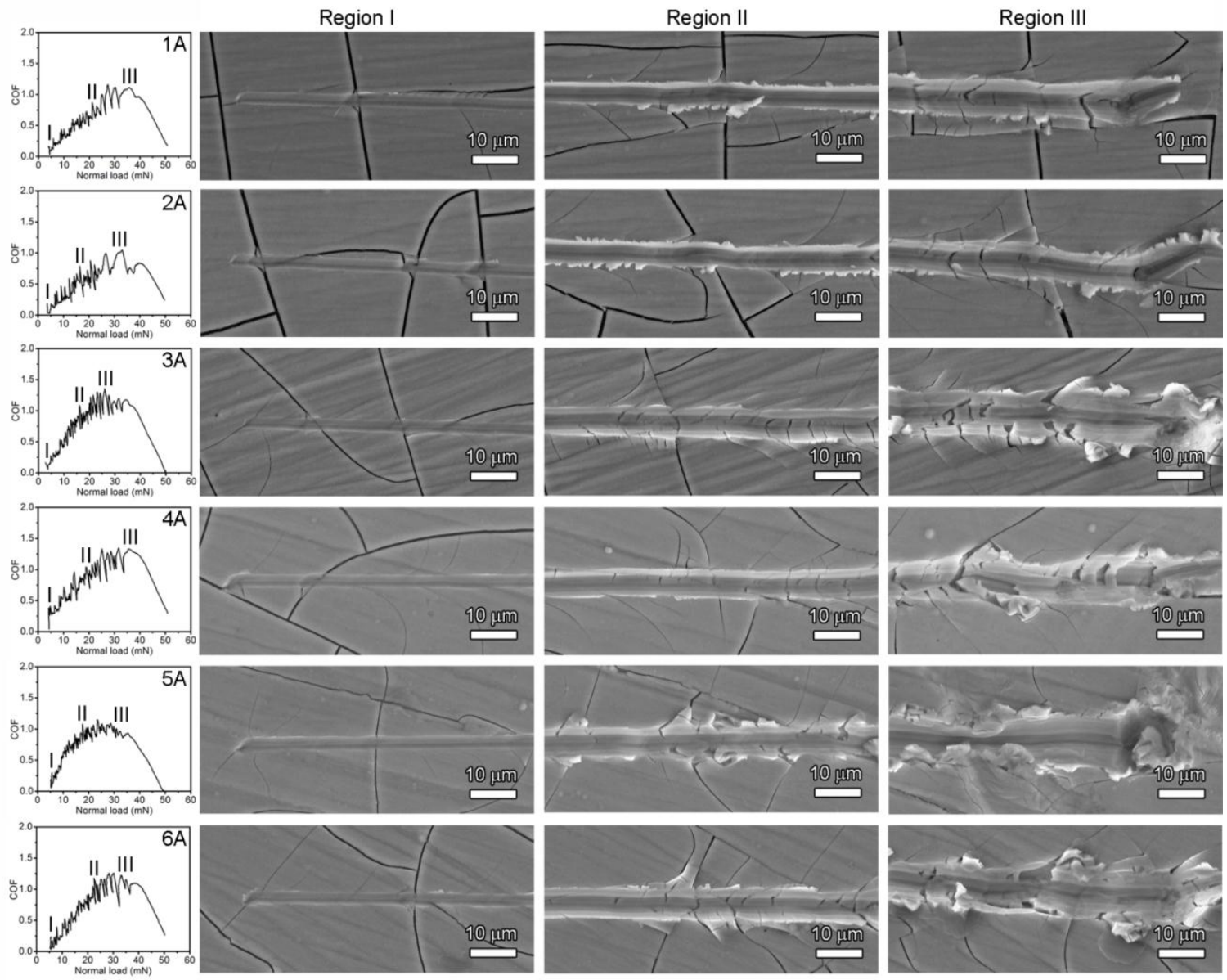

Figure 5.8 Coefficient of friction profiles as a function of increasing normal load and SEM images of three regions over scratches

Figure 5.8 shows the coefficient of friction as a function of increasing normal load and SEM images of three regions over scratches: at the beginning of the scratch (indicated by I on the friction profile), at the point of initiation of damage at which the coefficient of friction in- creases to a high value or increases abruptly (indicated by II on the friction profile), and towards the end of the scratch (indicated by III on the friction profile), for the six samples respectively. At the initial stages of scratching, all samples exhibit a lower coefficient of friction. And they exhibit a continuous increase in the coefficient of friction with increasing normal load before significant damage occurred to the samples. 
The SEM images show that below the critical loads all samples were damaged by plowing, associated with the plastic flow of material. In region I, shallower plowing scratch track was found without any debris on the side of the scratch, which is likely the cause for the lower coefficient of friction before the critical load. In addition to plowing scratch tracks, pile-up and debris particles were found on region II and III. Sample 1 and 2 exhibit the relatively smaller scratch track among the samples examined. For all samples, deep plowing with plastic flow of material and pile-up was observed on the side of the scratch and a curly chip was found at the end of the scratch. This is a typical characteristic of ductile metal alloys[71].

There were no cracks on all the samples, the cracks were caused by too much ultrasonic cleaning. The cracks might influence the result accuracy. Unfortunately, the machine was down, further tests were no longer available.

\section{Chapter 6 Conclusions and Recommendations for Future Studies}

\subsection{Summary and conclusions}

Two complex agents were used to promote the discharge of $\mathrm{Cr}^{3+}$ at the cathode side. A good ratio of main salts and complexes agents with a decent wide range of current densities for $\mathrm{Ni}-\mathrm{Cr}$ alloy was determined by Hull cell test. The control of $\mathrm{Cr}$ content in $\mathrm{Ni}$ $\mathrm{Cr}$ alloy coating was achieved in the optimized plating bath, ranging from $0 \%-87 \%$. The hardness of the coatings is very high without heat treatment. Cathodic polarization curves were recorded in different solution to study the effect main salts and complex agents.

The effects of DMF content in the solvent and current density on the surface morphology, chemical state and hydrogen evolution were studied, adding DFM as part of the solvent could effectively suppress hydrogen evolution and decrease the density of cracks on coatings. Additionally, the relative low deposition rate benefits the stress release of the deposit, which has similar function as low duty circle Cr electroplating for 
crack-free coatings. Crack-free $\mathrm{Ni}-\mathrm{Cr}$ alloy coatings with $\mathrm{Cr}$ content up to $58 \%$ was successfully obtained from 40\% DMF mixture electrolyte with wetting agent. The corrosion behavior was studied by anodic polarization curve measurement.

$\mathrm{Cr}-\mathrm{Ni}$ multilayers with thickness modulation of several tens of nanometers were prepared by pulse-current electroplating from a $\mathrm{Cr}(\mathrm{III})-\mathrm{Ni}(\mathrm{II})$ bath at room temperature. As characterized by transmission electron microscopy (TEM), the $\mathrm{Cr}-\mathrm{Ni}$ multilayers were composed of alternate amorphous $\mathrm{Cr}$-rich and nanocrystalline Ni-rich layers.

\subsection{Recommendations for future studies}

1. Study the effect of pulse parameter (eg: duty circle, frequency, and current density) on the coatings;

2. Deposit functional gradient coatings from this system. It could circumvent the problem with the interface between protective coating and the substrate, namely poor adhesive strength, Coefficient of Thermal Expansion(CTE) mismatch, and lattice mismatch;

3. In-deep study the role of DMF act as in the electrodeposition;

4. Study the interface between amorphous layer and nanocystalline layer;

5. Deposit $\mathrm{Cr}-\mathrm{P}$ coating instead of $\mathrm{Cr}-\mathrm{C}$ for better corrosion resistance performance. 


\section{REFERENCE}

[1] Polukarov YM, Edigaryan AA, Lubnin EN. Protection of Metals 2004;40:403.

[2] Song YB, Chin DT. Electrochimica Acta 2002;48:349.

[3] Mandich NV. Plating and Surface Finishing 1997;84:108.

[4] Fang J. Electroplating of Multicomponent Complex. Defense Industry Press, Peking, 1983.

[5] Zeng ZX, Sun YL, Zhang JY. Electrochemistry Communications 2009;11:331.

[6] Watson A, Anderson AMH, Elsharif MR, Chisholm CU. Transactions of the Institute of Metal Finishing 1991;69:26.

[7] Saravanan G, Mohan S. Journal of Applied Electrochemistry 2010;40:1.

[8] Smith A, Watson A, Vaughan D. Transactions of the Institute of Metal Finishing 1993;71:106.

[9] Patrick B. An Overview of Hard Chromium Plating Using Trivalent Chromium Solutions. 2011.

[10] Edigaryan AA, Polukarov YM. Zashch. Met. 1996;32:504.

[11] Baral A, Engelken R. Journal of the Electrochemical Society 2005;152:C504.

[12] Surviliene S, Cesuniene A, Selskis A, Butkiene R. Transactions of the Institute of Metal Finishing 2013;91:24.

[13] Zeng Z, Zhang Y, Zhao W, Zhang J. Surface and Coatings Technology 2011;205:4771.

[14] Hoshino S, Laitinen HA, Hoflund GB. Journal of the Electrochemical Society 1986;133:681.

[15] Giovanardi R, Orlando G. Surface \& Coatings Technology 2011;205:3947.

[16] Danilov FI, Protsenko VS, Gordiienko VO, Kwon SC, Lee JY, Kim M. Applied Surface Science 2011;257:8048.

[17] Surviliene S, Nivinskiene O, Cesuniene A, Selskis A. Journal of Applied Electrochemistry 2006;36:649.

[18] Rousseau A, Benaben P. Metal Finishing 2002;100:92.

[19] Li B, Lin A, Gan F. JOURNAL-WUHAN UNIVERSITY NATURAL SCIENCES EDITION 2007;53:184.

[20] Protsenko V, Danilov F. Electrochimica Acta 2009;54.

[21] Edigaryan AA, Polukarov YM. Protection of Metals 1998;34:95.

[22] Weil R. Plating 1971;58:137.

[23] Chien CW, Liu CL, Chen FJ, Lin KH, Lin CS. Electrochimica Acta 2012;72:74.

[24] Safonov VA, Vykhodtseva LN, Polukarov YM, Safonova OV, Smolentsev G, Sikora M, Eeckhout SG, Glatzel P. Journal of Physical Chemistry B 2006;110:23192.

[25] Edigaryan AA, Safonov VA, Lubnin EN, Vykhodtseva LN, Chusova GE, Polukarov YM. Electrochimica Acta 2002;47:2775.

[26] Protsenko VS, Gordiienko VO, Danilov FI. Electrochemistry Communications 2012;17:85.

[27] Edigaryan AA, Lyakhov BF, Polukarov YM, Buryak AK, Glazunov MP, UI'yanov AV. Protection of Metals 1999;35:107.

[28] Yashar PC, Sproul WD. Vacuum 1999;55:179.

[29] Qi Z. Processing, microstructure and mechanical behavior of nanocomposite multilayers. Louisiana State University, 2004. 
[30] Esmaili S, Bahrololoom ME. Surface Engineering and Applied Electrochemistry 2012;48:35.

[31] Cziraki A, Peter L, Weihnacht V, Toth J, Simon E, Padar J, Pogany L, Schneider CM, Gemming T, Wetzig K, Tichy G, Bakonyi I. Journal of Nanoscience and Nanotechnology 2006;6:2000.

[32] Tang XT, Wang GC, Shima M. Physical Review B 2007;75:10.

[33] Rousseau A, Benaben P. Plating and Surface Finishing 1999;86:106.

[34] Huang CA, Chen CY, Hsu CC, Lin CS. Scripta Materialia 2007;57:61.

[35] Protsenko, Gordiienko VO, Danilov FI, Kwon SC. 2011;109:33.

[36] Ibrahim SK, Watson A, Gawne DT. Transactions of the Institute of Metal Finishing 1997;75:181.

[37] Dasarathy H, Riley C, Coble HD. Journal of the Electrochemical Society 1994;141:1773.

[38] El-Sharif M, McDougall J, Chisholm CU. Transactions of the Institute of Metal Finishing 1999;77:139.

[39] Ward JJB, Christie IRA. Transactions of the Institute of Metal Finishing 1971;49:148.

[40] Bharucha NR, Ward JJB. British patent 1144913-A 1969.

[41] Watson A, Chisholm CU, Elsharif MR. Transactions of the Institute of Metal Finishing 1986;64:149.

[42] Hayashi T, Ishihama A. Plating and Surface Finishing 1979;66:36.

[43] Beer, Bernard H. U.S. Patent 3,632,498 1972.

[44] Zeradjanin AR, Schilling T, Seisel S, Bron M, Schuhmann W. Analytical Chemistry 2011;83:7645.

[45] McElhaney KW, Vlassak JJ, Nix WD. Journal of Materials Research 1998;13:1300.

[46] Ben Daia M, Aubert P, Labdi S, Sant C, Sadi FA, Houdy P, Bozet JL. Journal of Applied Physics 2000;87:7753.

[47] Lee DB. Materials and Corrosion-Werkstoffe Und Korrosion 2008;59:598.

[48] Pina J, Dias A, Francois M, Lebrun JL. Surface \& Coatings Technology 1997;96:148.

[49] Jorgensen O, Horsewell A, Sorensen BF, Leisner P. Acta Metallurgica Et Materialia 1995;43:3991.

[50] Beyragh MRS, AsI SK, Norouzi S. Surface \& Coatings Technology 2010;205:2605.

[51] Lin KL, Hsu CJ, Hsu IM, Chang JT. Journal of Materials Engineering and Performance 1992;1:359.

[52] Huang CA, Lin CK, Chen CY. Surface \& Coatings Technology 2009;203:3686.

[53] Etminanfar MR, Sohi MH. Thin Solid Films 2012;520:5322.

[54] Wang L, Kim DS, Nam KS, Kim M, Kwon SC. Surface \& Coatings Technology 2005;190:151.

[55] Huang CA, Lin W, Liao MJ. Corrosion Science 2006;48:460.

[56] Deng SH, Gong ZQ. Anti-Corrosion Methods and Materials 2003;50:267.

[57] Bahrololoom ME, Hoveidaei A. Surface Engineering 1999;15:502.

[58] Ward, Bernard JJ, Barnes C. U.S. Patent 4,107,004 1978.

[59] Ward J, Christie I. Transactions of the Institute of Metal Finishing 1971;49:148.

[60] Fawcett WR, Markusova K. Journal of Electroanalytical Chemistry 1989;270:119.

[61] Hoare JP. Journal of The Electrochemical Society 1979;126:190.

[62] Chen BH, Hong L, Ma Y, Ko TM. Industrial \& Engineering Chemistry Research 2002;41:2668.

[63] Lubnin EN, Sciences RAo, Edigaryan AA, Sciences RAo, Polukarov YM, Sciences RAo. Protection of Metals 2000;36:301. 
[64] Vykhodtseva LN, Edigaryan AA, Lubnin EN, Polukarov YM, Safonv VA. Russian Journal of Electrochemistry 2004;40:387.

[65] Huang CA, Liu YW, Yu C, Yang CC. Surface \& Coatings Technology 2011;205:3461.

[66] Tharamani CN, Hoor FS, Begum NS, Mayanna SM. Journal of the Electrochemical Society 2006;153.

[67] Joshi A, Kulkarni SK. Journal of Materials Science 1990;25:1357.

[68] Nemoshkalenko VV, Kindrat MM, Krivitskii VP, Mamko BP, Ostafiichuk BK, Senkevich Al, Kharlamov Al. Inorganic Materials 1981;17:717.

[69] Moffat T, Latanision R. Journal of The Electrochemical Society 1992;139:1869.

[70] Zeng Z, Liang A, Zhang J. Electrochimica Acta 2008;53:7344.

[71] Li X, Wang X, Bondokov R, Morris J, An YH, Sudarshan TS. Journal of Biomedical Materials Research Part B: Applied Biomaterials 2005;72:353. 